Portland State University

PDXScholar

$1-1-2012$

\title{
Cultural Hybridization, Glocalization and American Soccer Supporters: The Case of the Timbers Army
}

Jesse Harold Wagner

Portland State University

Follow this and additional works at: https://pdxscholar.library.pdx.edu/open_access_etds Let us know how access to this document benefits you.

\section{Recommended Citation}

Wagner, Jesse Harold, "Cultural Hybridization, Glocalization and American Soccer Supporters: The Case of the Timbers Army" (2012). Dissertations and Theses. Paper 937.

https://doi.org/10.15760/etd.937

This Thesis is brought to you for free and open access. It has been accepted for inclusion in Dissertations and Theses by an authorized administrator of PDXScholar. Please contact us if we can make this document more accessible: pdxscholar@pdx.edu. 
Cultural Hybridization, Glocalization and American Soccer Supporters: The Case of the Timbers Army

by

Jesse Harold Wagner

A thesis submitted in partial fulfillment of the requirements for the degree of

\author{
Master of Arts \\ in \\ Sociology
}

Thesis Committee:

Veronica Dujon, Chair

Daniel Sullivan

Robert Liebman

Portland State University

(C)2012 


\begin{abstract}
Soccer has a global reach and is entrenched in the lives of millions of people throughout the world, but the culture surrounding it is not as strong and never has been in the United States. Nonetheless, there is a recent emergence of American supporters groups that exhibit characteristics similar to those outside of the US. This ethnographic study focuses on one such group, the Timbers Army, to explore how they construct their own unique supporter identity and to understand how participants come to see the group relative to their understanding of the world at local and global levels. To explore this, this work employs globalization theory, in particular that of cultural hybridization and glocalization. In turn, through an iterative, grounded theory approach, the findings elucidate key concepts related to these theories. Briefly, the findings show how the Timbers Army's particular identity is constructed through multiple influences including an attachment to the city of Portland, a fierce regional rivalry, national references and recognition, and an awareness of and interaction with the global socio-cultural institution of soccer. This work is the first to acknowledge the burgeoning movement of American soccer supporters and provides a starting point for further inquiry into groups that exhibit both a strong local attachment and an outward looking global perspective.
\end{abstract}




\section{Acknowledgements}

There are numerous people who have supported me through this work in one way or another. To begin, I thank my wife and best friend, Lauren, for your continued support and belief. I could not have finished without you by my side. Next, I want thank my thesis committee: Veronica, thank you for providing direction when I needed it the most. Your insight, suggestions, critiques and discussions have made this work something I am very proud of. Bob, thank you for your guidance during proposal writing and for continuously offering new perspectives. Daniel, your initial encouragement is ultimately what made this thesis a reality; thank you for that and for providing the analytical foundation that has helped me so much throughout the entire process. Third, I want to thank the informants in this study; all of you were so open and provided such rich accounts of your experiences and perspectives. It would have been utterly impossible to complete this thesis without your help, and I hope you find my renderings an accurate portrayal of your words and experiences. Additionally, Chad, Cameron, and Jocelyn: thank you for bringing me into the fold before I knew anyone and giving me a place to stand match after match. I want to acknowledge my mother, my father, and my sister all of whom have encouraged me since I can remember. Dan, I do not know where to put this, but you are really awesome; thanks for being really awesome. Finally, I thank my cohort and some of those from the next: Laah, Meredith, Samantha, Brian, Michelangelo, Aundrea, Laura, Jessica, Dylan, and Katie. All of you provided helpful critiques, brilliant insights, profound friendships and so much support throughout an arduous process. 


\section{Table of Contents}

Acknowledgements. 


\section{List of Tables}

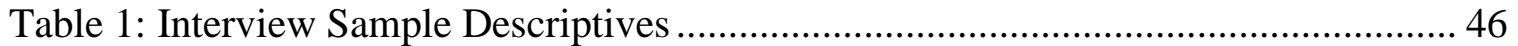




\section{List of Figures}

Figure 1. Socio-geographic Spectrum of How Timbers Army Participants Compare Themselves to Other Supporters Groups ....................................................................... 113 


\section{Chapter 1: Introduction}

On a global scale, soccer is an exceptional institution and is perhaps the single commonality connecting a number of disparate cultures, peoples, and countries throughout the world. There is not an existing global institution which means so much to so many people, wherein such issues as class, religion, politics, ethnicity, race and gender all interact in as many different variations. Despite numerous studies on the social and cultural significance of soccer throughout the world, scant attention has been paid to the phenomenon within the United States, especially regarding the most avid soccer supporters.

This study is among the first to look at the phenomenon of supporters in the United States and explore the intersections of the local and the global as well as points in between. This research focuses on the Timbers Army (TA), an independent supporters group in Portland, Oregon associated with the Portland Timbers soccer team. This work uses cultural globalization theory to explore the development and presentation of the group's local identity relative to global influences. Additionally, it explores the ways that individual group members see themselves and the TA in relation to comparable groups at various geographic scales. Two major concepts that are central to this work are: 1) cultural hybridization, which is the fusion of various cultural inputs into a new, unique cultural product, and 2) glocalization, which describes the relationship between the local and the global as interdependent and mutually constitutive. These concepts provide the foundation for understanding how a group like the Timbers Army comes to exist in a socio-cultural context where soccer culture lies on the periphery. In turn, the case of the 
TA illuminates some of the more abstract aspects of these theories and provides an opportunity for exploring how certain groups and individuals experience globalization in their local lives.

The Timbers Army is the focus of this research for three primary reasons: (1) Uniqueness; despite the fact that the team was not playing at the highest professional level of the sport in the United States, the TA are one of the largest such groups at any level of American professional soccer. (2) Geographical proximity; Portland is where I live, work and study. 3) Finally, it is clear, even from a cursory glance, that the TA uses multiple international and local influences in their behaviors. This makes it a perfect case for looking at the intersections of the local and the global in the formation of an American supporter group and to explore how global influences contribute to the development of supporter formations in the United States where soccer culture is not as entrenched into the social fabric as it is in other countries.

In approaching this research, I asked four main questions. The primary theoretical and analytical questions are: (1) Through what mechanisms is the collective identity established? and (2) How do participants contextualize their experiences and the overall group in relation to their understanding of the local and the global? Pursuing these questions was predicated on first exploring two other descriptive questions: (3) What is the Timbers Army? and (4) What does it mean to be a participant?

To answer these questions, I employed an ethnographic approach utilizing participant observation and in-depth, semi-structured interviews. Because I was not sure what I would find before entering the field, I used this approach to understand the group 
from the participants' perspectives and to provide an accurate account of the organization. This method allowed for emergent themes which presented themselves throughout the work and helped to focus subsequent stages of data collection, analysis, and presentation. Furthermore, participant-observation allowed me to explore the norms, behaviors and structure of the group and its members while interviews provided more targeted data from participants regarding their experiences, their understandings of soccer culture, and how they see themselves compared to other groups. Finally, these methods were necessary to construct a complete picture of the Timbers Army as little is known about avid American soccer spectators, especially from their own perspectives.

\section{Background}

\section{Structure of American Soccer}

To better understand the context within which the Timbers Army and the Portland Timbers operate, it is helpful to know about the structure of professional soccer in the United States. Like other countries, professional soccer in the United States follows a multi-level structure with different divisions and leagues. However, unlike many countries where there is the possibility for team promotion and relegation between the strata and divisions, in the U.S. the various leagues are not integrated with one another and teams generally remain in their respective division from season to season regardless of performance. Major League Soccer (MLS) is the highest echelon of the sport in the U.S. Underneath this, though not directly affiliated with it, are the United Soccer 
Leagues (USL). ${ }^{1}$ Within the USL, there are two primary divisions, in order of the highest prestige: USL1 and USL2. Thus, the USL1 was - until its recent restructuring - the second division of the professional sport in the United States. In addition to these two divisions, the USL has the Premier Development League (PDL) for players 23 and younger as well as Under -20 teams and youth teams. The USL women's league (USLW) began its inaugural season during 2009. During the period of research the Timbers played in USL1, but advanced along with Pacific Northwest rivals Vancouver to the MLS during the 2011 season. They also added a PDL team. Portland is also home to the USLW team, the Portland Rain. Although some members of the Timbers Army are present at local PDL and USL-W games, their support for the USL1 team was most apparent and is the central focus of this research.

\section{Portland Timbers and the Timbers Army}

The Portland Timbers, as a namesake and a team located in Portland, Oregon, goes back to the original North American Soccer League (NASL) which, prior to MLS, was the most successful venture for establishing professional soccer in the United States. The NASL began in 1968 as a merger of two leagues that started during the previous year: the National Professional Soccer League and the United Soccer Association, gained prominence in 1974 with the groundbreaking New York Cosmos' signing of the world's

\footnotetext{
${ }^{1}$ At the time of writing, the Portland Timbers have moved up to MLS. Additionally, second division soccer in the United States is in a point of transition. The USL1 and USL2 designations no longer exist and another league, the North American Soccer League (sharing the name with a previous professional soccer league that existed from 1968-1984). Although all of this has changed, the above describes the structure during the study period. MLS continues to be the highest division and will be adding another team from Montreal in the 2012 season.
} 
most famous player, Pele, but eventually petered out by 1984 (Goldblatt 2006). The Timbers joined the league in 1975 and played through the 1982 season. During this period, Portland became known as Soccer City, USA due to its large and enthusiastic crowds (Tossell 2003). ${ }^{2}$

The Timbers enjoyed a brief stint as a semi-professional team during the 1980s in the Western Soccer League, but once again folded. When the modern era team came into existence in 2001, the Timbers Army formed. ${ }^{3}$ At the time, the TA consisted of a handful of people gathering in the north end of the stadium who, according to the group's Myspace page ${ }^{4}$ wanted to "create a European-style rooting section...complete with drumming, flags, scarves, smoke bombs, and constant chanting and cheering" (Timbers Army Myspace 2010). Over the years, the organization grew from these few individuals into a well-known and easily recognizable mass consisting of anywhere between 1500 to 3000 people at home matches observed during the study period and has continued to grow since. Within the stadium, the Timbers Army went from taking up less than a full row of seats in an otherwise empty section to consistently filling three full sections. At the time of writing, the Timbers Army is even larger and encompasses the entire North End of the stadium.

The Timbers Army has certainly made an impact in Portland. In addition to being a visible and vocal contingent at home games, they also receive a fair amount of

\footnotetext{
${ }^{2}$ It is unclear how far this moniker went and how many people outside of Portland either thought of or referred to the city as Soccer City, USA.

${ }^{3}$ They first named themselves the Cascade Rangers, but changed their name to the Timbers Army shortly thereafter.

${ }^{4}$ It is clear that this page is no longer active, but still serves as a historical marker of the aims of the group.
} 
recognition from local politicians and media outlets. The bid for bringing MLS soccer to Portland was largely influenced by the concerted efforts of the group. In fact during the live broadcast of the March 20 ${ }^{\text {th }}, 2009$ declaration of MLS's selection of Portland, Don Garber, the MLS commissioner stated, "There are two shows in this town: the Portland Timbers and the Timbers Army." The decision included an MLS imperative that PGE Park be reconfigured as a "soccer specific" stadium, thereby displacing the minor league Portland Beavers baseball team. The issue created a stir in the city as Merritt Paulson, the owner of both the Timbers and the Beavers, tried to propose a publicly and privately funded plan for a new baseball stadium in another part of town. The Timbers Army has also been featured in local weekly papers such as the Willamette Weekly and the Portland Mercury. In the recent past, both papers ran numerous articles discussing the larger plan of bringing MLS to the city and also included features wherein reporters spend a night with the Timbers Army, interview various participants, and subsequently describe their experience (see Busse 2005, Pfennig and Dundas 2005).

The rest of this thesis is structured as follows: Chapter 2 provides an overview of the literature and presents the categorization of different types of soccer spectators and, in particular, includes an in-depth definition of supporters and the development of different spectator identities within soccer fandom. Next, it presents the theoretical framework that serves as a foundation for understanding and interpreting the findings with the key pieces being cultural globalization, hybridization, and glocalization. It ends with a brief overview of studies that have employed these concepts to explore soccer supporter culture. Chapter 3 is an in-depth description of the methods I used in this research 
including data collection, coding and analysis. Chapter 4 presents the findings from participant-observation and interviews. It is structured by geographic scale (local, regional/national, and global) and highlights key themes pertinent to the theoretical framework that emerged through data collection and analysis. Chapter 5 provides a discussion of the findings as they relate to the theory and literature. In addition, this chapter attempts to forward new concepts pertaining to the global-local nexus within socio-cultural production and diffusion. Finally, Chapter 6 concludes the study with a brief retrospective on the development and use of the theoretical perspectives I used and adds some suggestions for future research directions.

Before moving on, one note is necessary about some terminology in this work. By and large, people throughout the world use the term football ${ }^{5}$ in some variation to refer to what Americans and Canadians call soccer. In this thesis, the two words are interchangeable although there is an attempt to use the word soccer when not citing others' words. Any reference to the American sport of football will be qualified as American football or gridiron. Another term that appears throughout this work is $c l u b$. Generally speaking, the word club refers to a team. This term, however, carries more emphasis than team; it encompasses everything about the team including its supporters, its current players, it past players, its management, its colors, its history; essentially, the $c l u b$ represents all of the values that supporters instill into it.

\footnotetext{
${ }^{5}$ The sport is officially known as Association Football.
} 


\section{Chapter 2: Literature Review and Theoretical Frame}

This chapter examines the extant literature and provides the theoretical approach for the current study. It begins with an overview of different types of soccer spectators and their origins in order to better situate the Timbers Army as a supporters group. Following this is a discussion of cultural globalization and glocalization along with their corresponding concepts and terms. These theoretical perspectives are particularly useful because of soccer's global ubiquity and locally specific expressions. Conversely, because of soccer's expansiveness, it is a prime socio-cultural institution for studying globalization and localization. The particular concepts introduced in this chapter provide the theoretical framework for identifying the local particularities of the Timbers Army within a global socio-cultural field of soccer supporters. The chapter finishes with a brief presentation of studies that have used these theoretical perspectives to explore different facets of the world of soccer supporters. This provides much of the context for understanding what the Timbers Army is, how the group identity is constructed, and how processes of globalization and localization work in tandem to create new, unique social groups and cultural forms.

\section{Types of Soccer Spectators}

Soccer is different from other sports in that there are different levels of spectators (Bernache-Assollant et al. 2011), and in many cases, match attendees actually put on a performance for themselves, other spectators, and most importantly for their teams. They share along with their clubs and players in the creation and presentation of particular 
collective social identities (Bairner and Shirlow 2001; Giulianotti 2004; Goldblatt 2006; Magazine 2007). While other sports certainly have their fanatics, soccer is different in that clubs come to represent more than an allegiance, and, for certain spectators, more is on the line than winning or losing. The club becomes an extension of the individual's identity and a vehicle through which they express themselves and relate to others.

The following provides a short history regarding the initial impetus for sociological examination of soccer spectators. It then moves into a more in-depth discussion of the different types of spectators and how they relate to each other. To be sure, the general supporter category explained momentarily is the most pertinent in this thesis, although it is important to understand all of the different types of spectators in order to better understand the Timbers Army and where they fall within this larger spectrum.

The sociological and anthropological study of soccer spectators originated in Great Britain. The main catalyst for these studies was the growth of modern hooliganism during the 1970s and 1980s. Although supposedly evident within England since the 1880s (Dunning, et. al. 2002), the media and political promulgation of hooliganism gave particular salience to "the British disease" starting in the 1960s and culminated with indepth research in the 1980s. For most sociological and political purposes, hooliganism refers to the "social genesis of distinctive fan sub-cultures and their engagement in regular and collective violence, primarily with rival peers" (Giulianotti 2004: 49). According to Williams, Dunning and Murphy (1986), it was not until 1966 that the media began referring to the organized bands of young men at soccer matches who frequently 
engaged in violence as "hooligan gangs" (p 366). As a result scholars and policy makers sought to learn more about the men who made up hooligan 'firms' ${ }^{6}$ and explain what drove them to organized violence. In turn, this created a wealth of studies in the field that overemphasized the extent of the phenomenon while essentially ignoring other important sociological aspects of the game.

Hooliganism and other forms of soccer support grew out of British terrace culture (Giulianotti 2004). This refers to the time when there were literally terraces where spectators could buy cheap tickets to watch matches. In exchange, they stood, often packed into fenced in areas at the ends of the stadiums behind the goals. Part of this herding of the ruffians into the ends was due also to security, but the latent result of this was to "sharpen and sanctify the territorialization of the stadium" (Goldblatt 2006: 457). In addition to creating a perfect place for hooligans to organize themselves, this also led to a place where supporters began singing songs and chants for their players and clubs, infusing pop songs with soccer lyrics (Williams, Dunning, and Murphy 1986). This started in the late 50s and early 60s and as Williams, Dunning, and Murphy (1986) describe it, "soccer's new songs and chants, first heard in Liverpool, began to be heard elsewhere. Rival fan groups added material of their own and adapted "Liverpool" songs to local circumstances" ( $\mathrm{p}$ 365). This not only fueled hooliganism, but also created the basis for contemporary supporters groups.

After the initial preponderance of hooligan studies faded, scholars began investigating soccer spectator and supporter culture more. This grew into a larger body of

\footnotetext{
${ }^{6}$ Firm is another name for a hooligan gang.
} 
literature that examined both violent and non-violent forms of fandom and highlighted "the cultural differences that exist between supporters, at the local, regional, national, and continental levels" (Giulianotti 2004: 38). This is a particularly fruitful area for examining social relationships and collective identities throughout the world. As Goldblatt (2006) writes:

In football the crowd is unquestionably the chorus, not only supplying ambience, commentary and income, but actively shaping the tone and the course of the game. When in full carnival mode, the crowd can even move from out of the wings and take a place on stage. The opportunity that this provides for the collective dramatization of identities and social relationships, both spontaneous and organized, is without parallel in the field of global popular culture. (p 903)

To understand how soccer fuels these identities and social relationships, it is first necessary to comprehend the various classes of soccer spectators.

Using large ideal types, Giulianotti (2002) created a taxonomy of four different spectator categories: (a) Supporters, (b) Followers, (c) Fans, and (d) Flâneurs. Each category consists of four attributes that describe how individuals identify and interact with particular teams and players. Giulianotti further distinguishes these four spectator types based on whether they are "traditional" or "consumers" and whether they are "hot" or "cold." The traditional versus consumer aspect refers to an "individual's investment in a specific club" (p 31). Traditional soccer spectators, therefore, "have a stronger, more local and popular cultural identification with the club" (p 31), whereas consumers' relationships with clubs are "more market-centered" and especially evident in the “centrality of consuming club products" (p 31). Simply put, traditional spectators' relationships with the club are experiential while consumer spectators' relationships with 
the club are bought. The hot versus cool definition relates to the "degrees to which the club is central to the individual's project of self-formation" ( $\mathrm{p}$ 31) with hot spectators exhibiting intense loyalty, identification and solidarity with specific teams. For Giulianotti cool spectators are not so much defined as having specific attributes, but rather in lacking those that characterize hot spectators.

In the above scheme, supporters are traditional, hot spectators. As Giulianotti explains, supporters have "a long-term personal and emotional investment in the club." Furthermore, there is a "conscious commitment to show thick personal solidarity," and "showing support for the club in its multifarious forms is considered to be obligatory, because the individual has a relationship with the club that resembles those with close family and friends" (Giulianotti 2002: 33). Giulianotti goes on to explain that for supporters, the "club is an emblem of its surrounding community," and "supporters habitually have a "topophilic relationship toward the club's core spaces, primarily the home ground." It is in and around these home grounds where supporters perform their rituals and where they develop and enhanced form of "thick solidarity with fellow supporters" and the club (p 33). Finally, supporters interact with one another through subcultural relations whereby older participants socialize newcomers into the core collective values. These subcultural relations encompass the arenas wherein supporters contest local club questions, their own collective identity, gain and display various forms 
of subcultural capital, ${ }^{7}$ and stay abreast of other teams and supporters groups. In sum, supporters are characterized by "thick solidarity," "topophilic spaces," "subcultural relations" and a "grounded identity" tied to the club.

While supporters are traditional and hot, followers are traditional and cool. Followers may have specific clubs and players that they feel attached to, but, in general, they stay abreast of the game and often have multiple allegiances. The most defining element of followers is that they come to their identification with a team or multiple teams "through a vicarious form of communion" (Giulianotti 2002: 34-35). In other words, they know of the various cultures, values, and histories belonging to different teams not by experiencing it directly, but by watching it on television or the internet and staying abreast of happenings through social networks. Their solidarity with a particular club - fostered through symbolic exchanges rather than economic ones - can range between thick and thin. Moreover, Giulianotti is clear in stating that supporters of one club, through various social and subcultural mechanisms, may be followers of another club. Finally, while followers may express allegiances to multiple teams, they are "inured with the cultural politics of football [enough] to know that certain elements cannot combine." For example, they know that they cannot "declare a penchant for both Liverpool and Manchester United, or Fiorentina and Juventus" (Giulianotti 2002:36) because these specific clubs harbor a profound hatred for one another. Thus, followers,

\footnotetext{
${ }^{7}$ According to Giulianotti (2002), one example of this subcultural capital in the United Kingdom is evidenced by the higher status afforded to those who continued attending and supporting their club through unsuccessful periods.
} 
are quite aware of the soccer world and are summarized by a "nested identity," "thick/thin solidarity," "instrumental spaces," and "symbolic exchange relations."

Giulianotti describes the fan as a hot consumer type of spectator. Like the supporter, the fan identifies strongly with the club and knows the history and traditions of it. However, rather than the intimate relationship the supporter builds and feels with the club through experience and social interaction, the fan's relationship with the club is fostered primarily through consumption. As Giulianotti writes, "the individual fan experiences the club, its traditions, its star players, and fellow supporters through a market-centered set of relationships" (2002:36). As with followers, the feelings of solidarity can range between thick or thin, but in the end, the relationship between the fan and the club is uni-directional and defined by the market. Giulianotti sums up the four major attributes of fans as "product-mediated distances," "thick/thin solidarity," "nonreciprocal relations," and a "market identity" (2002: 31).

While the other three terms arise frequently in soccer related literature and conversations, Giulianotti introduces a fourth spectator type into his taxonomy: the flâneur. The flâneur is a cool consumer who follows soccer more for the celebrities than for personal or social affiliations; flâneur loyalty is rather fleeting, but what little exists is primarily associated with popular players rather than specific clubs. Furthermore, flâneurs evince "relatively thin forms of social solidarity with other fellow fans (Giulianotti 2002: 39). Giulianotti continues to describe flâneurs as transient, only interested in the immediate entertainment and attachment to a winning brand, and claims that "they are liable not only to switch a connection with teams or players, but also to 
forsake football for other forms of entertainment” ( $p$ 40). Moreover, flâneurs are cosmopolitan, but "not in the classical sense whereby constant perambulations produce a worldly merchant in ideas" (Giulianotti 2002: 40). Instead, theirs is a bourgeois cosmopolitanism; one associated with status, economic mobility, cultured tastes and brands. Teams "become appendages, selected for what they may say about the flâneur's personality" (Giulianotti 2002: 40). The four key traits of flâneurs are "virtual relations," "simulation spaces [and] non-places," "cosmopolitan identity," and "thin solidarity" (Giulianotti 2002: 31). In essence, flâneurs are disingenuous and fleeting in their loyalties, and Giulianotti concludes his article by stating that they are the target spectator of larger soccer clubs and the transnational corporations that advertise through them. Ultimately, Giulianotti sees the supporter and the flâneur as diametrically opposed to one another.

Although it is important to understand all four spectator types, supporters is the most essential for this work, as everything rests on an understanding of supporters and supporters groups. Based on the above, the definition of a supporters group is simply an organized collective of individual supporters. Important within this definition is that it is organized, represented by Giulianotti's "thick solidarity" between fellow supporters and between individuals and the club. This work assumes a priori that the Timbers Army, as a supporters group, fits into this definition and implicitly explores whether this is an apt description of the group. This assumption certainly leads to the expectation that individual participants will express their experiences and relationship to the Timbers in similar ways to Giulianotti's supporters. 
Within the larger umbrella of supporters, there are additional nuanced categorizations of spectators. One of the most prominent and diffuse categories consists of ultras. This style of support began in Italy during the 1970s and spread throughout Southern Europe (Giulianotti 2004). ${ }^{8}$ The ultra style of support is no longer confined to Southern Europe; the nomenclature and behavior appear throughout the supporter world as different groups attach themselves to or borrow from this style. These rather "informal, autonomous, and populist” (Giulianotti 2004: 55) groups initially began by emulating British terrace culture (Giulianotti 2004). As they defined their own method of support, the ultras became known for gathering in the ends of stadiums where they stand throughout matches, continuously chant and sing, perform pyrotechnic displays involving smoke bombs and flares, and use large banners, flags, and other accoutrements to express their support for the club and their group identity (Giulianotti 2004: De Biasi and Lanfranchi 1997). Ultra groups frequently - but not always - have political associations and are often associated with the radical left or the radical right (De Biasi and Lanfranchi 1997; Spaiij and Vinas 2005; Wilson 2008). Whereas soccer violence is a staple among hooligan groups, it can occur within and between ultras, but it is not a particularly defining trait despite matches serving as a "symbolic and theatrical" war between rival groups and soccer teams (De Biasi and Lanfranchi 1997: 99).

Very similar to the European ultras are groups within Latin America, particularly in Peru, Uruguay and Argentina, known as hinchadas or barras bravas (Giulianotti 2004;

\footnotetext{
${ }^{8}$ The ultra style of support is no longer confined to Southern Europe as the term ultras appears throughout the supporter world as different groups attach themselves to or borrow from this style of support.
} 
Giulianotti and Robertson 2007; Panfichi and Thieroldt 2007). What distinguishes these supporters from the ultras is merely the organizational structure of soccer in South America, wherein members of the Barras Bravas have more control and direct participation within the club (Giulianotti 2004). Aesthetically speaking, however, they exhibit very similar styles of support as the European ultras, and it is likely that the two styles have influenced one another to some degree.

There are other types of supporters, such as the Mexican porras (Magazine 2007) and Brazilian torcidas, but are less important in this work as they do not appear to have as strong of an explicit influence in the United States as other styles of support. Thus, because the terms will be revisited, it is important to have a working definition of barras bravas and ultras. Moreover, throughout this work it is important to understand that there are different types of supporters groups, that while very similar in some ways have sociocultural and geographic differences, particularly in their origins and organizational structure.

Finally, it is important to note that there may even be differences between supporters groups of the same club. Bernache-Assollant et al. (2011) studied two different groups at Olympique Marseilles and found that despite their support for the same team and the sharing of common elements, each had their "own culture and identity (p 80)." A few of the differences consisted of the class composition of the groups, their respective interpretations of success, and how deep their commitment to the ultra tradition ran. 
Despite these nuanced differences between supporters groups and traditions of support, there are notable similarities. For instance, the Social Issues Research Center published a large study in 2008 wherein researchers used a variety of qualitative and survey techniques to explore and compare the "feelings, expressions and behaviour [sic] of fans associated with support of their football teams" (SIRC 2008: 4) in 18 countries throughout Europe. While the authors note that there were some "quirks" between different supporters and countries, overall themes were very similar. One major theme was what it means to be a "true fan." For respondents to the SIRC study, this meant being loyal to a team no matter how well they perform and attending matches (both home and away) regularly. In addition, it also meant being an active participant to the point of being offended by the wrong classification of spectator. In the words of the authors, "In Norway, for example, the active followers of football would be offended by the term 'fan,' preferring 'supporter' as a way of describing their experiences” (p 13).

Furthermore, for the respondents, active participation resulted in a communion with the players and the club. Another theme in their study was that of rituals, particularly preand post-match rituals between individual supporters that "serve as bonding experiences between fans" ( $\mathrm{p} 25)$. This social bonding creates strong ties of friendship and also fosters strong relationships with families as inter-generational supporters often attend matches together. Other major themes that the study identified were associations between national and political identities and attachment to teams, the over-representation of male supporters, and finally, the relative ease the internet provides in facilitating following teams, watching games, and staying abreast of developments within the soccer world. In 
addition to the numerous similarities among supporters the study found, it also affirmed the need for specificity when looking at supporters groups by stating, "the specific social and cultural role that football plays in any given country [...] is heavily influenced by historical factors" (p 5).

\section{Theoretical Frame}

Because of soccer's stature as the global game, globalization theory provides an apt lens through which to examine supporter culture. The remainder of this chapter outlines globalization theory as it pertains to the creation and diffusion of global (sub)cultures. After a brief explanation of globalization as a whole, the concept of cultural hybridization is introduced followed by an explanation of glocalization. These concepts provide the theoretical foundation for the rest of the thesis. Briefly, hybridization is useful for examining and understanding how various cultural influences come together in specific formations while glocalization helps explain how individuals and groups experience the world in multi-scalar socio-cultural terms. Both of these terms are useful for examining supporter culture, because of the global nature of soccer and the immense role that local specificity plays in the construction of particular supporter identities. Finally, several soccer studies using similar theoretical lenses are presented in order to illustrate how others have applied hybridization and glocalization in soccerrelated research. 


\section{Globalization}

Globalization is a highly contested term referring to complex and interconnected processes and projects. As such, current academic discourse views globalization in very different ways, and the study of globalization involves more controversy than consensus in both academic and popular circles (Pieterse 2004). Furthermore, globalization includes "historical, political, economic, cultural, and social dimensions" (Giulianotti 2005: 190). Thus, the term globalization carries many disparate meanings depending on the context in which it is used. In this work, globalization refers to the process whereby individuals and groups become more aware of the interconnectivity of individuals, collectives, and cultures across geographic and social borders. As used here, it refers mainly to the cultural aspects of globalization and follows Robertson (1992) who states that globalization is "both the compression of the world and the intensification of consciousness of the world as a whole" (Robertson 1992: 8).

The two ideas of compression and consciousness arise frequently within discussion of globalization. Compression refers to the way in which the world has become increasingly interconnected and how individuals can conceive of or imagine (Appadurai 1996) the world as a single place more easily than was previously possible. There is, in effect, a compression of time and space as individuals and information travel further faster. Spaces and places become smaller and more intertwined as people are able to conceive of themselves as part of a larger space (i.e. the global) while simultaneously feeling connected to a single place (i.e. the local) (Massey 1994). This involves a paradox as people's worldview is at once larger in its global expanse, yet smaller because they 
have richer and more frequent contact with more people from further away (Hannerz 1996:7; Hognestad 2009). This leads to the idea of global consciousness, referring to the ways in which people and groups become more aware of the world as an interconnected space and how they contextualize their own position therein. To be clear, global consciousness does not imply global unity, nor does it mean that everyone experiences globalization in the same ways (Robertson 1992; Pieterse 2004; Robertson and Giulianotti 2009).

From a cultural standpoint, globalization is not a new phenomenon. It has been occurring for hundreds, if not thousands, of years (Appadurai 1996; Giulianotti and Robertson 2009; Gupta and Ferguson 1992; Pieterse 2004; Robertson 1992). The old ways of cross-cultural exchange included war, imperialistic conquest and colonization, the search for new trading routes, and religious proselytizing/expansion (Appadurai 1996). The speed at which globalization occurred in the past, however, was moderated by technology and physical boundaries (Appadurai 1996). Technological innovations paved the way for enhanced communication and travel, which, in turn, intensify the speed at which cultural ideas and products travel, leading some to refer to the current era of globalization as an accelerated form of global interconnectedness (Robertson 1992; Appadurai 1996; Pieterse 2004). This accelerated globalization is the result of: 1) the "increased mobility of meanings and meaningful forms through the media" wherein media consist of any written or spoken language, use of symbols, visuals, and so forth; and 2) the "increased mobility of people" (Hannerz 1996: 19). Thus, through 
globalization cultural products are shared amongst different social collectives more quickly and easily.

Like globalization, because culture is often a contested term, it is important to provide a definition of culture before moving on. Used here, culture is "that complex whole which includes knowledge, belief, art morals, law, custom, and any other capabilities and habits acquired by [an individual] as a member of society" (Tylor 1871: 1). There are three primary components of culture: 1) Individuals and groups learn and acquire it through social life, 2) It is a representation of a larger whole, and 3) It is difference (Gupta and Ferguson 1992, Hannerz 1996: 8).

\section{Three Paradigms of Cultural Globalization}

There are three dominant ways of viewing cultural globalization: cultural differentialism, cultural convergence, and cultural hybridization (Pieterse 2004; Ritzer 2007). Because of the borrowing and reconfiguring of different social and cultural influences that is apparent within soccer supporter culture, the focus in this work is on cultural hybridization. Nonetheless, a brief discussion of differentialism and convergence is necessary for two reasons. First, it is important to situate the hybridization perspective among alternative viewpoints. Second, as others discuss it, hybridization as a theory of globalization developed in response to differentialism and convergence arguments.

The first paradigm, cultural differentialism, is an "inward looking" view of culture and claims that distinctive local cultures and societies are not affected by forces of globalization (Pieterse 2004; Ritzer 2007). This view sees cultures and societies as 
essentially closed entities, existing within fixed physical boundaries often tied to the nation-state within which they exist (e.g., "Italian culture," "French culture,") (Gupta and Ferguson 1992). In sum, differentialism emphasizes difference between distinct cultures but does not allow for external influence on local cultures or societies.

The second paradigm, cultural convergence views global culture in terms of increasing homogenization or sameness. Whereas differentialism denies or ignores the transmission of culture across social and geographic boundaries, the convergence thesis acknowledges cultural diffusion, but views it as monolithic, emanating from a single center. Therefore, this notion is often associated with cultural imperialism and/or Americanization or Westernization with the producer of global cultural homogeneity being Western nations. This view also tends to focus more on the economic aspects of globalization arguing that global, neo-liberal capitalism is the driving force of the spread of culture. One major problem with this perspective is that it says nothing of global cultural flows that actually enter the United States via the rest of the world or the ways in which social actors localize particular customs, symbols, and/or beliefs.

In contrast to the previous two paradigms, hybridization is a mixing and new synthesis of preexisting cultural forms. Blending the discussions and definitions of others, cultural hybridization is the mixing of two or more cultural forms resulting in something new while simultaneously holding onto some identifiable aspects of the original cultural inputs (Archetti 1999; Pieterse 2004; Giulianotti and Robertson 2007; Ritzer 2007). Hybridization then involves a "fuzziness of boundaries" (Pieterse 2004:53). It tends to focus on the cultural heterogeneity and localized differences that occur due to 
the global diffusion and local indigenization of disparate cultural practices and social phenomena. In other words, external influences affect local cultures and produce various amalgams of cultural practices, meanings, collective identities and institutions in unique and different ways throughout the world (Pieterse 2004; Giulianotti and Robertson 2007; Ritzer 2007). Importantly, rather than a unidirectional view of culture emanating from the West, hybridization refers to the "idea that all societies are heterogeneous and marked by a complex variety of cultural encounters, rather than representing culture as a 'seamless whole"” (Hognestad 2009: 360). With so much emphasis on heterogeneity and difference, it is perhaps surprising that hybridization also incorporates an element of sameness. As Archetti (1999) explains, "hybridity makes difference into sameness, and sameness into difference, but 'in a way that makes the same no longer the same, the different no longer simply different'” (p 25).

\section{Glocalization}

Glocalization is somewhat of a companion term to hybridization. Most simplistically, glocalization is "the interpenetration of the local and the global, resulting in unique outcomes in different geographic areas" (Ritzer 2007). According to this definition, glocalization is the point at which both the global and the local intertwine. One may view it, then, as local globalization or interchangeably as global localization (Robertson 1992). Importantly, it recognizes the ways in which the local and the global interact and the ways that local cultures adopt and indigenize global trends differently. 
Just as individuals and collectives experience the global world differently, so too do they experience, interpret, and conceive of any given place or locality in different terms. As Massey (1994) writes, these experiences are intimately bound with one another. She states that any local place is in fact, "constructed out of a particular constellation of social relations" and is not defined by imposed or physical boundaries, but is:

imagined as articulated moments in networks of social relations and understandings, but where a large proportion of those relations, experiences and understandings are constructed on a far larger scale than what we happen to define for that moment as the place itself, whether that be a street, or a region or even a continent. And this in turn allows a sense of place which is extroverted, which includes a consciousness of its links with the wider world, which integrates in a positive way the global and the local. (Massey 1994: 154-155)

Although she does not use the term, Massey is approaching a theoretical conception of glocalization.

Rather than presenting the local and the global as opposite sides of a single sociogeographic cultural spectrum, glocalization recognizes the ways in which they act upon one another. It highlights both structural constraints and individual and collective agency by referring "to 'real world' endeavours [sic] to recontextualize global phenomena or macroscopic processes with respect to local culture." Thus, it "critically transcends the banal binary oppositions" of the global and the local and acknowledges the "co-presence of sameness and differences, and the intensified interpenetration of the local and the global" (Giulianotti and Robertson 2007: 168). It is thus defined "by social actor's fluid and critical engagement with, and reconstruction of, local and global phenomena" 
(Giulianotti and Robertson 2006: 173). When analyzing the diffusion of cultural artifacts, it is necessary to look at these local and global reconstructions. As Klein (2003) explains:

Cultural production does not [...] presuppose determinate, fixed or clear-cut messages. Instead, the process of adaptation therefore differs in potential from all others. This is also the reason why cultural globalization does not necessarily result in homogenization and standardization, or in a 'McDonaldization' of culture. On the contrary, globalized culture produces difference because of the different everyday life contexts of the consumers. Therefore the interaction of globalization and localization has to be considered when describing the circulation of pop cultural products. It is an expression of the relationship between homogenization and difference (p 43).

As the conclusion above states, where appropriate, the local and the global should not be studied in isolation from one another but as mutually constitutive parts of a single expression. It provides a lens through which to see both homogeneity and heterogeneity and allows an understanding of geographically specific responses to global forces. To further explain these points, Robertson (1992) utilizes other key concepts, most notably: relativization, the particular, and the universal.

\section{Relativization}

Relativization, as defined by Robertson (1992) and further developed by Giulianotti and Robertson (2009) refers to another aspect of the interconnectedness of local-global relations in that it discloses "the increasingly reflexive contrasts between 'local' cultures" (Giulianotti and Robertson 2009: 36). Further, it exposes "how globalization brings cultures into a sharper reflexive and comparative focus, thereby compelling these cultures to respond to each other in an ever-amplifying manner across 
the universal domain" (Giulianotti and Robertson 2009: 36). In other words, globalization brings people, groups, and cultures into more frequent contact and it allows ideas to spread further. In turn, individuals and groups use these expanded contacts and ideas in order to inform their identities and to contextualize their position within the global cultural milieu relative to their understanding of the larger world.

\section{The Universal and the Particular}

The universal, socio-culturally speaking, relates to global sameness, while the particular relates to local differences. These two aspects of globalization must be understood in relation to one another for "any particular experience, identity, or social process is only comprehensible with reference to universal phenomena, and vice versa" (Giullianotti and Robertson 2009: 32). Thus, any attribute of uniqueness may only be accurately interpreted within a generally accepted and understood framework consisting of common symbols, actions or behaviors, meanings, and contexts. Paradoxically, the universal consists of multiple particulars that come together to form the larger sociocultural framework.

Two interrelated processes of glocalization are the universalization of particularism and the particularization of universalism. The former "involves the extensive diffusion of the idea that there is virtually no limit to particularity, to uniqueness, to difference, and to otherness" (Robertson 1992: 102) and "gives rise to global similarities that structure [local] differences" (Giulianotti and Robertson 2009: 
41). On the other hand, the particularization of universalism refers to the ways in which "global features become tailored to specific local conditions" (Locher 2003).

It may be easiest to think of the universalization of particularism as universalized particularism wherein particular, local phenomena become globally (or largely internationally) relevant. Similarly, it may be best to understand the particularization of universalism as particularized universalism, wherein local social collectives adopt global (or largely international) socio-cultural characteristics and make them locally specific. In quotidian terms, universalized particularism is akin to saying, "We're all the same in different ways," whereas particularized universalism is like stating, "We're all different in the same ways." These two concepts are especially useful in exploring soccer as they provide a useful framework for identifying local idiosyncrasies and exploring how they relate to global trends.

\section{Models of, Models for}

Two final theoretical concepts employed in this thesis and integrated into the larger framework of globalization and glocalization are Clifford Geertz's (1965) models of and models for. Essentially, "Models Of” are reproductions or representations of existing cultural forms. "Models For," on the other hand, are cultural forms that serve as blueprints for action. In a global socio-cultural context, these two concepts may relate to the ways in which groups construct their identities, develop their behaviors and fit into a larger universe of social groups. 


\section{Globalization, Glocalization, and Soccer Studies}

Because of its worldwide appeal, soccer is a key institution for studying globalization. It is, as Giulianotti and Robertson (2004) write, "a vital site for theorization and empirical exploration of the multidimensional [...] process of globalization" (p 546). Even more pressing for this study is the exploration of the twin processes of localization and globalization within the construction of particular supporter group identities. Once again, Giulianotti and Robertson (2009) have a lot to say about globalization and glocalization and how it relates to supporters groups. They write:

Overall, supporter formations provide one of the richest zones for exploring the vibrant social transformation across football's global civil society....Transnational connectivity is highlighted through the socio-cultural exchanges of names, practices, and rituals that occur among supporters across a global terrain. 'Militant' supporter formations illustrate the 'duality of glocality', or 'common diversity' across cultures, for example in terms of their sharing generally the idea of intense rivalries with particular clubs, while being differentiated through their distinctive socio-cultural contents." (Giulianotti and Robertson 2009: 146-147)

Despite voluminous research on soccer spectators, there is relatively little looking at the intersections of the local and the global. Perhaps due to the emphasis on the need for specificity, most research on supporters groups remains confined to the specific city, region, or nation within which the groups exist. Despite the global nature of soccer, few studies contextualize their populations within a global setting, and most fail to make connections between the local and the global. There are, however, some scholars who do make these connections, most notably Giulianotti and Robertson, Hognestad, and Porat.

Giulianotti and Robertson are perhaps the most prolific authors when it comes to soccer, globalization, and glocalization. Though their work is based on years of study and 
knowledge, it is more theoretical than empirical. For instance, they clearly spell out how glocalization and its concomitant concepts apply to soccer in their works (see Giulianotti and Robertson 2004, 2007, 2009), but do not frequently apply these concepts in empirical studies.

They do, however, use glocalization as a lens to explore the diasporic communities of Scottish soccer fans of Celtic and Rangers living in different North American cities (Giulianotti and Robertson 2006; 2007). In these works, the two used participant observation and interviewed 108 supporters in eight different areas in the United States and Canada. First, the two find that both sets of supporters do not see themselves as any different from supporters living in Scotland despite their location in the United States. In addition to this, the respondents differentiated "themselves from other transnational fans who are perceived to possess a more fickle, consumerist penchant for 'glamour' teams like Manchester United” (Giulianotti and Robertson 2006: 181). They also found that the different North American clubs for the supporters serve, outside of soccer, as "important community resources" (2006: 181) for Scottish and Irish immigrants. Furthermore, they found that these diasporic communities adapted differently to their specific localities within North America, thereby producing different glocal hybrids of integration. Additionally, they found that these supporters had more favorable views of the Scottish national team and Scottish nationalism in general than those who live in Scotland, and that the respondents articulated this difference. They also found that the old sectarian lines that traditionally separate the two sides in Scotland were reconfigured in the North American context, and that in general, the sets of supporters 
enjoyed much more amicable relationships with one another, even sharing clubhouses during big matches between the two sides in certain areas. Finally, Giulianotti and Robertson (2007) found that the respondents resisted full assimilation into the American sporting culture by rejecting traditional American sports in favor of soccer.

Hognestad (2009) also uses glocalization to examine soccer supporters. Hognestad begins by explaining that in previous works he had done research on English soccer from 1999-2004. During this period, he states that "sameness rather than difference or 'otherness' characterized the experiences" in regards to the way English supporters viewed Norwegian supporters (p 360). Hognestad clearly situates this statement within a global-local framework when he follows with:

As a cultural practice football is closely associated with collective identities and football clubs are still intimately associated with specific localities [...] At the same time football is regularly described as the most globalized sport in the world with games from the biggest European leagues (notably the English, Spanish and Italian) being transmitted to a global television audience. Football is currently developing from these frictions of 'glocal' inclusions and exclusions. (p 360)

Hognestad goes on to explain how soccer is both global and local in a Norwegian context. He explains, "Football in Norway is part of a universe where the significance of the nation is contested and sometimes evaporates between a local, civic patriotism tied to the support of a local club and transnational allegiances to predominantly English club teams" (p 364). In the end, Hognestad concludes that in the world of soccer, the local is extremely important in the "symbolic construction of identities" (p 369) and the national is less important. Furthermore for Hognestad, globalization and its mediators (travel and technology) make it possible for people in one place to attach symbolically to foreign 
places. While all of this offers a very strong theoretical standpoint backed by concrete examples, it still lacks a formal analysis of specific supporters groups and how they relate to the local and the global.

Finally, Porat (2010) offers a unique look at the construction of the "fan football identity." Porat interviewed supporters of five Israeli soccer teams in his study. Though he does not use the term glocalization, he situates the construction of the supporters' identity in a local and global context. First, Porat argues that football fandom provides an opportunity for people throughout the world to choose various elements in a continual process of building "their profile of (social) identity" (p 278). Next, Porat posits that through globalization, individuals' social identities become fractured and are constantly changing based on different inputs. Consequently, these identities are not connected to anything concrete. This echoes Gupta and Ferguson's claims that "a transnational public sphere has certainly rendered any strictly bounded sense of community or locality obsolete" (1992: 9). Nevertheless, and in tune with others (Hognestad 2009; Giulianotti 2002, SIRC 2008), Porat finds that among soccer supporters, the "football fan identity" dominates other aspects of their lives, and the supporter "is constantly engaged in bounding his relations with the club" ( $\mathrm{p} 287$ ) to the point where this identity remains 'safe,' stable, and grounded despite a “a volatile world of unstable identities" (p 277).

While some have looked at cultural globalization and glocalization as it pertains to soccer, most work is of a theoretical nature, and there are not a lot of actual studies exploring the processes in specific supporters groups. The previous works illustrate the ways that scholars have employed these concepts but they still offer little new empirical 
evidence in regards to how specific supporters construct and view their world at different socio-spatial levels. Additionally, there are no studies of American supporters groups despite the fact that they are becoming a larger presence within American soccer. Thus, this work seeks to fill these gaps by examining an American supporters group - the Timbers Army - in order to learn how participants construct their overall group identity and how they view themselves relative to other similar groups at various sociogeographic levels.

This chapter presented the relevant literature regarding soccer supporters, supporter culture, and the theoretical concepts related to cultural globalization and processes of glocalization. In addition, it provided a review of studies that have applied these concepts in exploring soccer culture and supporters.

The Timbers Army offers a lot of potential for further exploring and applying these theories and concepts. First, it provides a specific case to explore how individuals and groups experience and interact with forces of cultural globalization. Second, studies regarding soccer and supporter culture tend to focus primarily on very local aspects rather than global ones. Thus, we know a lot about different local supporter groups, but relatively little about how they interact with the global field. Additionally, from a sociological standpoint, we know nothing about American supporters, and the Timbers Army provides a perfect opportunity to explore this due to their size and prominence within American soccer despite the fact that during data collection, the team was playing in the second tier of professional soccer in the U.S. In sum, in the United States where the sport and its surrounding culture do not have a long popular tradition, the TA presents an 
example for examining the emergence and development of a particular supporter identity and how local and global influences affect the creation and expression of this identity. 


\section{Chapter 3: Methodology}

This work utilized a two-stage ethnographic study design, which was necessary due to the exploratory nature of the study. It allowed me to gain an insider's perspective so that I could accurately describe the Timbers Army and engage individual participants at length to understand how they contextualize their experiences. The first stage consisted of participant-observation at Timbers matches and at various Timbers Army gatherings. The main purpose of the first stage of research was to gain a grounded understanding of the TA from within the group and to inform the second stage of research. After a full season of observations, the second stage of the research commenced wherein I used semistructured interviews to engage longtime TA members in focused discussions. Interviews were analyzed extensively using line-by-line qualitative coding. The following chapter provides an in-depth description of the process.

\section{Research Design}

Due the relative dearth of scientific knowledge regarding soccer supporters and specifically those in the United States, this study required a flexible, qualitative approach. I used Lofland and Lofland's (1995) Analyzing Social Settings: A Guide to Qualitative Observation and Analysis to guide my data collection, and I employed a two-stage, iterative and inductive research design for this study. The two stages were chosen because I was a newcomer and outsider to the group and needed to understand the rituals and norms before proceeding to ask deeper questions regarding group identity and how it is constructed and experienced by participants. Finally, because I entered the field 
without specific a priori assumptions as to what I would find, the flexible, inductive design was necessary in order to allow for emergent themes. As a result of the flexibility built into the research design, I ended up using a grounded theory approach to data collection, coding, and analysis.

The first stage consisted of participant observation wherein I participated in various group activities and logged detailed observations based on my experiences in the field. I began with two questions that guided the first wave of data gathering: (1) What is the Timbers Army? and (2) What does it mean to be a participant? My observations and experiences influenced and informed the second research phase; that of face-to-face interviews with the Timbers supporters. Interviews added nuanced understandings to my original questions and answered additional inquiries, namely: (1) Through what mechanisms is the collective identity established? And (2) How do participants contextualize their experiences and the overall group in relation to their understanding of the local and the global?

\section{Research Stage I: Participant Observation}

Participant observation was the first stage of my study and benefited the work in a number of ways. This method allowed me to fully explore and understand various aspects of the Timbers Army including organizational structure, norms, values, behavior, interactions and an overall comprehension of what it takes and means to be a part of this group. My overall goal was to achieve a comprehensive understanding of the Timbers Army and how 'members' conceive of the group and their participation. Therefore, it was 
important to participate so that I could convey what it means from an insider's perspective. This hinges on the Weberian concept of Verstehen as an interpretive means of understanding social behavior from within a social situation (Tucker 1965). This approach was important because of certain nuances that would not be apparent from a fleeting encounter or an outsider perspective. Finally, my observations provided a means of data triangulation when analyzing interviews thereby enhancing the validity of gathered data. In sum, participant observation further refined my research question and aided in developing a pointed interview guide.

\section{Time in the Field}

Fieldwork began for a graduate level ethnographic methods course, which coincided with the beginning of the 2009 season. For this course, I attended several communal gatherings along with five home games and four away game viewings. Following the course, I developed the framework for a full thesis project and continued to attend home games, away game viewings, and group gatherings. In all, I attended 18 out of 20 home games during the 2009 season and was present at nine away game viewings along with several pre- and post match gatherings. In the interest of full disclosure, I continue to participate with the Timbers Army by playing on an amateur soccer team comprised of supporters and attending matches and viewings. 


\section{Primary and Secondary Data Sites}

I frequented a number of data sites during this study. The primary location for gathering observational data was PGE Park, the Timbers home grounds on the west side of Portland. On match days, I also attended pre- and post-match gatherings at two frequented pubs near the stadium. When there were tailgates, held in a parking lot across the street from the stadium, I attended them.

Secondary data sites were all of those instances where I visited and participated outside of home match events. For away game viewings, I frequented a pub situated in the central eastside of Portland. Although there are a number of locations throughout Portland that broadcast away games, I chose this location because it draws large crowds, frequently broadcasts other soccer matches, and seemed to be the most frequently

mentioned place on the online message board for people to watch away matches. A final secondary data site was the online forum Soccer City U.S.A. which hosts both a message board entitled Talk Timbers and match reports and statistics from each game.

The online forum was useful in gathering and corroborating information. I used the message board as a means of understanding how the group works. Many participants use the site to discuss a variety of topics including the Timbers, the Timbers Army, worldwide soccer, soccer culture, supporter culture, and other teams and supporter groups within and outside of the United States. Many interviewees described this message board as the 'organizational' heart of the Timbers Army, and it was a useful tool for staying abreast of current information. 
I took the initiative in the formation of a small sub-group called the Bike Brigade. I generally rode my bicycle to games and after attending a few, I became aware of the multiple bikes locked-up outside of the park during games. I enjoy biking in larger groups and suggested via the message board that some of us begin meeting prior to matches and riding together en masse. Several match-goers responded and throughout the rest of the season and into the following one, we rode to games together. This initiative did not actually influence the overall Timbers Army, but it did allow me to meet more participants.

\section{Researcher Role}

My role within the field varied throughout the research. I originally began as an unknown investigator navigating a large group. I was initially worried that if people knew that I was researching them, this would affect their behavior. Nonetheless, a handful of individuals did know about the research: a fellow graduate student, being a semi-regular participant herself, invited me to join her and some friends when the season began. Her friends were initially inquisitive about my 'take' on the Timbers Army, but after I presented my position they were receptive and invited me to join them every game. In the end I did not include them in interviews out of fear that our association might influence the results.

As the season progressed, I met more people and sometimes broached the subject of my research. Overall, this was met with encouragement. The circle of people I stood 
with at games was also increasing, and in the course of various conversations, I formally recruited some participants.

\section{Thinking Units}

Initially entering the field and trying to record observations was a difficult task, particularly during home matches, due to the amount of people, the different group dynamics, and the general tumult that occurs in the North End. To better focus observations, I utilized a number of thinking units (Lofland and Lofland 1995). These units included: (a) Practices of the group. These are "recurrent categories of talk or action on which the observer focuses as having analytic significance" and include "rituals and taboos" (p 103). This analytical unit helped in identifying specific rituals which, in turn, through the use of Turner's (1967) discussion of the use of symbols in ritual, helped identify overarching norms, behaviors, values, and the importance of some symbols relative to others. (b) Roles: these "are consciously articulated and abstracted categories of social "types of persons"” and "is both a label that people use to organize their own activity and one that they apply to others as a way of making sense of their activity" (Lofland and Lofland 1995: 105). This was useful in understanding both the social structure of the Timbers Army and the informal expectations of participation. The first two thinking units assisted in understanding the third one I employed: (c) Organizations, being "consciously formed collectivities with formal goals that are pursued in a more or less articulately planned fashion" (p 109). Linking this with both Practices and Roles, "major aspects of the analysis of organizations include...how they recruit and control 
members, the types and causes of the goal-pursuit strategies they adopt, and the causes of their growth, change, or demise" (p 109).

Lastly, the thinking unit of (d) Social Worlds provided a larger picture and related specifically to globalization theory. As Lofland and Lofland state, "modern means of transportation and communication provide the basis for the rise and proliferation of a nebulous type of social unit that contains most if not all of the units described above but which is not reducible to any of them." Drawing upon David Unruh's 1983 piece, the authors continue:

A social world may be said (1) to encompass a large but indefinitely known population, (2) to have vague boundaries that can be crossed simply by choosing to stay abreast of events in that world (through the relevant communications media), (3) to have no or weak central authority, (4) to have a high rate of social change, and (5) to contain predominantly informal social roles - although in some instances, roles may be quite formal. (Lofland and Lofland 1995: 112)

Together, these thinking units focused my observations within the field and largely informed my interview guide for the second stage of research.

\section{Recording Observations}

Initially, while acting as an unknown participant observer, I took notes in a small notebook with the objective of being unobtrusive. I also taught myself how to remember in chunks of 45 minutes - the length of each half - and recorded my observations at halftime and directly after matches. As the season progressed, and my researcher role became more apparent to others, I recorded important observations as they occurred. The 
day after observations, I transformed my in-field jottings into extensive write-ups being sure to use value-free language.

\section{Research Stage II: Interviews}

The second phase of research consisted of one-on-one, in-depth, semi-structured interviews. These supplied additional information regarding how participants view the Timbers Army and their participation. This phase also added insight into the first two research questions and helped answer questions pertaining to the construction of a collective identity and how individual participants come to view their experiences. Lastly, interviews provided supplementary information pertaining to issues such as the genesis of the group, how it has changed, and how participants anticipate the future.

I used a flexible interview guide to conduct eleven interviews, ranging from 42 minutes to just over two hours. I conducted all of the interviews in a conversational manner allowing for divergent topics, recorded them with a digital audio recorder, and transcribed them. The interviews mostly occurred during the offseason; the first one took place approximately two weeks after the last match in 2009, and the last was recorded three weeks into the 2010 season. Analysis of the transcripts was an iterative process; I read them multiple times allowing for emergent themes and categories in each iteration. In the following section, I outline participant recruitment, the interview guide, and the process of coding. 


\section{Participant Recruitment}

I used three criteria for participation in the study: (1) respondents had to associate themselves with the Timbers Army, (2) they had to attend home matches on a regular basis: at least ten games out of the fifteen regular season matches, and (3) they had to have been attending matches for at least two full seasons. I used these criteria in order to select individuals who had some vested interest in the group. I was not interested in newer 'members' because I wanted to talk to people who could speak at length about their participation and the overall dynamics of the Timbers Army. Of note, most respondents had been attending matches for much longer than two seasons with some having been part of the Timbers Army from the very beginning of its formation. I did not interview individuals with whom I had developed a close friendship while in the field in order to ameliorate potential biases our relationship may pose.

Interview participants were selected via purposive and snowball sampling. These sampling techniques were necessary because there is not an official member list and the group is open to anyone who expresses a desire to be "Timbers Army." I identified two individuals from my time in the field to start a snowball sample. One of these was chosen because of her apparent commitment to the organization and length of involvement. I chose the other because he had expressed interest in the study during a conversation and he had been coming to matches since the Timbers played in the NASL. Starting with these two, I gathered participants using snowball sampling. At the end of each interview, I asked whether the respondent could recommend other participants who would be important for the study and may be willing to participate. 
Three interviewees were not part of this snowball sample. Two were recommended to me by a student in a class in which I was a Teaching Assistant after an in-class presentation on fieldwork methods. Although they were not part of the initial snowball sample, the individuals they recommended at the end of interviews were some of the same ones others had identified. Towards the end of the interviewing process, I purposefully selected an additional female interviewee with whom I was vaguely acquainted. I had only interviewed two other women and felt it was important to get the perspective of at least one other woman because although women are numerically in the minority, they constitute a relatively large proportion of the Timbers Army, and I wanted to get an approximate fit with the overall population in this regard.

I contacted potential recruits through various ways. The primary means of recruitment was through the online message board using a private message function that is similar to sending a personal email. In other instances, I approached respondents in person or via telephone. Overall, the responses to my requests for participation were overwhelmingly positive with only one person refusing to participate. ${ }^{9}$ There were a few non-responses to my messages, but this was likely due to the fact that some people do not check their messages frequently rather than outright refusal. ${ }^{10}$

Once establishing initial contact, I asked respondents to select a convenient time and place to meet. We were not discussing sensitive or private issues, and most of the

\footnotetext{
${ }^{9}$ Although this individual refused to participate, he indicated that it was due to a lack of time rather than an unwillingness to participate and was very polite in his refusal, even offering me luck in my endeavor.

${ }^{10} \mathrm{~A}$ few of the non-responses did in fact get in touch with me later, and indicated that they would have been willing to participate, but do not check their online private messages very often. Others who did end up participating in the study did not respond to my messages for a couple of months and indicated that they too do not check their private messages often.
} 
interviews occurred in coffeehouses or pubs in Portland. Out of convenience, I did conduct one interview in the respondent's house.

Before conducting interviews, respondents read and signed the Informed Consent Form (see Appendix A) after which I allowed time for any questions. Before proceeding, each participant verbally consented to recording our conversation. For those who wanted one, I later provided a transcription of the interview.

To ensure confidentiality, I use pseudonyms for all respondents throughout this thesis. I invited respondents to choose their own pseudonyms and provided one for those who did not give one. In addition to using pseudonyms to protect confidentiality, I have also omitted some information - particularly that regarding specific roles within the Timbers Army - that would almost certainly identify interviewees.

I conducted the interviews in a semi-structured manner. Using an interview guide (see Appendix B), I addressed each question during the conversation and allowed room for divergent discussions. At the end of each interview, participants were encouraged to add additional thoughts. Following this, I asked participants to self-report on a set of brief demographic questions; this information is presented below in Table 1 .

\section{Analyzing Interviews}

I began performing a very preliminary form of coding while transcribing interviews. During this elementary stage of analysis, I highlighted phrases and blocks of discussion which seemed important and tried to link colors within certain interviews with emergent relational themes and categories. 
Table 1: Interview Sample Descriptives

\begin{tabular}{|c|c|c|c|c|c|c|}
\hline $\begin{array}{c}\text { Years in Portland }^{\mathrm{c}} \\
\#(\%)\end{array}$ & $\begin{array}{c}\mathbf{2 - 5} \\
1(9 \%)\end{array}$ & $\begin{array}{c}\mathbf{6 - 9} \\
0(0 \%)\end{array}$ & $\begin{array}{c}\mathbf{1 0 - 1 4} \\
3(27 \%)\end{array}$ & $\begin{array}{c}\mathbf{1 5 - 1 9} \\
2(18 \%)\end{array}$ & $\begin{array}{c}\mathbf{2 0 +} \\
5(45 \%)\end{array}$ & $\begin{array}{c}\text { Total }^{\mathrm{a}} \\
11(100 \%)\end{array}$ \\
\hline $\begin{array}{c}\text { Age } \\
\#(\%)\end{array}$ & $\begin{array}{l}\mathbf{2 0 - 2 9} \\
1(9 \%)\end{array}$ & $\begin{array}{c}\mathbf{3 0 - 3 9} \\
3(27 \%)\end{array}$ & $\begin{array}{c}\mathbf{4 0 - 4 9} \\
4(36 \%)\end{array}$ & $\begin{array}{c}\mathbf{5 0 +} \\
3(27 \%)\end{array}$ & & $11(100 \%)$ \\
\hline $\begin{array}{c}\text { Seasons with } \mathbf{T A}^{\mathrm{c}} \\
\#(\%)\end{array}$ & $\begin{array}{c}\mathbf{2 - 3} \\
1(9 \%)\end{array}$ & $\begin{array}{c}\mathbf{4 - 5} \\
5(45 \%)\end{array}$ & $\begin{array}{c}\mathbf{6 - 7} \\
2(18 \%)\end{array}$ & $\begin{array}{c}\mathbf{8 +} \\
3(27 \%)\end{array}$ & & $11(100 \%)$ \\
\hline $\begin{array}{c}\text { Race/Ethnicity }^{\mathrm{b}} \\
\#(\%)\end{array}$ & $\begin{array}{l}\text { White } \\
9(82 \%)\end{array}$ & $\begin{array}{c}\text { Hispanic } \\
1(9 \%)\end{array}$ & $\begin{array}{l}\text { Italian } \\
1(9 \%)\end{array}$ & & & $11(100 \%)$ \\
\hline $\begin{array}{c}\text { Gender } \\
\#(\%)\end{array}$ & $\begin{array}{c}\text { Male } \\
8(73 \%)\end{array}$ & & $\begin{array}{l}\text { Female } \\
3(27 \%)\end{array}$ & & & $11(100 \%)$ \\
\hline
\end{tabular}

${ }^{\mathrm{a}}$ Due to rounding, some percentages do not equal $100 \%$.

${ }^{\mathrm{b}}$ I asked respondents to self-identify; some said Caucasian and they are represented in this category. Additionally, one respondent replied "Euro-mutt" which is also represented here.

${ }^{c}$ These figures indicate the number of years in Portland and seasons with the Timbers Army as of the end of the 2009 season. Of note, every respondent continues to participate in 2010.

Later, I thoroughly read each interview multiple times and used a line-by-line coding scheme (Charmaz 2006) wherein I attempted to give each idea or thought a code. ${ }^{11}$ As I read each transcription in its entirety, I also looked for salient connections within and between interviews. In later iterations, I used a form of "focused coding" whereby my analysis was "more directed, selective, and conceptual" (Charmaz 2006:57) than the initial line-by-line coding.

As I analyzed each interview, I maintained two other open documents. In the first, I extracted quotes pertinent to emergent themes that illustrated specific aspects of the participants' experiences and perspectives. I copied the text from transcripts and

\footnotetext{
${ }^{11}$ This is slightly different than giving every single line its own code. Instead, this gives each complete thought that the interviewee articulates a code. This is more pragmatic and useful than a true line-by-line coding scheme as people do not necessarily think and speak according to the lines on a page.
} 
placed them directly into this document which I refer to as the Quotes Document. I organized these quotes under their respective emergent categories. I also kept a Coding Document open while analyzing transcripts. In this file, I transferred my comments from the actual transcript so that I could see how certain codes connected to others. This helped develop the major sections and categories of analysis. In addition to these two documents, I maintained a Memos file wherein I wrote short explanations for myself regarding specific themes, categories, and codes.

After reading and analyzing the transcripts multiple times, I returned to my Quotes and Coding Documents. Comparing the remaining quotes to the Coding Document, I reorganized the quotes to fit better with the themes, categories, and codes. After analyzing this file, I cut out the prominent codes and categories and physically arranged them into a cohesive narrative. Seeing the codes in front of me allowed me to conceptualize how they fit with one another and illustrated additional information I needed to include. This process provided an outline for presenting my findings and added a new level of analysis by reengaging the most prominent text. 


\section{Chapter 4: Findings}

This chapter is divided into three main sections: 1) the local, 2) the regional and national, and 3) the global. The first section describes the major practices, organizational structure, and dominant themes of the Timbers Army at the local level. The second section deals with the ways in which the Timbers Army and its participants view themselves at the regional and national levels. The third section pertains to global influences and participants' contextualization of the Timbers Army at the global level. I have attempted to separate dominant themes and categories from one another, but because these topics converge in participants' experiences and perspectives, there is significant overlap in some areas.

\section{Part I: The Local}

The Timbers Army (TA) is a large, eclectic, and amorphous group of people who come together to support the Portland Timbers soccer team in Portland, Oregon. The group started in 2001 when the Portland Timbers joined the USL. At that time, there were only a handful of members, choosing to stand in Section 107 because it appeared to be directly behind the North End goal on a stadium map. Despite being slightly askew from the map's rendering, the group stayed in the section, claiming their place in the stands by banging on buckets, standing throughout matches, and continually chanting. From this small group of approximately 12 initial people who could barely occupy a single row of seats in 2001, the Timbers Army expanded to an estimated 1500-3000 in 2009. 
While the Timbers Army became a visible presence at matches beginning in 2001, the foundations of the group were established before then. David, a free-lance photographer, played an active part in establishing the TA and recounted how he had been compiling an email list for several years of people who frequently convened at local pubs to watch foreign soccer games, and as Emma, a 43 year-old technical analyst, added, to follow the US Men's National Team. When the Timbers announced in July, 2000 that Portland would once again have a professional team, David, Emma and others began organizing the supporters group. David used his email list to gather people and spread information, and passed out business cards with the group's name on it in an effort to get people to join. Emma explains the initial formation:

Yeah, [the Timbers] started in 2001, so it was before the team started. You know, it was kind of a loose organization of soccer fans kind of trying to prepare for the new team to start[...]I do remember one kind of meeting - like I said I think it was 7 people - we said, 'Are we going to do a supporters group for this new team? You know, let's get together and talk about it.'

Thus, before the team had begun playing, there was a conscious effort to form a supporters group that grew out of an existing, loosely-organized group of people who enjoyed watching soccer together. Though it started relatively small, with approximately 12 people in the first couple of games, Emma estimated that the group had grown to 60 people by the end of the first season, and as is evident, it continued to grow from there drawing in people from different backgrounds who came together through a commitment to the Timbers and, eventually, one another.

To be sure, not all of the people who come to matches and stand in the North End are as invested in the group as those I interviewed, three of whom have been with the 
Timbers Army since the first season. Overall and in their own words, interviewees feel the Timbers Army is passionate, participatory, loose-knit, united, chaotic, diverse, welcoming, a community, a commitment, and a party. Before moving into a more nuanced presentation of these sentiments, it is important to begin with an understanding of group practices, match experiences, and organizational structure.

The Portland Timbers' home ground is PGE Park ${ }^{12}$ - often referred to by the Timbers Army as Piggy - located in the center of Portland's Westside. Until the end of the 2010 season, the Timbers shared the arena with the Beavers, Portland's Triple-A baseball team. The soccer field runs north to south, and the seating area forms somewhat of a $\mathrm{U}$ (see Appendix C). Running along the eastern side of the field is a large wall, approximately 60 feet tall. On top of the East Wall are a single row of seats. ${ }^{13}$ On the opposite West Side, are the majority of seats. At the South End, the field abuts the Multnomah Athletic Club building, and there are no seats here. The North End, however, contains a large amount of seats and is entirely General Admission seating. This is where the Timbers Army stands and participants refer to it as "The Shed," and "The North End." The North End and the West Side both have two levels separated by a concourse between them: the 100 level is closest to the field, while the 200 level is higher up, separated by a concourse between the two levels.

\footnotetext{
${ }^{12}$ It is no longer named PGE Park. When the Timbers began playing in the MLS it coincided with renaming rights for the stadium. It is now named Jeld-Wen Field due to a change in sponsorship. ${ }^{13}$ This too has changed since the Timbers moved to MLS. The stadium was remodeled and seats were added to the Southside of the stadium and the East Wall.
} 
Each level is divided into sections. The Timbers Army began in Section 107 and, over time, spread into adjacent sections. Within the North End, many supporters are attached to specific sections. Each section the Timbers Army occupies has its own name and identity. 107 is important because of its history and the number appears frequently in TA merchandise and references; sometimes it refers to the overall group rather than the specific section. Section 106 is referred to as the Fighting 106 while 105 is known as the Howitzers. 108, on the other hand, is alternately referred to as the Irregulars or the Lazy 108s. When observations began, the Timbers Army regularly occupied three full sections $(108,107$, and 106). During the 2009 season, the group established 105 as a distinct TA section and in the following season also began spreading into 104. Frequently, Section 109 is on the periphery with many participants in the section, especially on nights with particularly large crowds. It is also common for the Timbers Army to extend upwards into the 200 levels. ${ }^{14}$

Lastly, the baseball team's dugout is in front of the North End, stretching from the middle of 108 to the end of Section 105. Its flat top often serves as a makeshift stage during Timbers matches; tifo displays (see below) are sometimes orchestrated from the platform, Timber Jim and Timber Joey ${ }^{15}$ use it as an area for rousing the crowd, and at the end of games, the actual Timbers players will sometimes come onto the dugout to interact with the Timbers Army.

\footnotetext{
${ }^{14}$ Now that Portland is in the MLS, the entire GA section (101-108 and 201-208) is under the Timbers Army umbrella with the lower levels being the more active, and all seats throughout the entire stadium are filled.

${ }^{15}$ Timber Jim was the original mascot, dating back to the NASL era. He retired in 2008, but occasionally still comes onto the dugout to lead chants. Timber Joey is the current mascot for the team.
} 
During home games, the North End is the most densely packed area of PGE Park. The main Timbers Army sections fill up first, and, since the TA stands, there are often more people squeezed into rows than there are seats. This trend, coupled with the fact that there is no formal membership and that the Timbers Army extends beyond these main sections, makes it difficult to know how many people actually make up the Timbers Army at any given match. Additionally, attendance, even in these sections, varies from game to game. With that being said, I estimate the Timbers Army to be between 1500 and 2500 strong. On certain nights, the TA may even reach up to 3000 people. Corroborating this, Emma, a 43-year-old technical analyst who has been active in the Timbers Army since its inception, stated:

I once counted heads on a really high resolution picture that I had, and there were about 450 to 500 people in a section that had 350,375 seats because they're crowded in.....And a lot of those games fully have six sections completely full; frequently, at least three. So I figure when there's three sections full, that's at least a thousand people... Some games, it just goes from one end to the other; it's eight sections, and that's got to be at least 3000 people.

To put this number in context, 2009 regular season attendance ranged from 6,427 to 14,103 with the total regular season average being 9,734 .

\section{Soccer Speak}

Before proceeding, it is necessary to outline some of the lexicon of the game and its culture because they frequently appear throughout the findings. These words are common throughout the world and participants in the Timbers Army use them as well, indicating a high degree of knowledge of the rest of the world. Some terms parallel those 
used within the American sporting vernacular and are often interchanged with the soccerspecific references in a form of mixed soccer speak.

The most important interchangeable terms are those of soccer and football. Both are used by participants to refer to the same game despite the prevalence of the word football in the United States referring predominantly to the sport of Gridiron, exemplified by the National Football League (NFL). In the Timbers Army, it is generally understood that football is synonymous with soccer. References to the NFL version are almost always distinguished by qualifying it as American football. At other times, completely different terms, such as pointy ball or throw ball, differentiate the two sports.

Besides football and soccer, there are other interchangeable terms. For example, a field is a pitch, a rivalry is a derby, a game is a match (or alternately, a fixture), uniforms are kits, and teams are clubs. ${ }^{16}$ Again, these terms are transposable and participants may use one more than the other, but both carry the same meaning.

Other words have specific meanings and are frequently used throughout the world and by the Timbers Army. The first among these terms is tifo, coming from the Italian word tifosi, meaning 'ardent fans.' Tifo is a choreographed display usually occurring just prior to kick-off. These displays frequently incorporate pyrotechnics such as smoke

\footnotetext{
${ }^{16}$ In many places throughout the world, the entire team franchise is referred to as a club with the top-level team being the main focus. For instance, Liverpool F.C. generally refers to the top-flight team playing in the English Premier League (EPL). However, Liverpool F.C. also includes a development academy for youth players, a women's professional team, and a reserves, or second-string players', team. Other clubs, such as F.C. Barcelona, not only have similar levels of soccer teams, but also host other sports teams (e.g. handball, basketball, figure skating, and wheelchair basketball), with soccer being the most predominant. The initials F.C. stand for Football Club.
} 
bombs (often colored) and flares, banners, flags, streamers, overheads, and two-sticks. ${ }^{17}$

Tifo displays are a mainstay within supporter culture but were first associated with Italian ultras. Another term originating in Italian supporter culture is capo; someone who helps lead chants and keeps the whole group in sync. Capos stand in visible places with their back turned towards the field and provide visual cues to the supporters who face them. They also communicate with each other across sections and frequently assist in ensuring tifo displays are performed smoothly.

\section{Home Games}

The home-match practices begin with participants gathering before the game at nearby pubs or at pre-game tailgates held in a parking lot near PGE Park. Because matches tend to be loud and boisterous, pre-match gatherings are a way for people to bond more intimately. Participants come together during these get-togethers to enjoy one another's company, converse and meet people, exchange merchandise, and share drinks. The numbers of those in attendance vary; pub gatherings frequently draw 40 or more TA participants while tailgates range from an estimated 50-150 people.

Following pre-match gatherings, match-goers enter the stadium. As people file into the stands, chants occur sporadically becoming more frequent and louder as kick-off approaches. The first is often a call for those sitting to rise with, "For the Rose City, stand up." One chant that almost always occurs before the match is a response to the visiting

\footnotetext{
${ }^{17}$ Overheads are banners or flags stretched over the stands, sometimes covering multiple sections. Twosticks are banners usually held by one person that have two poles on either side; they range in size but are generally between 3 ' -4 ' wide and 4'-5' tall.
} 
team and the refs; as participants jingle their keys overhead, they sing the words, "Go home you bums" to the tune of Auld Lang Syne. Though other chants are heard while people find their seats, this signifies that the game is about to begin and is generally the loudest one up to that point.

Preceding every match is the National Anthem, and this has its own ritual within the Timbers Army. Following each line of the song the Timbers Army utters the sound "chhhh," emulating the sound of a cymbal. Simultaneously, participants throw their scarves into the air and catch them. As the vocalist sings the closing words, "and the home of ...," the Timbers Army erupts with "The Timbers!" Following this, people begin swinging their scarves over their heads, waving flags, throwing streamers, and repeatedly singing "Heeeeey, Portland Timbers."

In addition to standing the entire match, the Timbers Army continuously sings chants. Chants occur in a variety of fashions: denigrating opponents and referees; praising players, the team, and the city; and even extolling the Timbers Army. Some chants are in response to on-field play, while others occur at specific times during the game. In addition to the capos who help coordinate chants, drummers and trumpet players provide the tempo and melodies of different chants, thereby adding to group cohesion.

Most chants have been in use by the Timbers Army for several seasons and are regular mainstays. New chants generally take several games after their initial introduction to become part of the regular repertoire. Newcomers to the Timbers Army can easily learn most of the established chants as the words are printed on Chant Sheets distributed 
via a Timbers Army information table located in the stadium concourse near the North End entrances. Notably, many of the chants heard at Timbers games are derivatives of others from throughout the world but contain locally specific words; others are based on popular songs with altered lyrics.

The Timbers Army also regularly sings two songs towards the end of each match: (1) You Are My Sunshine at the $80^{\text {th }}$ minute and (2) Elvis Presley's Can't Help Falling in Love at the $85^{\text {th }}$ minute. The first song has its own unique history, established in 2004 when Timber Jim, accompanied by his granddaughter, led the Timbers Army in a rendition of the song in memory of his daughter who had recently died in a car accident. As the TA sang, a player for the Timbers scored a goal by heeling the ball into the net. That particular goal became part of the Timbers Army folklore, immortalized as The Sunshine Goal, and the TA continues to sing the song. The second song does not carry as much weight, but expresses a sentimental attachment and undying love for the Timbers. During both songs, participants hold their scarves aloft, displaying the "Timbers Army" side (see below).

\section{Tifo Displays}

Not every fixture involves tifo displays, but when they occur, they directly follow the National Anthem as the players take the field. The displays are usually match-specific 'one-offs' occurring at either important games (e.g., the end of the regular season, against heated rivals), or to mark a significant moment (e.g., Scot Thompson, a player who the Timbers Army holds in particular high esteem received a display honoring his $100^{\text {th }}$ cap 
for the Timbers). Notably, these displays are created by people within the Timbers Army and are not funded or choreographed by the Timbers' front office (FO). They involve the coordination of many people at the match and multiple hours outside of the match by individuals who volunteer their time and money to produce ideas, sew flags, paint banners, and engineer the display.

Two noteworthy examples from the 2009 season serve as illustrations for these types of displays. The first was during a U.S. Open-Cup ${ }^{18}$ match against the Seattle Sounders. The second was created for the final match of the season. These two cases highlight the diversity and importance of tifo displays in the Timbers Army and wider supporter culture. Also, both of these displays were cited when the rather subjective MLS supporters' award for best tifo went to the Timbers Army despite the fact they did not play in that league (see Gray 2009).

The Sounders were in the USL-1 with the Timbers up until the 2009 season when Seattle moved to MLS. The rivalry between the sides - established during the NASL days - did not falter when the Sounders moved up, and the Open Cup match was the only time during 2009 the two sides met each other. The game, hosted in Portland, was the only sell-out of 2009 with 16,382 in attendance, and the tifo signified the importance of the match for supporters. Following the national anthem, a 20-25 foot replica of Seattle's Space Needle was hoisted aloft by wires in front of the North End. Next to Seattle's iconic building, a similar-sized depiction of the Timber's former mascot, Timber Jim,

\footnotetext{
${ }^{18}$ The Lamar Hunt U.S. Open Cup is a yearly tournament in which all levels of American (male) professional soccer compete. It also allows an allotted number of adult amateur teams to participate.
} 
wielding his signature chainsaw rose before the crowd. Simultaneously, supporters lit green, white, and purple smoke bombs while others waved approximately 100 green and white, checkered flags. As the current mascot, Timber Joey, revved his real chain saw below the two cut-outs, the Space Needle was released and fell to the ground, leaving the Timber Jim replica standing triumphantly.

The display, which lasted only about two minutes, indicates the creativity, coordination, and time commitment necessary. Ernesto, who worked on the project, described the effort that went into executing it:

[Security] luckily gave us access down to the field where we could actually measure the entire dugout and could measure the height of the pole. And there's a couple guys in the Timbers Army, they're civil engineers...They did all the math and a bunch of the guys, I don't know, it must have been at least, I mean hundred and twenty, thirty hours of man-time to paint... And, of course, Merritt [the owner] had to see it, because he didn't want some 'Seattle, fuck you' banner or [something]. He knows our hatred towards that team and their supporters, and he was just like, pretty amazed with it. There was a couple of dry runs the day before the game and the day of to make sure, because we didn't want to have a display failure like they did in Seattle; they had [an] upside down [overhead]. Upside down or like, it fall, so there was a couple of dry runs.

As the above quote illustrates, participants invest a lot of their own time and energy to insure the displays come off well. It also indicates the intensity and importance supporters place in this rivalry (which will be discussed later).

The second example of TA tifo demonstrates another aspect; honoring players. This display occurred during the last match of the regular season and involved multiple of two-sticks and a large homemade banner. The cartoon show The Simpsons served as the overall theme. The banner, stretched out in front of the North End, depicted the Simpsons family in Timbers and Timbers Army gear, complete with TA scarves, and with Lisa 
holding a smoke bomb overhead. "The Timbers" was written in large letters copying the font used in the cartoon. Each two-stick depicted a Timbers player drawn as Simpsonsstyled caricatures. In addition, those not holding the two-sticks held twelve inch squares of green paper overhead creating a field of green (see Appendix D for a photograph of this display). At the end of the match, the players came onto the dugout; they danced, joined in chants, and received their Simpsons caricature along with a Timbers Army scarf.

\section{Goals}

As Uruguayan author, Eduardo Galeano (1998) writes, "The goal is soccer's orgasm....and the crowd goes nuts and the stadium forgets that it's made of concrete and breaks free of the earth and flies through the air" (p 9). The importance of goals within a soccer game is obvious, and the Timbers Army responds to Timbers' goals and opponents' goals in two distinct ways.

When the Timbers score, the North End becomes electric and the frenzied display of elation is comparable to Durkheim's (2001) description of the aboriginal corroboree wherein a collective "effervescence" results in a general tumult that momentarily suspends normalized codes of conduct. After goals people in the TA often embrace one another, dole out high fives to those around them, and swing their scarves overhead in a helicopter motion. Participants also wave flags and some light smoke bombs. In addition, the Sunshine Flag - a large, green and yellow overhead depicting a Japanese-style Rising Sun - travels throughout the North End. 
As all of this occurs, Timber Joey, using a chainsaw, cuts a slab of wood off a twelve-foot log situated in front of the Timbers Army. After sawing off the piece, he hoists it overhead, and the crowd explodes with cheers. The slab is often passed into the stands where spectators touch - or, even kiss - it before it returns to the field and is laid in front of the log. The whole scene transforms the fleeting moment of the goal being scored into a tangible object in which both the supporters' and the team's efforts are imbued.

Contrasting the group's elated response to a Timbers' goal is the ritual involving the opposition's goals. When the other team scores, it briefly stifles the Timbers Army's momentum; chants immediately cease and disbelief can be seen on the supporters' faces. Within seconds, however, participants raise their outstretched scarves above their heads and sing a couple of rounds of "Rose City Till I Die" to the tune of Camptown Races.

\section{Post-Match Salutation}

After the match, the entire team walks over to the North End and applauds the Timbers Army. Players who tally goals then receive their log slices and raise them overhead towards the Timbers Army in a gesture suggesting that players not only appreciate the support, but view the Timbers Army as an influential factor in the game. During this salutation, the TA waves flags and continues to chant until the players exit. When the Timbers win, the whole interaction is prolonged and players often join in singing the chants. Contrarily, when the team loses, the players are less jubilant when raising their slabs and proceed to walk sullenly off the pitch. 
After the game, many participants return to nearby pubs where they converse with one another over drinks. On nights after victories, the bars are packed, and sporadic chants commonly make their way through the crowd. When there is a loss, however, chants are less frequent and the pubs are not as full.

\section{Away-Game Viewings and Extra-Match Gatherings}

Away games are usually broadcast via a live internet stream, and several pubs throughout Portland host viewing parties. As may be expected, these are not as well attended as home matches and contain significantly less symbolic actions. Nevertheless, many participants attend these viewings.

Attendance at these away-game gatherings varies depending upon the time, day, and importance of the match; the smallest crowd I witnessed was approximately 30 people whereas the largest was well over 150. The crowd consists of mainly men, but there is also a substantial number of women present at an approximate ratio of three men to every two women. Like home games, people frequently wear team colors, kits, and Timbers Army scarves and gear. Chants appear at viewing parties, but are rather infrequent. Similar to games at PGE Park, when the Timbers score goals, the crowd goes wild, jumping out of their seats, throwing their hands into the air, and embracing one another.

There are also events and gatherings throughout the season and even in the offseason. For example, 'members' gather at bars on the first Thursday and third Saturday of every month during the offseason. In addition, there is, as Ernesto stated, "a 
civic minded' characteristic to the Timbers Army, whereby, quoting Arthur, participants engage in "altruistic efforts of raising funds and participating in things that benefit the community." These include - but are not limited to - volunteering for local non-profits such as Friends of Trees, local chapters of Habitat for Humanity, participating in Oregon Public Broadcasting fundraisers, and donating money to Dornbecher Children's Hospital. For many, this is an important aspect of the Timbers Army, and it allows them to 'give back to the community.' Whether it is through the message board, attending monthly gatherings, or volunteering their time, many participants are in continuous contact with one another at all times of the year and consider this an integral part of the TA.

\section{The Scarf}

In general, scarves are a ubiquitous symbol throughout world soccer; national and professional teams and supporters groups all have scarves that display their colors and names. The Timbers Army is no different, and the most prominent symbol of the group, used in multiple game-day rituals as described above, and as a signifier of 'membership,' is the Timbers Army's green and white "No Pity" scarf. Normally, there is black fringe, but this sometimes varies due to commemorative run, e.g., the order containing the $5000^{\text {th }}$ scarf the TA produced had green and gold fringe. One side of the scarf has the words "Timbers Army" in bold, black lettering, while the other has the words "No Pity." During games, participants often display one side or the other during specific moments or chants. The No Pity side is usually reserved for times when opponents are injured or 
feigning injury and is accompanied by the chant, "There's no pity in the Rose City," or "You're going home in a Portland ambulance."

Like other TA-produced merchandise, the scarf is not endorsed by the FO, is not available in the team's shop, and cannot be sold in PGE Park. Instead, the Timbers Army independently produces and sells scarves at production cost through informal channels; individuals 'sponsor' sets of five scarves and then sell them to others via the message board, at tailgates and gatherings, or through friends. ${ }^{19}$ These scarves are half the price of those produced by the FO, but are substantially more valuable to participants. As Peter explained, obtaining the scarf is akin to perhaps the only initiation into the group, "I mean, the process...finding out about the message board and finding out how to get a scarf is initiation in itself. 'Cause you have to, you have to have a relationship with somebody. I had to go way out of my comfort zone [to get my first scarf]." In addition to the regular No Pity scarf, the Timbers Army occasionally produces other commemorative or special design, limited-run scarves.

\section{Organizational Structure}

The Timbers Army is a 'leaderless' organization that runs on a do it yourself (DIY) ethic. Once again, the TA is open to anyone simply by their willingness and desire to participate. While the group is formally leaderless and open, some individuals have

\footnotetext{
${ }^{19}$ Other Timbers Army merchandise (e.g. stickers, t-shirts, patches, etc.) is also sold at production cost. It is not permissible for sellers to make a profit. In some instances, sellers will add an additional dollar onto merchandise; this is acceptable as long as they donate the extra money to charities or to fund tifo displays. As an aside, the Timbers Army recently acquired a trailer and sells merchandise from it before and after matches, thereby creating a more centralized way of distribution. People do, however, still sell TA products using informal social networks.
} 
voluntarily assumed leadership roles. Additionally, some changes to the structure occurred during the research process.

The Timbers Army is a 'leaderless' group and does not have a formal structure. 'Membership' is open, ultimately defined only by a willingness and desire to participate. As Emma stated, “It doesn't have a leader, it doesn't have an organization, it doesn't have a subscription, it doesn't have a membership card." At the same time, some individuals have stepped into de facto leadership roles in various capacities. All of these roles, however, have been created because people saw a need for them and then voluntarily took it upon themselves to fulfill that role.

The Timbers Army's formulates and actualizes goals through a Do-It-Yourself (DIY) mentality. This first became apparent during the pre-season organizational meeting that was open to anyone who wanted to attend. The primary speaker at the meeting presented ideas and projects that had been generated at a previous, invite-only meeting. The speaker presented each project and asked if anyone wanted to volunteer to see them through. He also stated they were 'just ideas' and implied that if no one wanted to see them come to fruition, then they simply would not happen. Those who volunteered were then referred to as 'engineers' and 'co-engineers' rather than leaders of their respective projects.

While the previous example highlights one instance of the organizational structure, the DIY ethic manifests in a variety of situations. First, a single person created and continues to maintain the online message board, which, in turn, has become the organizational 'heart' of the Timbers Army. It is a forum where anyone can contribute to 
ongoing discussion about all things soccer, the Portland Timbers, the Timbers Army, and so on. Next, tifo displays only occur because individuals want them to happen and volunteer their time, energy, and other resources so that the TA can produce game-day displays. Similarly, capos assume their roles voluntarily. Bob explained why he began doing it, "I just felt, I guess, a kind of responsibility to give something back to the club... I mean, there was no one stepping up, we needed someone.” Lastly, there are 'liasonnaires,' a rotating group of TA who periodically meet with the FO to discuss supporter-related issues. Like other aspects, the liasonnaires operate on a purely voluntary basis.

During the course of data collection, the 107 Independent Supporters Trust (107ist) was established, slightly altering the Timbers Army organizational structure. The 107ist, based on similar British supporter trust models, is a member-based, non-profit organization. A yearly membership costs 25 dollars and provides members with a range of benefits (e.g. a membership card, discounts at local establishments, special merchandise). It also allows them to run and vote for officer positions in the Council of $X I$, essentially, an eleven-person board of directors facilitating different aspects of the organization.

Through a variety of channels, the 107ist aims to raise funds for tifo displays, to donate to charities, to initiate local, soccer-related projects, to provide an 'official' voice to supporters, and to protect the identity of the Timbers Army. The protection of the identity is important, signified by trademarking certain symbols like the group's crest. In sum, the Timbers Army has created a specific identity, and they moved to protect this as 
they enter the more corporately centered MLS so that they can maintain ownership of certain aspects. Ultimately, the two entities are related but slightly independent from one another; while the 107ist is member-based, the TA remains open to all. As Ernesto stated:

[The TA has] always been like this leaderless, I guess, anarchist group of people, and now, it's being - almost like being formalized into a non-profit group. Like the ethos isn't changed; if you were, you know, you are who you are, you're still Timbers Army, so come to the game and get a scarf - We will never charge for this. I think that's an important thing...to make sure people understand.

\section{Informal Expectations}

A frequent motto of the Timbers Army is, "If you want to be TA, then you already are," signifying that the group is open to anyone who wants to be a part of it. Because of the openness of the organization, respondents were hesitant at times to state that there were any specific requirements for inclusion. Nonetheless, throughout conversations and during field observations, it became apparent that there were certain, albeit informal, expectations and taboos for those who identify as Timbers Army. Many respondents referred to these "loose norms" of behavior as the Timbers Army "culture," or, as Doug put it, "the Culture of 107" and indicated that it is important for newcomers to understand this culture. Although Doug references a specific place in the stadium (Section 107), the Timbers Army spreads throughout and outside of PGE Park; as frequenters of the message board often express, the TA is not a location, but a "state of mind."

Many respondents were hesitant to define what it means to be a 'member' of the Timbers Army. David, one of the founders, said, “I don't really think of it that way... like 
[everyone has] their own kind of idea of what being a member is, I guess. There's no set kind of deal with that." Similarly, Avon, a 54-year-old native Portlander currently living in Vancouver, WA, did not have a clear explanation. He stated:

You just got to show up and be, you know, support the side. Sing and clap, I guess. You know, we've got the tourists ${ }^{20}$ and stuff, but I mean it's not really a member...it's really weird to be, you know, to consider myself [a member], you know. Well, that's just it - what is it?

These two responses illustrate the reluctance of participants to establish rules of conformity, and the difficulty they have in actually defining 'membership.'

Other respondents were more direct, pointing toward a loose set of expectations.

As P.T., a 50 year-old hairdresser, explained:

Basically, if you want to be in the Timbers Army, you come and stand with us and you stand the [entire] game, and you shout. And that's basically the only thing. And you don't even really have to do that, but that's the thing that we try to, like when new people... or when friends of mine come in or something, I'm like, 'here's the lyrics sheet, dude, and you're going to be expected to yell. And, you're going to have to stand. And, if you don't want to, you can go over there. That's cool, too. Because...if you want to be here, with us, you're gonna be expected to yell and shout, and sing for victory.'

As P.T.'s statement indicates, there are certain expectations for those in the Timbers

Army section. Others expressed similar sentiments, but also included caveats. Ernesto, a

39-year-old dockworker, explained that there are some expectations and informal indicators of group 'membership,' but that these are not categorically applicable:

\footnotetext{
${ }^{20}$ Tourists is a common reference for people who come into the North End/TA sections infrequently and to be there for the spectacle rather than to explicitly support the team. As the moniker implies, they are present to see the sights, but do not necessarily adopt the lifestyle of a Timbers supporter. Similarly, noobs, are individuals who come to matches, but are new to the Timbers Army (and, in some cases, to soccer in general). Though both tourists and noobs are uninitiated in regards to the Timbers Army culture, noobs often express an enthusiasm towards participation and a willingness to integrate into the larger group.
} 
There really is no formal membership... Once you're in the section and you have a scarf, you're Timbers Army. Or, even if you don't have a scarf, as long as you come there and you support the Timbers, and you have fun at the game, and you sing songs or scream obscenities, or whatever you want to do. I mean, that's pretty much Timbers Army.

Peter, a 34-year old teacher, added:

If you stand, and you sing, and even if you don't stand, and even if you don't sing, you're oftentimes, you're welcomed and you're appreciated and you're, as long as you're abiding by this weird set of loose norms then you're going to be accepted as a part of it, a part of something bigger than who you are.

Later in the interview, Peter continued explaining expectations by detailing what people should not do in Timbers Army sections:

And, yeah, everything's socially pretty much okay, as long as you follow a certain set of norms: Don't throw shit onto the pitch, don't be a doofus and sit down in a place where you know you should be standing - if you want to sit, go to the right place and be there.

Thus, participants are expected to 'support' the team and contribute to the group in whatever capacity they can, and if they are not prepared to do this, then there are other calmer places within the stadium where they can watch the game.

As Peter's last statement indicates, one of the major taboos within the Timbers Army is the throwing of objects onto the pitch. Although it occurred only at a couple of games throughout observations, some people, usually at a perceived bad call from the referee, do throw things at/onto the field. In one instance, someone threw a wine bottle from the 200-level section, narrowly missing spectators in the lower sections before landing on the field. Like similar incidents, other supporters and capos immediately 
identified and chastised the offender, thereby making him (in all observed cases the thrower was male) feel embarrassed and unwelcome.

Similarly, there are other prohibitions 'members' are expected to follow. As a whole, Timbers Army participants pride themselves on being an inclusive, diverse, and welcoming group, and as such, they do not tolerate racism or homophobia. As Arthur, a 40-year-old teacher put it, "You can say the most foul mouthed, abusive kind of crap to the players and to the other teams from within the Army, but you will get immediately shut down for yelling 'faggot;' wildly inappropriate and totally unaccepted within our culture." Observations and secondary sources corroborate Arthur's statement. As further evidence, an official blogger for the Seattle Sounders recently alleged that he heard racist chants coming from the Timbers Army. The response from the Timbers Army was swift, asking for evidence so that they could respond to the offenders. The accuser did not provide any reliable evidence and eventually issued a meek apology for the accusation.

In sum, the overall expectation is that individuals within the North End will actively participate in the collective effort to support the team. This includes standing the entire match, singing and shouting, and participating in tifo. Additionally, there are some informally forbidden behaviors such as throwing objects and engaging in bigoted language. When individuals break these rules, the TA responds by self-policing and publicly chastising offenders. Lastly, participants are aware that some fans do not want to engage in the same acts and respect these wishes but insist that these individuals have plenty of other spaces throughout the stadium to watch the match in a calmer fashion. Ultimately, Arthur best described the overall essence of being a Timbers supporter when 
I asked him what he felt the most important part of our interview was. His response, "Because I used the word many times already, I'll say it again; Participatory. It's that anyone who is in the Timbers Army is more than just a witness."

\section{'True Supporters Forevermore'}

The expectation of participation stems from the 'supporter ethos,' which is an integral part of the Timbers Army. The concept of supporters is prominent within global football, and TA participants' largely inform their definition of supporters based on external, foreign examples and awareness. Thus, it would perhaps be more prudent to include this in the section dealing explicitly with global contextualization, but because the term appears frequently, it is important to understand, early on, how participants define this concept and come to view themselves as supporters. Of note, some interviewees clearly distinguish between supporters and fans while others tend to use the terms interchangeably.

To begin, some participants described their conceptions of supporters. Bob, who spent most of his youth and adolescence in Italy, referred to the supporter's ethos.

Adding a personal touch to his explanation, Bob said:

I've always been a pretty stubborn person, so when I choose something, I stick with it. You know, through thick and thin, and that's really what the ethos of a supporter should be. You know, support your side through thick and thin...Usually, the supporter ethos also [involves] support[ing] your local side.

Moreover, in response to the question what does it mean to be a 'member' of the Timbers Army, Peter replied: 
Support your team any way you can. You've heard the phrase, "If you wanna be TA, then you're already TA." And that's really how it is, and it's about supporting as best you can and in the way that you can individually, and giving it your all in that direction. And if you don't, you're not supporting, you're a fan. There's a difference. Which is okay, but don't call yourself a supporter when you're not.

Though he does not offer a definition of what it really means to be a supporter, Peter views the Timbers Army as a supporters group and clearly distinguishes them from regular fans. Ernesto, on the other hand, not only placed his own participation within the category of supporters, but also offered a more detailed explanation:

Well, for me to support a team is I come in, you know, I try to do the best [tifo] display as possible. I try to sing for ninety [minutes] no matter what; try to get people into the game. It's like, if we're down two-nothing, just keep singing, or three-nothing, just keep singing. You know, instead of, like, not boo your team, not get all agro about it. I mean, it's disappointing, but then that's just part of the experience. I'm not sure how other people feel about support, but for me, it's like, yeah, going to the pub, getting all my friends together, going to the game and making sure we all sing ninety, and like, we have a good time win, lose, or draw. And make sure the boys know that we're there, you know, we'll be there regardless.

Ernesto's account clearly indicates that he is actively involved and routinely participates in "supporting" the Timbers. In addition, there is a social bonding component to his response involving friendship and a feeling of community that will be discussed shortly. Supporting a team, as respondents describe it, involves participating and coming to matches regardless of how well the team is doing. Doug, a 47-year-old carpenter currently pursuing a master's degree in education, contrasted this with what he sees as the American view of sports consumption:

People that pay money to go watch performers compete against each other; they feel like they're entitled to a win, and I'm guilty of that, too. Whereas, if you read some of these stories and people's accounts that live in Madrana, or live in 
Sheffield or whatever, they'll go and support their club no matter what is happening. They're still going to be there, 'cause they love the game and they love the opportunity for them to win, you know. They see it as, "Well, kick off time, that's an opportunity for us to win.' Not an obligation, 'cause in America, I think we have that kind of entitlement mentality.

Bob's following statement summarizes the distinction between supporters and fans and illustrates the uniqueness of supporter formations within the United States. Additionally, it adds an element of organized, group cohesion. In Bob's words:

I hate the term a group of fans, because it - fans - doesn't mean much in this country and in terms of organized support. I mean, you see every weekend 80,000 seaters for NFL filled with people, and they're all fans, and they're doing what they think is supporting - which it is to a certain degree - but they're all doing it on an individual basis. It's not like what the Timbers Army has, which is based on, you know, European and South American supporters groups where people come together collectively to work together to one end. Where it's like, not just one person making a little sign, you know, that makes a play on NBC letters to get on TV. It's everybody coming together, and sure, if the cameras see it and show it to the world, that's great; that's a plus for our club. But it's not the direct aim of, of these, you know, supporters. It's for the team to see what we're doing, and for them to get inspired by it. To show that they have us at their backs, and that we're going to do whatever it takes to push them onto victory. So, that collective group of people working as one is what makes it unique in the States in terms of fan groups.

Like others, Bob clearly sees the Timbers Army as a supporters group based on international models. Similar to Doug, he also contrasts this with an American view of sports fandom, ultimately finding the Timbers Army to be unique in this regard.

\section{The Timbers Army as Community}

One of the most salient themes throughout interviews was that of community. In some form or another, participants unanimously mentioned that the Timbers Army constitutes a distinct local community defined by inclusivity that draws people together 
from divergent backgrounds. Although soccer is the cohesive element, participants generally spoke about the TA in non-sports-related terms using words such as community, collective, family, and camaraderie. In addition, there are many subcategories within the theme of community: unity and social cohesion; inclusivity and diversity; a strong civic pride; and lastly, a belief that being involved in the TA is indicative of participating in 'something larger.'

Some respondents explicitly described the Timbers Army as a community. For example, Kristen, a 37-year-old healthcare worker, was very clear; when I asked her what the most important part of the interview was, she promptly replied, "This is a community." Others were just as straightforward. Bob stated:

It's community. It's coming together for a common cause. It's giving your all for the full ninety minutes. And, you know, for those who can, because not everybody can, it's for putting in extra time, free stuff, making banners, or doing, helping out at a table, or whatever you can. Some can, some can't and...you do what you can. There's not really much else to say. It's the collective.

In a similar manner, Arthur described the Timbers Army in communal terms when explaining what it is that sustains his participation:

Beyond simply that it's fun, there's a sense of belonging. There really is a sort of camaraderie of people. I've gained great friendships here... It would be hard to point to, say, the Blazers, the Beavers...the other major sporting events in the Portland area. Or, pick any city and see any kind of community that genuinely sprung from those. Yeah, sure there's a sense of collective identity while you're at the game maybe, but the Timbers Army is spread well beyond that. You know, of meaningful connections.

Arthur later continued highlighting the significance of community within the Timbers Army and compared this to other supporter groups: 
Certainly, we follow the profile of the supporter anywhere in which the individual, at least for ninety minutes, becomes not the individual, but part of the collective. But I don't know how much it extends beyond that [in other places], because, as I say, I think we are very unique in the sense that we are incredibly inclusive of non-white males. And, that it is from a very participatory element and that that's true for lots of places...But, I don't know that there's this true sense of community [with other supporter groups] in which people all know each other, or will welcome them in.

For Arthur and others, the Timbers Army is defined by a sense of camaraderie and community, brought together by supporting the local soccer team.

While some interviewees clearly associated the Timbers Army with community, others described it in terms of friendship and family. Sam, a 54-year-old nanny who regularly attended matches during the NASL days and began sitting in the North End during the Timbers' first USL season, described the group as "a family," noting, "because that was the original feel that [she] had from them." Peter went a bit further in his description, but ultimately echoed Sam's response when he said the Timbers Army is:

[A] loose-knit group of supporters that are bound together by supporting the PTFC and consider it...just as much a lifestyle as it is a sport to follow...instead of just keeping the stats and being just casual fans, it's about having a relationship with the entire club, I would say. It's a family, I would say.

Others described the friendship evident within the community. Kristen explained:

I feel that the more I get to know people, this is very friendship-based for them. So, it's not just the sport and the soccer, but it is getting together and being with people and looking forward to being with people and meeting friends...It's fun just to watch it, and I love it, and I love the people that are, you know, are extremely passionate about it for the friendship.

This friendship and familiarity extends beyond those with whom participants are intimately familiar. Because of the size of the Timbers Army, it is impossible for a 'member' to be close with everyone else. Despite this, they feel a connection established 
through mutual participation in the group even if they do not know one another's names.

As Avon commented:

I've been going for like four years, and I know like ten guys by name, you know. And, everybody else, it's, 'How ya doing?' and you wave to them and say, 'Hi.' But, I don't know their fucking names. I don't know half of their board names. But I know them, you know; I know where they stand, I know what they drink, I know what their kids look like.

Emma added:

I'm not that social [of a] person, so for me to be involved at the level where, you know, I know all these people and go up and say hi to them. You know, and to walk along the concourse over at PGE Park before the game and to know so many people. I don't know most of them by name, some of them...I know they're on the message board, but I don't know who they are. But, I know I know them. And, I can go up and talk to them.

Emma's statement illustrates how this feeling of community draws out a more social side of her than she usually experiences. As all of these quotes indicate, participants find friends through their participation in the group and feel a mutual bond with others even if they do not know them personally.

Participants frequently describe the Timbers Army as diverse, welcoming, and inclusive. As Emma stated, "It's a loosely knit but very passionate group of soccer fans from all backgrounds who are united behind supporting the Portland Timbers...It's a very loose and very welcoming group." Kristen described it similarly, adding that the unifying aspect of soccer produces a sense of awe for her:

One reason I find it so fantastic is it's completely all different walks of life. It, everyone is so randomly different, but everyone likes each other 'cause they all support the same thing. And, I think that's why people really enjoy it, is just that one thing in common, and it blows me away. 
For many participants, diversity is one of the most significant aspects of the TA and illustrates an aspect of hybridization that contributes to the overall group identity. Avon's statement encapsulates this sentiment nicely:

Well, one thing is, you've got an old fucking white guy that's in management, you know. And, I'm standing around with college kids and anarchists. And people from, you know, foreigners, and we all just kind of come together. I mean, that's the coolest thing about it, just the hodgepodge of different people from all different cultures and races, and we're there for one thing.

Along with race and culture, Avon mentioned political affiliation and occupation as contributing to the diversity of the Timbers Army. At least three other respondents also mentioned these characteristics when describing the TA's diversity.

One of the most distinctive features of the Timbers Army is the large proportion of women, especially when compared to other supporters groups. While still a numerical minority, I consistently noted that during games and smaller group gatherings, the ratio of women to men was approximately 3 to 5, and I estimate women to make up 30-40 percent of the overall group. As further evidence, the 107ist's board of directors consists of three women and eight men elected by members of the 107ist. ${ }^{21}$ Notably, there is also a female capo, something I have never witnessed nor heard of throughout the world of football supporters. $^{22}$

On the surface, the Timbers Army is largely White. However, there are numerous non-White participants who appear to feel comfortable and respected. From observations,

${ }^{21}$ Of note, my sample of eleven participants has the same proportion of women to men as the 107ist's board of directors.

${ }^{22}$ Likewise, Tom Dunmore, editor and contributor to Pitch Invasion, an internet blog covering numerous topics pertaining to soccer and its culture, notes in a piece about capos, that he too, has never heard of a female capo (See Dunmore 2009). 
it is clear that the TA strives to become more racially and ethnically diverse, and as previously stated, the group is conscientiously anti-racist. In the end, the Timbers Army seeks to create an open, welcoming atmosphere for everyone. Arthur - emphasizing issues of race, gender, and sexual orientation - explained why he describes the TA as an inclusive group:

There is a great feeling of camaraderie. As I say, the Army is incredibly inclusive. And I mean that [not only] in terms of just welcoming people, but also... in the sense that Portland's incredibly White and that's still going to be the case for the Army, but that people of color are very welcome, and there have never been any kind of incidents. And, that we adopt lots of things from our Mexican and South American members, from Eastern European people...but, more so, there's probably in the Army a significantly, if not monumentally, higher participatory aspect by women than probably any other major sporting event in the country. Really welcoming of women and also of non-heterosexual aligned people... A combination as I say, part because kind of a leftwing background. There are people who are conservative or who are not left, but if you were to categorize it, and slightly even more than the liberal that is Portland. As a result, that's part of [why] I say it's inclusive.

Arthur's statement summarizes the aspects of community that others continuously brought up during interviews: camaraderie, inclusivity, and diversity. It also illustrates an important facet of the Timbers Army: reflecting and connecting to Portland.

\section{Reflecting and Connecting to Portland}

One important aspect of the Timbers Army community is an intense connection and loyalty to the city of Portland. It is extremely common to see Portland flags sewn onto scarves or other articles of clothing among the Timbers Army. As mentioned, in addition to lauding the team and players, numerous chants praise the city. Furthermore, 
interviewees repeatedly provided nuanced descriptions of the high importance the city has in the group's overall collective identity.

Before beginning the research, I expected the group to attach strongly to Portland, but it became obvious at an early stage that the city and the team are two of the primary focuses of the group. During the pre-season organizational meeting, the main speaker referred to a trinity comprised of the Portland Timbers, the Timbers Army, and the city. Thus, at an early stage in the research, this was already becoming a dominant theme, and it continued to arise during interviews. Arthur stated that the Timbers Army and Portland "are intimately related." Additionally, Ernesto referred to the Timbers Army as "a huge reflection of Portland itself," and later stated, "It's just people that actually love the city and enjoy watching the Timbers play. And they all feel the same passion and sit in the same section." Bob invoked the same connection to place and reiterated the idea of a diverse yet unified group when he described the Timbers Army as:

....an incredibly diverse group of individuals who come together for the love of their city to cheer on a team that represents them and their values; basically, through thick and thin. You know, through whatever happens - come what may all these people from all kinds of different walks of life, they come together and they do whatever it takes - yelling, singing, dancing, painting - to support their team and to show the love for their city.

As Bob's statement indicates, the TA's love of Portland is commensurate with other aspects of the group: participation, loyalty, and active involvement.

Others pointed out how the Timbers Army actually facilitates a connection to the city rather than just reflecting it. Ernesto explained:

I think the whole thing [is] that you're proud to be, like, people love Portland. They're proud to live here. And they see, like, 'Wow. There's a whole group of 
people that are just crazy about this team and crazy Portland people, I want to be a part of it.' It gives you kind of an identity, you know, if you're new here, or you lived here for a while and you never realized there's a bunch of, you know, a group of crazed fans that support soccer.

Peter reiterated how the Timbers Army provides a collective identity closely tied to the city of Portland:

I like that they are so hooked into the city and hooked into Portland, and...I'm not just supporting the club, I'm supporting Portland in general, and I like the sense of identity...It's maybe made me even a little bit more, more proud to be a part of something, proud of Portland I would say. And, maybe even a little bit more prideful in the region.

He later explained how this is socially and ritualistically accomplished:

That naturally happens, especially when that is reaffirmed, at least communally, fifteen times a year in this group, in this group of thousands of people reaffirming that this is a beautiful place to live... we have reason to take pride in here. And I think there's something, maybe not even connected to the Timbers, but it allows us to, it allows - it might even be a peer pressure thing - I don't know, like 3000 people telling us, that Portland is a beautiful [place to be]. You know, "We love you so, and where you go, we will follow."

From Peter and Ernesto's accounts, along with observations, it is clear that the Timbers Army not only displays a love for Portland, but for some, actually facilitates a connection and identity tied to the city.

As further evidence, Peter's last statement cited a chant frequently heard in the North End. The Timbers Army uses similar chants to express love for the city, but the most striking of these is Rose City Till I Die. As previously mentioned, this chant only appears when opponents score. With their scarves held aloft, displaying the Timbers Army side, participants sing "Rose City till I die...I know I am, I'm sure I am, Rose City till I die." Using one of Portland's nicknames, this action illustrates that, even in the 
worst of circumstances, participants are essentially wed to the city and will offer their support to the team regardless of the outcome.

\section{Something Larger}

Finally, this community extends well beyond PGE Park, the Timbers, and perhaps even the city of Portland. The following two quotes sum up this idea and serve as a segue into how participants in the Timbers Army conceive of themselves in larger social terms. First, Doug said, “There's definitely a level of pride there. I think anybody, no matter what your affiliation, or how long you've been calling yourself a member of the Timbers Army, you're definitely a part of something much, much bigger." And, in Peter's view:

There's a resonant chord that, that being a soccer supporter hits with everybody. Again, it comes back to this community and being a part of something greater than ourselves...And, I think that's what the PTFC offers and the Timbers Army offers is being involved in something greater than ourselves; in this community that's something bigger than what we are in our individualness, that there's something greater as a whole.

It is unclear whether respondents are referring primarily to the overall Timbers Army organization as 'something larger,' or if they are referring to participation in a broader global soccer culture. Either way, the Timbers Army, while constituting a distinct local community, interacts with and is aware of a much larger community of soccer fanatics that extends well beyond Portland. 


\section{Part II: Beyond Portland - Rivalries, Friends, Region, and Nation}

Thus far, I have described the Timbers Army and presented the ways in which participants view the group as it relates to the local. Now I turn to the ways in which the TA interacts with the soccer world outside of Portland. In this section, I present findings related to regional rivalries and the ways in which 'members' contextualize their experiences and the overall group relative to their understanding of soccer and other supporters groups in the United States.

\section{Rivalries - A Regional Construct}

For the Timbers Army, there are two main rivalries in terms of teams and their respective supporter groups: 1) The Seattle Sounders and 2) the Vancouver Whitecaps. All three teams (including the Portland Timbers) played in the original NASL and have had various incarnations since. This sets the stage for a historically fueled rivalry between each team. The Sounders, previously in the USL, began playing in MLS in 2009. The Timbers and the Whitecaps will move to this league in 2011 restoring Cascadian Rivalry. This tripartite rivalry is highly important to each team's supporters evidenced by the Cascadian Cup; a supporter created trophy awarded to the winning team's supporters group. $^{23}$

\footnotetext{
${ }^{23}$ The Cascadia Cup, established in 2004, pits the three teams against each other with different points allocated for wins and ties during regular-season matches. The team with the most points wins the Cup, with its supporters' group holding onto possession of the trophy. During the 2009 and 2010 season, the Cascadia Cup was contested only between the Vancouver and Portland teams because Seattle was not in the same league. The Timbers had never won the trophy until 2009 and retained it during the 2010 campaign.
} 
Each team has a main supporters group with Seattle's being the Emerald City Supporters (ECS) and Vancouver's being the Southsiders. ${ }^{24}$ Although both teams are rivals, the Timbers Army exhibits an absolute vitriol for all things Seattle, while Vancouver supporters enjoy a much better rapport, separated by 90 -minute intervals of mutual derision. Thus, this Rivalries section comes in two segments: the first concerns the Seattle Sounders (aka, 'Shittle Flounders') and the second pertains to the Vancouver Whitecaps (aka, 'Wankover Shitecraps') and their respective supporters groups.

\section{Us and Them: Seattle Supporters}

I don't think we have any problems with any supporters groups in the world other than Seattle. -Emma

I would sooner walk a mile to piss on their grave than I would to cross the street to save their life....This is Hatfield and McCoys to the Nth power, and it's been a great ride over the years. -Arthur

As the opening quotes demonstrate, the Timbers Army harbors an intense abhorrence for the Seattle Sounders and their supporters. This rivalry, as interviewees indicate, has little to do with soccer, but is the result of an already extant enmity between the two cities; the hostility merely shows itself very strongly when football is involved. There is a feeling within the Timbers Army that denizens (and thus, supporters) of Seattle

${ }^{24}$ The Sounders, like the Timbers, have other subsections of their main supporters' group. While I refer to the ECS as the Sounders' supporters' group, some instances may involve other extensions. Therefore, I use $E C S$ to refer to the Sounders' supporters in general. Prior to the establishment of the ECS, the group was called The Pod. As for the Whitecaps' supporters, there may be subsections of the Southsiders but I do not know of any. 
believe Portland is, as Arthur put, the "younger, dumber cousin" to Seattle. Additionally, the Timbers Army finds numerous reasons to dislike Seattle supporters. The following documents the ways in which TA participants conceive of themselves relative to Sounders supporters and illustrates the importance of this rivalry in the construction of the TA's collective identity.

The Seattle-Portland soccer rivalry extends beyond the game, but soccer becomes the vehicle through which supporters display their city's virtues over the other. As Peter stated, "there's always been a rivalry between the two cities. Take soccer completely out of it and...there's this rivalry, tension. Then to give a stage for that really makes sense that it would just blow up for that rivalry and that sort of animosity." Bob offered a parallel explanation, relating it to soccer rivalries throughout the world:

Seattle people probably see themselves as superior or whatever to Portland just because they're a bigger city in the same region, and that happens in all other footballing nations in the world. It's the same thing: big city people, big urban centers, people who live in them tend to look down on anybody who comes from the countryside or even just a smaller city than them... I mean, rivalries...the way I grew up with them [in Italy], are all about regionalism. It's all about people in the same town supporting different soccer groups or people within the same region, whose cities have historically had, you know, rivalries anyways that then transmute those rivalries into their soccer teams.

Thus, this rivalry is akin to others geographic rivalries and is merely amplified by the sport.

While the rivalry is partially based on geographical proximity, other aspects intensify it. Many interviewees cited instances when they felt they or other participants were treated unfairly - mostly by security - while attending away matches in Seattle. 
Emma recounted one such occasion, which she marks as elevating the animosity between the two supporters groups:

And I saw that year, a Timbers Supporter get pepper-sprayed in the face for asking questions. He was asking why another fan got ejected and he kept asking. Finally [security] sprayed him right in the face. And they had four or five Timbers fans on their knees with their hands behind their heads. I think that game is when it turned really hostile, to be honest... That was the 2004 playoff game; the second game of the series up there where we lost. ... It turned very hostile - I think that game turned it- I've not been up there since.

Others told similar stories, and like Emma, some indicated that they did not want to return to Seattle because of their experiences with either the other team's supporters or security.

The geographic proximity between the two sides put them into reoccurring contact with one another resulting in the two groups developing alongside one another, and many Timbers Army members say they have always outnumbered Seattle's supporters. Thus, as respondents tell it, the ECS (or, the Pod, as Seattle's supporters group was once known), began to grow in response to the Timbers Army and allegedly adopted Timbers Army chants as their own. ${ }^{25}$

Although they had a relatively small fan base and supporters group during their USL days, the Sounders' attendance levels exploded upon entering MLS. In 2008, their last season in the USL, the Sounders averaged 3,386 people per regular-season game (Andrews 2008), but during their first season in MLS, Seattle set a new MLS record for average, regular-season match attendance at an astonishing 30,943 people per game

\footnotetext{
${ }^{25}$ There are certainly chants which both supporters' groups use, but I do not purport to know which one came first, though TA members will be among the first to say that the ECS copied Portland chants. In fact, many of these duplicated chants are derivatives of ones used by foreign supporter groups.
} 
(Sounders FC Public Relations 2009). The American professional soccer scene took notice and applauded the atmosphere at Sounders games, thereby escalating the Timbers Army's ire. Rather than being subdued because Portland and Seattle would not meet each other in regular-season play for another two years, the rivalry grew stronger. As Ernesto explained:

It has made the rivalry quite stronger. 'Cause, now, they actually think they are better than us, but no matter what, we'll always be better than them, because we've supported our team, our growth has been from day one from the twelve guys banging buckets to the 2000 people that show up now. And, it's going to get bigger and better. I mean, but as far as like, how we do things, we'll always be way better than they'll be, because everything we do is ourselves.

Ernesto was the only one who explicitly stated the rise in attendance adds to the rivalry. Nevertheless, many interviewees referred to Seattle's explosive attendance and expressed both contempt and awe at the achievement. Interestingly, they spoke in wholly oppositional terms about Seattle's supporters; whereas the Timbers Army are 'independent,' 'organic,' and 'DIY,' the whole Seattle club, including its fan base, is 'corporate,' 'plastic,' and 'manufactured.' In addition, the new Sounders fans are frequently referred to as 'customers.' The following three quotes represent commonly held beliefs in the Timbers Army. Emma said:

I separate their supporters from the big, you know, attendance they have, the customers. So, they have, they probably have about 500-1000 supporters who are kind of organized... You know, so they do, but they were a very small group until all these new fans were added in the last year, you know after - I don't know how they did it, but you've got to give them credit for it, but their supporters' sections is still relatively small. And they do lead chants and stuff over the PA now like at an NBA game.

P.T. added: 
And when I was [in Seattle] I started to actually realize, 'Holy shit, they do have something going on here.' Granted, you know, they're customers, and it's kind of this whole manufactured thing... As a Timber[s] fan, I can sort of see that it's, you know, just fake, and I hate them, but as far as the MLS goes, it's like, 'Wow, that's awesome...' I think that's inherently good. It's just that since it's Seattle, it's kind of like, 'Fuck,' because you want to hate them so bad... If that had been generated more organically, it'd been like, 'Okay.' But, the fact that it's so completely manufactured. It's just like so blech.

Lastly, Arthur stated:

There's apparently 30,000 of them now, but for the previous nine years, there was maybe 3000 of them. And that was just people in attendance. In terms of supporters, they would have about twenty. And it is very much that, you know, high-powered marketing and really, a successful PR coup has produced something that is incredible in terms of the, I'm putting up air-quotes, but 'Support' that they have up there, and that the number of people that are coming out to see professional soccer in America. Great, fantastic. I'm all for that, except that they're Shittle... I am happy that the sport is doing well in America. And, it's very much the idea that everything is provided for them by a corporation at a profit. It makes them very much customers as opposed to the[...]Timbers Army; we're participants.

In sum, TA members ultimately believe the Sounders' outstanding attendance is good for

American soccer. Simultaneously, it fuels the pre-existing contempt they have for Seattle.

Finally, the above quotes show how TA participants define themselves in opposition to

Seattle supporters.

\section{Respectable Rivals: Vancouver Whitecaps}

Vancouver...the fans up there are, they're nasty when you're at the match, but they're really nice when you're away from it. - Sam

Unlike the Seattle-Portland rivalry, there is a mutual respect between Whitecaps and Timbers supporters. This rivalry revolves more around the actual matches than a 
fundamental hatred between the two sides. Supporters from each side often travel when the teams play each other. While there is an Orwellian-esque 'ninety-minute hate' between supporters groups during the contests, outside of matches there is a generally good-natured relationship. I did not travel to any away games in Vancouver, but when the Southsiders visited Portland in 2009 and the Whitecaps ended the Timbers' playoff bid, many Timbers Army 'members' congratulated the visiting supporters and shared drinks with them at a local bar.

Interviewees stated that they enjoy the rivalry with Whitecaps' supporters. Peter explained: "[They are] good, nice, cordial people that want to propel the game of soccer, but then to be complete enemies for ninety minutes. They're good at turning that on and off, and I like that about the Southsiders." Similarly, Arthur explained how the two sides generally interact:

There is incredibly cordial relation of we'll say horrible things about them on the field and in the terraces but then are happy to meet up afterwards. And, that's generally how it's been up there. Almost every time I'm up there, lots of people come shake my hand, thank us for coming, say '[We] really enjoy it. It adds to the atmosphere, it's a great time.' It's never the case in Seattle. Never the case!

Of note, at the end of his statement, Arthur vigorously contrasted the Timbers Army's relationship with Vancouver supporters to their relationship with Seattle supporters.

Two respondents said that in the past there were actually more physical altercations with supporters from Vancouver than with those from Seattle, but these incidents apparently do not taint the relationship between the two supporters groups. David alluded to these altercations when he said, "they support their team pretty well, and...there's been more intense times, I think, like with Vancouver as far as one-on-one 
situations, but in the end everybody, it's like, I don't know. It's like they understand passion, I think more than Seattle." Thus, despite these 'more intense times,' the two sides seem to share a similar passion for their side that appears to ameliorate any negative feelings caused by individual scuffles.

Observations and respondents identified two main rivalries of the Timbers and the Timbers Army: the Seattle Sounders and the Vancouver Whitecaps. Both teams exist within a relative geographic proximity to Portland, but there is a palpable hatred for the Sounders and their supporters and fans, whereas the Whitecaps and their supporters are held in a higher regard. Ultimately, TA participants define themselves largely in opposition to the Sounders' fan base, but find more in common with Vancouver supporters.

\section{The National}

At the national level, the Timbers Army is internally and externally recognized as a unique, authentic supporters group. This is due to a variety of reasons: (a) They are one of the largest supporter groups in the US at all levels of soccer. (b) The Timbers Army has grown over the past ten years independently from (and, at times in opposition to) the Front Office while participating in the second division of U.S. professional soccer. (c) Other groups outside of the city and region recognize and highlight the actions of the TA and the atmosphere they create.

Timbers supporters are cognizant that in the United States, soccer and its supporter culture is, as Bob put it, "something which is underground in this country." 
P.T. referenced the marginalization of soccer in the U.S. while recounting a Saturday

Night Live skit wherein soccer was the punch line to a joke. He recalled:

It was funny. But it was also kind of like, "Damn. Why are we the butt of a joke?" Because, we're not, you know, we're kind of still a joke. It pissed me off that we don't get the kind of attention. I mean we can't get it in the paper, you know, we just can't get it.

Because the sport is marginalized within the United States, there is - despite some rivalries - an air of solidarity between American supporters groups, and the Timbers Army is one of the best-known groups in the country. News articles and blogs frequently feature the group, and, as previously mentioned, the TA received the 2009 MLS Supporters Award for the best tifo display. Furthermore, following the July 2009 Open Cup match between Seattle and Portland, a large, full-color photograph of the Timbers Army in action appeared in Sports Illustrated. Moreover, some interviewees explained how they felt welcomed when visiting other cities and attending MLS matches because of their affiliation with the Timbers Army. Lastly, there are inter-group connections between other supporters groups, most prominently seen in the Section 8 (of Chicago) and Timbers Army 'Alliance.' All of these factors influence the ways in which Timbers Army 'members' view themselves and the group.

Participants view the Timbers Army as one of the best and largest supporters groups in the United States. Comparing the TA to other groups in the USL, Doug expressed:

I think as far as our league, Timbers supporters, Timbers Army is unique, if you look at the USL, and I've been to enough pub watching, where you see a match on some satellite feed, and end up watching these different clubs, and when we're 
playing Rochester and we're playing in Atlanta, and you know, it's crickets. There's nobody there, even their hardcore support base pales in comparison.

Others responded similarly, but placed the Timbers Army into a larger realm that includes the MLS as well. Avon stated, "Nobody at this level has anything like it. I mean, we're approaching over what people do at the next level," and later in the interview, "We're not even MLS yet, and it's like we're peers already." Similarly, Arthur, bridging the gap between the first and second divisions, stated:

Certainly at our level, the Timbers Army is bar none, the biggest supporters group in the country. And, you could make an argument for in the nation, period, or North, well I can't say North America because of course the Mexico league has huge supporters group[s], but within MLS or USL/NASL.

Arthur later continued:

There are certainly huge fan bases, yeah, but within just the supporter groups, I don't think there is much else in the United States and Canada that compares...in terms of numbers... and that's quantity. In terms of quality, I don't think you will find things that are better in terms of participatory, DIY, inclusive; the things that I think are really our hallmarks, and that are active. You know, we are fanatical in the best of possible ways.

Likewise, Emma said the Timbers Army is among the best supporters groups in the United States, comparing it to two other well-known groups:

Normally you'd talk about the best supporters [in the United States], you'd talk about DC United, Chicago, and us. You know, we're above most of the MLS already...The only thing that's holding us back right now is that we're in the USL. But still right now, we're talking about, what $-1000,1500$ a game?

Like Emma, other participants frequently referred to the DC United and Chicago Fire supporter groups as American exemplars and placed the Timbers Army alongside them in terms of quality. For example, P.T. explained: 
[The Timbers Army is] better than anything I've seen. I mean, even when I would watch DC United or Chicago, they might have more people, but it just seems like to me we have more heart. And I don't know, I mean, it's hard for me to say, because I'm in the middle of it[...]so, of course, I think we're great[...]I think we got it.

At the national level, participants are keenly aware of other supporters groups, but also frequently noted that other groups in the U.S. are aware of the Timbers Army. This constitutes a reverse awareness whereby the Timbers Army is recognized and legitimated by other supporters groups. Broadly speaking, David alluded to this when he said:

People pretty much know who the Timbers Army are, as far as people [in the United States] who follow soccer. I'd say up until about halfway into last year, people knew who the Timbers Army were, but they didn't know who the Timbers were... I mean, yeah, you could ask someone if they knew who the Timbers were, and they'd probably say no. And then, if you asked them who the Timbers Army were, they'd know exactly who they were even if they'd never been to a game.

David later explained that other supporters groups respect the Timbers Army:

There's respect. I mean, if you go on message boards or whatever there's always - like when you put up supporter's photos that's supposed to be MLS, they have no problem with us putting stuff up like that. I mean, we're going to come in with an already established club.

Others had more pointed examples of reverse awareness, sometimes citing their

experiences while attending MLS matches in various cities throughout the country.

Kristen recounted an anecdote about her time at a New England Revolution ${ }^{26}$ game: $^{2}$

The fans were really quiet and we were like, "What the hell is going on? They're just not hardcore like we are." And, next thing you know, they erupted. We're like, "Oh god, we're going to go sit over there." So, we got up and when we went over there and when they noticed we were Timbers Army fans, they're like, "We did what you guys did." And we're like, "What are you talking about?" And they [said], "We protested the first couple of minutes of the game." They sat down;

\footnotetext{
${ }^{26}$ An MLS team based near Boston.
} 
they were purposefully silent 'cause we did that years ago at a game, because we were told we were being inappropriate, and all these different things, so[...] the Timbers Army was quiet during the [game].

In another example, Avon recalled a time when he attended a D.C. United match. He contacted one of the main people in Barra Brava, one of the DC supporters groups. ${ }^{27}$ Because of his affiliation with the Timbers Army, Avon was provided a ticket to the match, invited to the pregame tailgate where they supplied free food and beer, and then stood with Barra Brava during the game.

Lastly, there is an affiliation with Section 8 of the Chicago Fire. A group of Chicago supporters came to Portland during the summer of 2009 and travelled with some TA participants to a match in Seattle between the Fire and the Sounders. Commemorative scarves announced an 'Alliance' between the Timbers Army and Section 8. David described the association:

There's a loose [affiliation] with Chicago. And, it's not necessarily like we're fans of Chicago or anything like that, but it's more like a respect, like we respect each other, or whatever. 'Cause Chicago kind of set the standard for the league. I mean, they don't run their organization like how we run it, it's totally ran differently, but there's like, but like the passion and just the way they deal with the team is the same, you know.

Ernesto added:

There's the so-called alliance with Chicago. They came out here a couple of years ago, and they've always shared a wealth of information with us in regards to their organization, and you know, their flag suppliers or scarf suppliers. They help mentor - not how we support or how we do things - they help mentor how we should organize ourselves, because they understand, you know, there's going to be huge eventual growth in the section, and in order, you know, to capitalize to

${ }^{27}$ DC United has a number of well-known supporters' groups: Screaming Eagles, Barra Brava, and the more recent addition, District Ultras. In this study, the only one participants referred to were Barra Brava. 
our benefit and to what we do, we need to organize a certain way, which is what the non-profit's going to be.

As the preceding quotes illustrate, the Timbers Army is in direct contact with Chicago's Section 8 , and there is a mutual respect between the two supporters groups. Nonetheless, respondents were quick to point out that while they have a loose affinity for Section 8 , the Timbers Army is, in some ways, different from Section 8 and other groups.

It is obvious that participants view the Timbers Army as one of the best supporters groups in American soccer. They frequently name two other MLS teams' supporter groups as leading the way: Chicago Fire's Section 8 and DC United's Barra Brava, and, despite the lower division in which the Timbers play, they feel they are on par with these groups. While they place themselves at this level, they also distinguish themselves from these groups because of their history of support at the USL level. As Emma said, reiterating one of David's statement, "we're gonna be set apart from those groups...in that we're going to come in pretty frigging established." Bob echoed this when he said:

It's different because we started in the minors, we grew from... a couple dozen members and, I guess, most of those groups did start out with small groups and amped them up to the numbers that they are today, but few can claim to have started in the minors and to have developed a fan base in the minors before we ever hit the majors. I mean, we have a proper supporters group. We have 2-3000 people in the curva ${ }^{28}$ almost every weekend for minor league soccer.

Ultimately, the Timbers Army is keenly aware of the American context of the sport and different teams' supporters groups. Their position of being considered one of the most ${ }^{28}$ Curva is another word - Italian in origin, but also used elsewhere, particularly in European countries - to
describe where supporters stand. 
successful such groups also rests upon external validation and a reverse awareness, meaning that they are not only aware of other groups, but that these groups are also aware of the Timbers Army.

\section{Part III: The Global}

Toward the end of the 2009 season, the Timbers began their MLS marketing campaign. The first advertisement produced by the Front Office ran for several months, appearing on the outside of MAX cars, ${ }^{29}$ on the Internet, and in the local newspaper. The ad featured the Timbers Army in action, with yellow and green streamers aloft.

Juxtaposed over this image, in yellow lettering, were the names of four well-known soccer clubs: Liverpool, Milan, Barcelona, and Madrid. Rounding out this list was Portland, written in white. The advertisement exclaimed, "Finally, we are on the world's pitch" (see Appendix E). Based on this advertisement, the FO connected the 'promotion' of the Timbers to MLS with 'real' support and compared the club to famous ones in Europe. Obviously, the FO saw the global reach of soccer and attached this to the local; in the process, it used the Timbers Army to convey the bridge between the local and the global.

Throughout data collection, it was clear that the Timbers Army draws heavily from foreign supporters groups in constructing its collective identity. Because the sport and its culture is on the margins of mainstream society and until recently, was - at least in terms of consumption - relatively difficult to come by in the U.S., those who wanted to

\footnotetext{
${ }^{29}$ The MAX is Portland's light rail, part of the city's public transportation system.
} 
follow the game, had to watch foreign leagues. In turn, this exposed people to foreign supporters groups. Hence, when the Timbers Army began, and as it grew, it adopted, emulated, and localized external supporter traditions.

In addition to the practices and behaviors at and away from matches, the use of soccer argot and specific terms such as ultras, tifo, supporters, capos, and football signifies an internalization of global soccer lexicon. Moreover, by standing in a specific end of the stadium and using smoke bombs, chants, and banners, the Timbers Army is clearly adopting behaviors exhibited by supporters throughout the world. Further, many of the chants are derivatives of those used by foreign supporters groups. As participants explained, the TA appropriated numerous chants from English supporters, while others are local adaptations of chants from other places in the world, such as a version of Dale Cavese, originally a Boca Juniors (from Argentina) chant, or a loose rendition of Horto Magiko, a chant originating from Panathinaikos (from Greece) supporters. ${ }^{30}$ There are many other examples of appropriated chants, symbols, and behaviors that combine to produce the overall effect of the Timbers Army. Ultimately, the TA creates its own distinct identity, but does this by selectively appropriating from the 'symbolic warehouse' (Hobsbawm 1983) of global supporter culture.

Even at the incipient stages of the Timbers Army, the group had global influences. After learning that David was one of the founders, I asked about his initial

\footnotetext{
${ }^{30}$ Some TA participants say the group does not have a Horto Magiko chant because of certain differences between the Timbers Army version and the original. Nevertheless, the chant is obviously an adaptation wherein the Timbers Army created its own version; instead of Horto Magiko, participants call this chant North End Noise or, alternatively, the Greek Chant.
} 
desire to form a supporters group. David answered, "I mean, just my whole life, I've watched stuff that happens in Europe, and I've been to matches in Europe and Mexico and stuff like that, so I...figured why not here." Hence, the very origins of the Timbers Army rest in an awareness of world soccer culture.

Like David, many participants in the Timbers Army are well travelled. In fact, all interviewees said they have travelled abroad. Significantly, eight of the eleven have also attended matches outside of the United States. Additionally, all but two respondents said they follow foreign leagues, and eight of the eleven actively follow specific teams in these leagues. All of these experiences provide a general reference for participants to conceptualize how their group fits into global supporter culture.

These experiences and the resultant globally attuned awareness allow participants to further understand and appreciate other cultures. As Arthur stated, "One of the beauties of the sport, is that there are wildly different cultures, and their football cultures reflect that in the way that different supporters groups operate in different countries." As an example, he explained how he "was a little shocked" when he attended a West Ham United game in London and heard "really coordinated, but impromptu" chants from home supporters admonishing West Ham players. He continued his anecdote by citing his experiences in East Asia:

Contrast that with, I went to a few matches in South Korea, where ostensibly, they look very similar: there are flags and banners, there's clapping, there's chanting, there are songs. But that it was very much an even cadence just support of your own guy. They had lots of personalized chants for all of their players, and while they laughed hysterically at the adaptations I had made that were abuse towards the other team based on Timbers chants, it was something that was a bit beyond 
the pale for them. And...they found it funny, and they kind of liked it, and they liked hearing me do them, but that it was not part of their culture.

Of note, Arthur placed the Timbers Army somewhere in between his West Ham and Korean soccer experiences: he was 'shocked' at Upton Park (where West Ham plays) because supporters denigrated their own players, something the Timbers Army does not publicly do. ${ }^{31}$ Yet, Arthur notes that the Timbers Army is "famous...for reviling the others." In contrast, Arthur found South Korean supporters much more likely to eschew this type of behavior in favor of only praising their own team and players. Like Arthur, respondents who attended matches abroad used these experiences to compare and contrast the Timbers Army to other supporters.

Drawing from their knowledge of different supporter traditions, participants view the Timbers Army as a fusion of supporter styles which combine into something uniquely "Portland." David stated, "We're doing exactly what has been done all over the world, pretty much. I mean, we're doing it in our own way. I mean, we kind of have a fusion of all different kinds of styles I think." As he later explained, this facet has been a continual work in progress. After asking him how the Timbers Army has changed over time, David replied:

It's more evolved than changed. I mean, even though that's kind of the same thing, but it's more like, cause that was the whole point at the beginning. There [were] people saying do it this way, do it that way, and everything. And I was always like, 'let's just see what happens,' like what direction you go and stuff like that. Because there [were] always people that wanted to be more, like, Latin. Or, wanted to be more English or more whatever, and it was like, I was always like,

\footnotetext{
${ }^{31}$ This is not to say that certain players do not receive any type of criticism. On the contrary, the team, the coach, and individual players are often the subject of criticism in personal conversations and on the message board.
} 
'Let's not worry about that. Let's just see what direction it goes' or whatever. So...it's definitely turned into more of like a Portland thing, you know.

As is evident from this account, TA participants have brought a variety of outlooks to the group throughout its growth and development. In a slightly different vein, Ernesto explained the various cultural inputs and international traditions that coalesce in the Timbers Army:

Well, right now, as far as like, the songs, it's very, I mean, I think 90 percent of the songs are based from English chants. But, little by little, it's becoming like a mixture of like South American, and like, maybe like Italian and Spanish style supporters. Because, I mean, initially it was just a bunch of guys sitting around just singing English songs. But, now, in the last couple of years, there's more flags, there's more two-stick displays. People are bringing their own two-stick displays, there's more drummers, there's trumpets now. So, it's becoming more, I guess a reflection of the supporters culture worldwide than anything else.

Ultimately, the Timbers Army exhibits a blend of global supporter traditions that have combined into something that is uniquely local.

Participants view the Timbers Army as comparable to other well-known supporters groups and place themselves within the global football supporter landscape.

Bob said:

Well, I mean, it's called the global game for a reason. Everyone plays it everywhere...I mean, as a supporter, a supporter in Portland is the same, in the end, the aims, the objectives are probably the same for a supporter in Portland as they are in Rome, as they are in Buenos Aires, as they are in Moscow. You know, you all want the same thing for your team.

When asked to compare the Timbers Army to supporters groups globally, Bob continued:

How does it compare? I mean, in terms of passion, you've got the same. You know, I'd say [the Timbers Army is] right up there with any other supporter group in Europe and South America. I'm very unfamiliar with supporter groups in Asia. I mean, I know that Japan has some very good following in their leagues...I'd say any supporter throughout the world, if they went and just kind of saw what the 
history of the TA was and where we came from, they'd be pretty favorably impressed.

Emma also compared the TA to other supporters groups at the global level. She stated:

We kind of do it like they do it in places like Germany and Italy and Spain, and even Brazil, you know. And, that's why the group is the way it is, I think, because we don't really play by the American rules; we play by the rules that soccer has, you know, organically grown. And, I think that we do compare favorably for just - you know for the size of our team and the size of our league and the size of our supporters... So it's grown a lot like, basically like most football around the world grows. But that's because we're not really playing by the rules that American soccer's supposed to be... Compared to a lot of other countries, where things are a little bit more natural and organic, I think it's exactly what, you know, we do exactly what they do.

Emma clearly sees the Timbers Army as fitting in with supporters groups from throughout the world and punctuates this by naming specific countries famous for their soccer fervor. Of note, Emma mentioned the size of the team, league, and supporters in her response. Others were also quick to emphasize that while Timbers Army is similar to foreign supporters groups, it is smaller in numbers. For example, Doug asserted, "Internationally...we're a small representative of kind of the same thing" and later qualified what he meant by 'small representative:'

I'd put our supporters against anybody's in the world. If we had as many, that's just it. If you look at London, or you look at Lisbon, or you look at Madrid, or any of these places, there are a lot more people that are soccer fans, so, therefore a lot more people are going to be coming. Therefore, a lot more people have their grandpa and their dad that were supporters there. It's just been handed to them. It's their rite of passage, 'You're going to support this club.' If we had that, we'd have 5000 people there, every match no matter what, in unison. I think we do pretty well.

In sum, participants view the Timbers Army as carrying on the traditions of other foreign supporters groups. They see their history of growth and development following similar 
trajectories of groups in a variety of countries with much stronger footballing histories and traditions. While some respondents note that the TA has fewer numbers than their international counterparts, all of them believe that their behavior and passion matches other supporters groups.

\section{International Reverse Awareness}

Similar to the national level, reverse awareness occurs at the international level, and reinforces participants' views about the Timbers Army and its place in global supporter culture. Gaining external respect as an American supporter group may be a difficult task, for as Bob explained:

The worldview of America from the outside has always been one of this, 'Oh, they'll never get soccer. You know, they have their own sports, and they'll never get soccer. They'll never be good enough. It's the one thing that we can always hold onto and be better than the States in.' So, most Europeans have a very kind of snobbish attitude towards American soccer. Little do they know of the kind of underground support that there is, which is now really starting to come to the surface.

In spite of this, the Timbers Army has gained recognition from foreign supporters. For example, when the English team Sunderland AFC travelled stateside in 2005, they played an exhibition match against the Timbers. Sunderland supporters followed their club and, during their visit, established a friendship with the Timbers. Ernesto described the occasion, "When Sunderland came here, they were, I mean, like 400 of them came here, and they were in awe of our hospitality and how we sang and, you know, they were amazed, [that] football was here and they invited a lot of people back to Sunderland with 
them." The following April approximately 30 Timbers supporters travelled to Sunderland where the two groups reconvened and attended matches together. Emma, the only interviewee who made the trip, retold her experiences and mentioned that BBC North interviewed the travelling TA contingent; yet another example of external validation.

In another instance, a German supporters' magazine, Erlebnis Fussball (translated: Experience Football), featured an 8-page article and interview with the Urban Crew. The now defunct Urban Crew was a sub-group of the Timbers Army that, according to Arthur, lasted between four to five years before disbanding sometime after 2007 for unknown reasons. They were influenced by the ultras style and were responsible for some of the TA's early banners and tifo displays. The 2007 article, printed in German, featured full-color photographs of the Timbers Army. The entire issue focused primarily on supporter groups and tifo displays in Germany. Some exceptions included an article on Argentinean supporter groups and a photo spread showing various tifo displays by French supporters. This type of recognition bolsters the TA's global rapport and influences how participants view the group.

External recognition is also established via the Internet. I asked Sam how she thought the Timbers Army compared to other supporters groups. She responded:

It must be really close because I know that we have had a lot of response from other countries saying they've seen different things on Youtube. And, 'keep going. You guys are doing great.' And everything you know, 'You really do have the spirit,' and all that. I know [there has been] a lot of response like that from people. 
In a more recent example, the Timbers hosted a 2010 friendly match against Manchester City, one of England's top clubs. A video of the Timbers Army, shot at the match, appeared on an online forum for Manchester City supporters. The responses varied, but some discussed the possibility of adopting a specific chant from the Timbers Army, and one poster replied, "Depressing when the Yanks have a better atmosphere for a friendly game than we do for most league home games."

In a related current, some participants view the Timbers Army as a means of transcending national and cultural boundaries. Kristen emphasized this when she said:

I guess, by default, my god; it really puts us on the map. I mean, people know about us. ...And, now we talk about Portland or we talk about soccer and our soccer community -or, my cousin in England, is a huge soccer supporter... and, I've told him about us; he's so impressed by us. He can look up anything, and he's just amazed at what he sees - I do believe, I think it opens up the world in a sense. I know that might sound cheesy, but it really does. It does, it opens up. It lets other cultures in...It's like world-wise, it does, it opens doors.

As Kristen's statement indicates, soccer, and, by virtue, participating in the Timbers Army provides a dialogue between cultures, allowing - on one hand - participants a better understanding of different cultures and the world at large, and on the other, the ability to establish a place in the global supporter culture whereby others become aware of Portland and the Timbers Army. In a similar narrative, P.T. described how the Timbers Army might appeal to Latin American immigrants living in the United States. He began by referencing a 2008 friendly with Morelia Monarcas, a Mexican Primera Division team:

It's a huge Mexican team, like huuuge. They're big. And there was more fans for them there were Timbers fans. We scored first, and it was like, "Yeeeeah." And 
then they scored and it was just, like, thunderous. It was insane. It was so incredibly loud... It was also fun seeing their fans too, because they're mad; they had clickers and these girls were running back and forth, and the security was trying to control them, and [the girls] were just like yelling at them and it's just like, to me it was just like, "Okay, these are soccer fans guys. We're not so bad," you know, like...

P.T. continued:

They were all...fans of that team, you know, but they hadn't come out [to Timbers games]. And, I think actually after that game, when they saw us there doing what we do, we got more fans because they were like, "Oh, well they do have a culture. They do have something that's like, and it's not just, we're not just going to go see a bunch of, whatever," you know, "these American guys," you know. They saw, and it was like, "Aww, alright, they're into it," you know, "they got posters, and they yell, and they scream," and [the Morelia fans] were into it. I think we got some definite fans [from that game].

While P.T.'s comments are slightly different from Kristen's statement, the main point that the Timbers Army is capable of bridging cultural gaps - remains the same.

Finally, for some, the Timbers Army creates an international dialogue with other

supporters. Ernesto, who participates in creating some of the tifo displays, explained:

Well, I mean, the one thing is like, for us, like regarding our displays or our tifosi, or our tifo, or whatever you want to call it, is that we're not competing with like, we're not, you know, competing with U.S. supporters. We want to compete with like the Drughi ${ }^{32}$ or the ultras of AC Milan, or like Marseille. We want to compete globally in regards to how we do our displays and how we show our support. I think we're on par with that level, and almost there. I think maybe, like, Section 8 and Barra Brava had like, they're like top. Barra Brava's like number one as far as game day displays [in MLS]. And, like, we want to be able to top them, and you know, we want guys in Europe to say, 'Holy cow. It's like in Portland, it's like, this is real, or it's growing.'

\footnotetext{
${ }^{32}$ The Drughi are supporters of Juventus based in Turin, Italy.
} 
This statement once again highlights the 'authentic' and 'real' atmosphere that participants feel is part of the Timbers Army. In addition, it illustrates a global awareness wherein the TA creates its own distinct place among the world's soccer supporters.

\section{Hooliganism and Violence:}

One aspect of world football not prominent in the Timbers Army is hooliganism. Of course, there have been some instances of physical altercations between the Timbers Army and other supporters groups, but for the most part, this is very rare. In fact, during observations, I did not witness any violence between supporters, although I did hear about a limited number of incidents, mostly surrounding the Seattle-Portland Open Cup match. Additionally, some interviewees talked about past scuffles, namely with Seattle and Vancouver supporters. Nonetheless, the limited number of altercations between groups signifies that, at least at this point, the phenomenon of hooliganism and violence not a part of the Timbers Army.

There was not a direct question regarding hooliganism, but the topic arose in some interviews. Those who discussed it were unanimously against any type of soccer violence, but were also aware that some people in the U.S. conflate any type of organized soccer support with hooliganism. Ernesto explained:

I think it would be an incredible deterrent to the sport in the US if something like that should ever happen, because any time any sort of violence happens in the US, if it's in a soccer game, the first word that comes out of the press is like, Hooligans or Soccer Riots, or whatever... I don't think Americans understand. I mean anytime an American that doesn't understand soccer or soccer supporter culture, and they just see a crazed soccer fan with like a flag and singing, 'Oh my god, that guy's a hooligan.' They just, it's just a misconception of people. It's 
hopefully something that we can change... Like, a real hooligan doesn't give a shit about his team. Because, you know, to bring those sort of actions - violence and whatnot - to the stadium is just, it pretty much just screws your team over. You'll end up playing in empty stadiums like Juventus did or like AC Milan did last year when - or was it the year before - they threw that Vespa [scooter] off the second [tier].

Likewise, Doug discussed hooliganism and the Timbers Army:

If you know anything about, you know, supporters throughout the history of the game anywhere in the globe, there are varying degrees and levels of fanaticism, but ours is nice; ours is good. You know I've heard it referred to as 'hooligans lite.' Where you don't have to deal with getting your head kicked in to go to a match and be a part of that; you don't have opposing fans that their whole reason to go to a match is just to kick it out. You know, punch and get punched. That's so nice not to have to worry about.

Lastly, Avon discussed his fear that any potential violence would be detrimental to the sport in the U.S. He said, "We're not the biggest sport, and people hate us, because, just because we're soccer. And so, I'm just afraid there's going to be a kneejerk reaction. That's the only thing; I'm afraid a few guys could ruin it." It is apparent that participants view hooliganism and violence negatively. Though the subject did not arise in every interview, respondents who discussed hooliganism indicated that it is detrimental to the game and its culture, and that it would be particularly damning to the emergent American soccer culture were violence to become a mainstay in American soccer. 


\section{Chapter 5: Discussion}

This study had three objectives: (1) to describe the Timbers Army and what it means to participate; (2) to explore the processes whereby participants create the group identity; and (3) to examine how the participants contextualize their experiences relative to their understanding of the local, the regional, the national, and the global. This chapter offers a discussion of the findings as they relate to other research and the theoretical framework.

\section{Supporters United}

The Timbers Army is a supporters group. Participants refer to it as such and they clearly fit into Giulianotti's typology of supporters. This was somewhat of an a priori assumption going into the research, but during interviews, it emerged that this was a large part of how participants see themselves. Similar to the SIRC study in Europe, participants described themselves as active participants whereas fans were merely passive consumers of the game in front of them. All of this is important because it is the starting point for further discussion of the global diffusion of supporter culture and cultural hybridization.

Even for those who do not delineate a clear line between supporters and fans, the ways in which the participants talk about themselves parallels Giulianotti's taxonomy. Like Giulianotti's supporters, participants: (a) constitute a local subculture (that certainly is part of a larger global soccer supporter subculture) wherein they have their own history, symbols, and norms and values; (b) express a thick solidarity with one another, the players, and the club; (c) their social identities are, to some extent, grounded in the 
group and are a result of their experiences related to supporting the Timbers and following soccer, and finally; (d) they are highly topophilic, expressing a strong sense of connection to the city of Portland and the Cascadian region. These attributes primarily point towards a very local expression of community, yet the fact that participants refer to themselves as supporters and have adopted this type of language and behavior points to a rather outward looking, global perspective. Moreover, the ways that TA members attach to the club and the city and interact with one another resonates with the findings of other studies focusing on supporter culture.

Part of the development of the Timbers Army into its current state as a large supporters group certainly has to do with the physical anchoring within the home grounds to a specific area, most notably the North End and the specific sections within which members stand regularly. This attachment to specific areas in the stadium is a trait of supporters groups throughout the world, and as the number 107 frequently appears in other TA symbols and in general parlance (e.g., "the culture of 107"), it is evident that this particular section is an important part of the TA's history. It is important to keep in mind that, except for a few specific matches, when the TA formed and for many years thereafter, there were not as many people attending games as there currently are. Therefore, there was space to claim in the stadium where likeminded individuals could congregate to show their support. This in turn offered an area in the stadium that served not only as a place for the first participants to commune and formulate their burgeoning identity, but it also served as a visible place, spatially anchored in a specific section that could then draw in others. Importantly, this was also in the general admission section 
which offered cheaper prices and tickets were not assigned to specific seats. These aspects, combined with the fact that there was ample room within the North End to grow, allowed the TA to expand over time as more individuals were drawn into the group. All of this is significant as it would undoubtedly be much more difficult to come into a stadium already full and start a group such as the TA. Similarly, without that initial space for the group to claim and the availability of surrounding sections, it is likely that the group may not have been able to grow as it did. For other supporters groups in stadiums with larger initial attendance and/or physical barriers disconnecting potential supporters from one another, the ability to coalesce into a unified group and continue to expand may be much harder.

\section{Cultural Hybridization}

As presented in the findings, participants describe the overall group as a fusion of different supporter styles and traditions all coming together. In line with cultural globalization theory, these various inputs intersect through greater and more rapid exposure to a wider array of cultural forms than previously existed. Of particular importance here is that these different international forms intermingle to create something that is simultaneously locally and globally relevant.

The DIY, free-flowing, participatory, and decentralized, 'leader-less' characteristics of the Timbers Army coupled with the global nature of soccer provides an opportunity for individual participants to bring various influences and experiences into the group where they comingle and create a new style of support. Participants are often 
well travelled, and they frequently follow foreign teams and leagues, and some have attended matches while living or travelling abroad. In addition, the internet and specialty cable channels allow individuals to follow foreign soccer more easily and to stay abreast of happenings with other supporters group, both domestically and abroad. Finally, the internet provides an additional forum for interaction between supporters groups and individual participants.

Because it is so easy for individuals to contribute to the group, their diverse experiences, knowledge, and awareness about global soccer and supporter culture come together to create the Timbers Army. The resultant synthesis exhibits some characteristics from the original inputs but is, in and of itself, a distinct entity. It is rather easy to find examples of multiple different styles ranging from British chants found in terrace culture, to elaborate displays reminiscent of the ultras, and the use of musical instruments that reflect a Latin American influence. At the same time, they combine all of this in ways that reflect their view of Portland. Strikingly, TA participants are self-aware of this and articulate the combination of different international styles and local Portland-ness as simultaneously reflecting worldwide supporter culture and creating something "uniquely" Portland. This illustrates how collective groups learn, absorb, and indigenize global and international influences in ways that make them their own. More importantly this hybrid style of support is not isolated to the TA, but may actually be the defining feature of an emergent American style of support. 


\section{Glocalization}

The hybrid nature of the Timbers Army is the result of individual, local actors actively contributing to the construction of the overall group by using a variety of local and foreign cultural references. This mélange of influences produces an overall group identity that fits in the larger global supporter culture. Participants show a strong global awareness, especially when it comes to soccer, yet they also attach strongly to the local and create a broad community through a common interest in soccer. Hence, hybridization explains the nature of the Timbers Army while glocalization illustrates how participants view themselves relative to their understanding of the local, the regional, the national, and the global.

While there are certain traits common to all supporters, the Timbers Army illustrates how groups can distinguish themselves and create unique, particular identities while acting within the parameters of larger frameworks and expectations. Although participants do not explicitly talk about glocalization or the particular and the universal, they certainly convey these ideas when they proclaim that (paraphrasing several respondents) they "do it just like everyone else, but in [their] own way." Furthermore, in practice the TA particularizes universal traits by imbuing them with local meanings and values. This is minutely different from hybridization in that these are universal traits, common to most, if not all, supporters groups, but not necessarily associated with specific groups or traditions of support. One rather simple example is the scarf. As mentioned, the scarf is an almost necessary accoutrement for all supporters. Similar to other supporters groups, the TA differentiates itself from other groups by incorporating specific symbols 
and words on the No Pity scarf that are relevant to the group's history, traditions, and rituals. Further, because it is only available through social networks, acquiring the scarf becomes a particular ritual that helps integrate newcomers into the group and its community. Of note, since the writing of this, the No Pity scarf is now available through the Merchandise Van, where the TA sells its wares outside of matches. In addition, some TA merchandise is available through an online store, although, as they recognize the symbolic value and history of the inter-personal exchange of the scarf, this is not available via the Internet.

Another example of this within the Timbers Army is the overall group's attachment to place. While the particular city of Portland is central to the Timbers Army identity, supporters groups universally express feelings of topophilia. Nevertheless, supporters express their love of place in different ways; some may attach to certain areas of a city - this is especially relevant for cities that have multiple teams - rather than to the overall city. The Timbers Army attaches specifically to Portland, and this is evident in their chants, flags, banners, clothing, and, in some cases, tattoos. The TA also attaches to the Cascadian Region, something that, no doubt, helps fuel the rivalries with Seattle and Vancouver. These specific characteristics are unique to the Timbers Army, but love of place is part of global supporter culture. Ultimately these two examples illustrate how the TA is similar to other supporters groups throughout the world in the ways in which participants assert their difference. 


\section{Sameness and Difference}

The tension between sameness and difference lies at the core of glocalization and discussions of the universal and the particular. The Timbers Army provides an example of how social collectives, through glocalization, view themselves in terms of sameness and difference regarding other ostensibly similar groups. This adds to a deeper understanding of the relationship between the universal and the particular and shows how group identity can be produced at a glocal level by constant comparison with other similar groups.

It became clear from analysis that respondents spoke in very different terms when comparing themselves to other supporters groups depending upon what socio-geographic level they were speaking about. Figure 1 depicts how, as the physical distance increases, the more participants compare themselves to other groups in terms of similarities, whereas the closer the other group, the more participants differentiate themselves.

At the global level, participants regularly state that the TA is similar to other supporters groups, with some saying the only real differences are in group size and history. As the geographic scale contracts, participants began to differentiate themselves more. At the national level, participants indicate that they view the TA as similar to some other American supporters groups (mostly the ones that they deem the best) but simultaneously differentiate themselves in some key areas. The largest major difference respondents mentioned is that the Timbers Army is so large and organizationally 
established at a lower level of professional play. ${ }^{33}$ In addition, participants differentiate the Timbers Army by size and growth, a DIY ethic, autonomy from the front office, and being open and inclusive to all. When asked to compare themselves to other groups at the national level, respondents usually referred to MLS groups as points of comparison rather than those at their own professional level in the USL. Even when differentiating themselves from MLS groups, participants never spoke in denigrating terms except when talking about the Seattle Sounders supporters. Finally, they frequently cite Barra Brava and Section 8 as two of the best other supporters groups in the U.S. While both groups have interacted with the TA in positive ways and shared lessons learned, interviewees did not further indicate why they view these two as some of the standard setters of American supporters groups.

\section{Figure 1. Socio-geographic Spectrum of How Timbers Army Participants Compare} Themselves to Other Supporters Groups

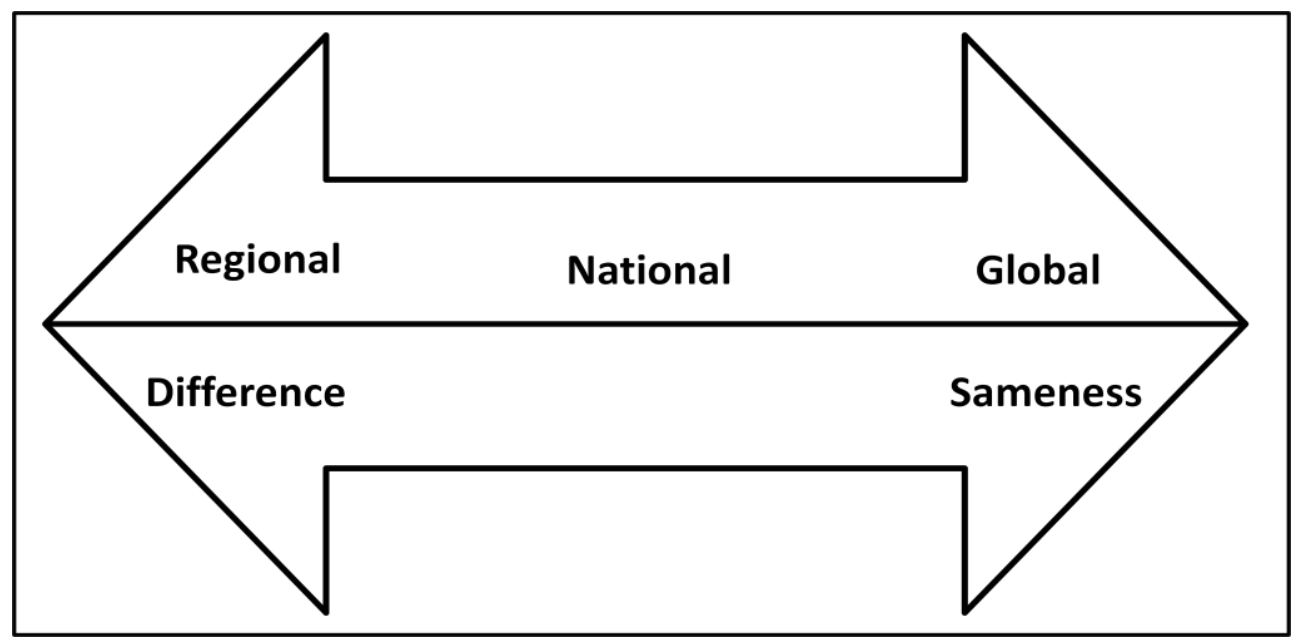

\footnotetext{
${ }^{33}$ For the most part, other major supporters groups began while their teams were playing in the MLS.
} 
The regional level is where the Timbers Army really asserts its own unique identity in terms of difference. As presented in the Findings chapter, participants do not hold the same animosity for Vancouver supporters as they do for Seattle, their closest rivals. Interestingly, TA participants more frequently talk in terms of sameness rather than difference when discussing Vancouver, saying that both sides share a similar understanding of the game and passion for their respective sides. Contrarily, supporters speak in wholly oppositional terms when it comes to Seattle. Although many of the world's fiercest rivalries (both in terms of supporters and players) are contested between sides sharing close social and geographic space, ${ }^{34}$ some of the hostility respondents expressed may be a relic of the time during which this research occurred. To be sure, an extreme dislike between the two sides existed already. However, Seattle entered the MLS before Portland or Vancouver, attendance exploded, and American soccer pundits lauded Seattle as a hotbed of soccer enthusiasm. This stoked the enmity between the two sides. On the other hand - and related to the concept of relativization - the Timbers Army self identity as DIY, organic, autonomous, and real was reinforced in response to what members see as manufactured, fake, and plastic in Seattle. Interestingly, all of the terms respondents use referring to the TA point to a self-identity mirroring the definition of Supporters according to Giulianotti's taxonomy, while those they use to describe the Seattle fan base relate to Flâneurs, cool spectators whose connection to teams is

\footnotetext{
${ }^{34}$ This, of course, has further implications related to identity theory, but a full exploration of this thread is not within the scope of this work.
} 
primarily through 'market relations. ${ }^{35}$ Aside from Seattle, however, participants in the Timbers Army overwhelmingly talk in terms of sameness regarding other supporters groups at fundamental levels of behavior, passion, and loyalty, but also maintain a unique, particular identity.

Although participants use a vocabulary of difference to distance themselves from, primarily, Seattle and, to some extent, assert their uniqueness at the national and international level, they celebrate the fact that Timbers Army constituents are so 'diverse.' This is extremely salient as almost all members describe the Timbers Army in ways that point to the eclectic social, cultural, political, and economic backgrounds of participants. In this sense, instead of using difference to distance themselves from one another, participants use their differences as a further means of expressing the uniqueness of the Timbers Army, not only as a supporters group, but also as a social group. Coupled with the adoption of multiple international styles of support, this trend shows an understanding and an appreciation for a larger, outward looking view of the world and of culture in general; a worldview that stresses and appreciates differences as unique markers of collective social identity. Ultimately, difference, in this situation, is an attribute and something to be celebrated.

\footnotetext{
${ }^{35}$ To reiterate, I am not saying that Seattle Sounders supporters or fans represent Flâneurs or are any less of supporters and fans than those in Portland, but that this is how the Portland supporters view their closest rivals, and in turn, reinforces, how they think about themselves.
} 


\section{Local-Global Dialectic}

The Timbers Army not only illustrates how the local and the global intersect and, importantly, how the regional and national come into consideration when exploring local-global relationships - but also shows how the local can be an influential agent at the global level. This point should not be overstated, but as American supporters groups grow and gain recognition outside of the United States and Canada, it is conceivable that some aspects of this ‘American' style of supporter may transfer to non-U.S. groups. Just as it has recently become easier for Americans to access world soccer, it is also easier to broadcast local supporter traditions to the rest of the world. Furthermore, as the Timbers move into the MLS, it is likely they will play exhibition matches against other more established clubs coming primarily from Europe and South America; some supporters of these clubs will follow their teams, thereby coming into direct personal contact with the Timbers Army and other American supporters groups that they previously may not have known existed.

Furthermore, as Ernesto indicated, some Timbers Army participants have their eyes set on becoming well known for their tifo at the global level. The internet allows different groups to share photos and videos of their displays with one another via websites and message boards. Herein is another opportunity for the local to essentially talk back to the global and to potentially influence other groups, either by providing material for emulation or by raising the standards of what is considered a 'good display.' This, like other aspects of the Timbers Army and supporter culture in general, is 
illustrative of relativization and the "ever-amplifying" manner in which groups respond to one another in order to assert their unique identities.

Relativization is an important part of glocalization theory and helps to explain the ways in which individuals and groups contextualize their experiences within a global frame of reference. The Timbers Army uses this constant comparison in order to develop its own self-identity and assert its distinctive qualities through an understanding of supporter culture. It is through this process that participants come to understand where they fit into the global supporter environment. For the Timbers Army, relativization results in expressions and feelings of authenticity. Authenticity, in this case, is important because of soccer's marginalized cultural status in the United States. This is not to imply that the Timbers Army is especially concerned with being authentic, ${ }^{36}$ but rather that they have come to see themselves and others refer to them as an "authentic" supporters group. When this legitimization comes from external sources (e.g., BBC North, foreign supporters groups, independent supporter fanzines, and even Sports Illustrated), it certainly influences the ways in which the group comes to see itself.

Thus, while Giulianotti and Robertson's use of relativization is extremely helpful in grasping how TA participants see the group, this case provides an important addition to the concept; what I refer to as reverse awareness. Drawing upon globalization's twopart definition, reverse awareness refers to instances where others at a global or international level become conscious of cultural phenomena in other places. Therefore,

\footnotetext{
${ }^{36}$ It would require further investigation to state whether or not 'being authentic' is a true goal or if it is something that arises through their behavior and group identity.
} 
within globalization, it is not only that individuals and social collectives become aware of the globe as a single place, but that they become conscious of other similar people and groups occupying the same cultural space at a global level. In addition, the concept of reverse awareness involves the local group realizing that others at an international or global level are aware of them and incorporating that in the presentation of their glocal identity. Incorporating this idea produces a more complete picture of global-local cultural flows and further shows how the global and the local form a dialectic relationship. The Timbers Army illustrates this quite simply: (1) The group exhibits very high levels of global awareness when it comes to soccer. (2) Other foreign (this also applies to the national level) supporters and various media outlets are aware of the Timbers Army (perhaps not at a completely global scale, but certainly at some international level). (3) Participants are conscious that others are aware of them and use this to further contextualize their identity and experiences relative to their own and others' conceptions of soccer support.

\section{Future of Supporters Groups in the United States}

The unique status of professional soccer within the United States has historically required American followers of the game to look outside of their own national borders to follow high-level teams and to learn the traditions of supporters groups. When MLS began in the mid-90s, it provided a relatively high level of soccer in the United States that had been absent since the collapse of the original NASL. Over time, supporters groups in the U.S. emerged in response to the higher level of play, and these groups, like the 
Timbers Army, had international cultural influences. While more groups continue to form, the most prominent supporters groups in the U.S. appear to be DC United's Barra Brava, Chicago Fires' Section 8, and the Timbers Army. Seattle's fanbase gained quick attention when they entered MLS, but their supporters group, by all accounts, was quite small when the Sounders played in the USL.

The 'promotion' of the Timbers into the MLS along with the renewed vigor of the Cascadian Rivalry raises the exposure of soccer throughout the country. Were it only the Timbers moving up, then the TA may not receive as much publicity, but having all three geographically proximate teams together in the same league will draw more attention to the sport and supporters groups. This spotlight coupled with the TA's extant reputation among American supporters makes the group and their regional counterparts more prominent at national and international levels. More importantly for this discussion, it also highlights how global cultural flows create new models for group construction, action, and representation. Clifford Geertz's concepts of a model of and a model for are helpful in understanding the maturation of the Timbers Army and provide a potential picture for the future shape of American supporters groups. It also shows how processes of globalization and glocalization create new templates and references for action.

As participants tell it, when the TA began it more or less emulated an English style of support. At this early point, the small group of supporters relied on their understanding of English supporters and adopted English chants. In essence, they were a model of English supporters, using their understanding of English supporters groups as a blueprint for their own development. As mentioned throughout the findings and in this 
discussion chapter, the TA slowly began transitioning to a hybrid version of various supporter traditions and relied less on a single style of support for inspiration. At an early hybrid stage, the TA was still a model of, but represented a style of support based on multiple traditions merged into a single mélange.

As the TA matured, participants developed their own histories, traditions, adopted chants more selectively, and maintained an autonomous, DIY ethic. They had created a new, unique group identity through the infusion of strong local and global influences. This is where the Timbers Army currently is although the dynamics are always changing; there is certainly the possibility the group will mature further, and its identity will change slightly as well. At this time, the TA has moved into a position to serve as one example of a model for others who want to create similar groups in the United States. That is, other groups are going to look toward the TA for inspiration and will use some of their traditions and strategies in the construction of their own group. This is likely to occur more prominently among groups that are either in the nascent stages of formation or in those that encounter problems such as stagnation in growth or dealing with the front office. Some examples of this emulation already exist. For example, when the New England supporters said the idea for their protest came about through the Timbers Army's previous protests. Another instance, if true, ${ }^{37}$ is in participants' claims that Seattle supporters 'stole' certain chants from the TA and adopted them as their own.

\footnotetext{
${ }^{37}$ I have no reason to disbelieve the TA participants, and there are certainly chants that both supporters groups share. However, I am under the impression that supporters in Seattle would likely say the same thing about the TA (i.e., "They stole our chants."), and at this point there is no way in verifying who sang what first. Moreover, in this work, I am not interested in taking sides between the two rivals, but I am presenting the positions of many Timbers Army participants and using these outlooks to extrapolate their understandings to broader situations.
} 
Important to remember is that the TA took many of these same chants from foreign supporter groups and subsequently indigenized them to make them their own. Participants do acknowledge that their chants are not necessarily original, but that they had laid claim to them before Seattle supporters.

To be sure, the Timbers Army is not the only model for other supporters groups, but it does add another prominent example to the few that currently exist. As the Timbers enter MLS, the Timbers Army will become more visible to more people both inside the United States and outside of it. In tandem with other groups, they are adding to a new style of support that may be indicative of the locally focused, yet globally aware nature of American supporters. In the past, supporters had to look to the rest of the world to find examples they could emulate and use to create their own domestic groups. Now, there are American groups that can serve as models for other supporters. This is not to say that supporters will no longer be globally aware, but that a number of domestic examples currently exist from whence to draw inspiration.

As should be clear by this point, the fact that people may emulate certain aspects of existing supporters groups does not exclude the necessity for the creation and assertion of unique, particular identities among new groups. Indeed, groups are expected to create their own unique identities within the overall milieu of supporters groups. This echoes Robertson's claim that among social collectives, there is a global expectation of particularity and uniqueness; that different groups will assert their individuality. Thus, the creation of new domestic examples of supporters groups simultaneously creates a reference against which other groups can differentiate themselves. 


\section{Limitations}

There are certain limitations to this research, and before extending the results to other areas, it is important to take these into consideration. Although this work occurred throughout the course of a season and a half, it only looks at a small period of time for the Timbers Army. They had already existed for eight years before research began and at the time of writing, they are about to enter the eleventh year. They have since joined the MLS and grown in numbers. In addition, while still remaining an independent supporters group, they have more formalized roles and a more formal organizational structure. Thus, this work is a snapshot of a particular time for the Timbers Army, and it should also be remembered that it was a time of transition. Therefore, certain aspects may be different now than they were previously.

Another limitation as far as representativeness of the population is a small, nonrandomized sample. A randomized sample however was impossible to achieve as there was not a member list of participants. Furthermore, it was not desired as this research sought to understand the experiences of devoted participants who were therefore purposefully sampled. Finally, additional interviews may have yielded different results, but among the 11 interviewees saturation was reached. Nonetheless, readers should take caution in applying individual experiences and quotes to the whole group or to other supporters groups.

Finally, this work purposely looks at participants who had been with the TA for a number of years and had attended regularly. It is highly likely that newcomers to the group would have different experiences and reasons for participation. Thus, while it may 
be fruitful to engage these participants in future research in order to determine how people become drawn to supporters groups, this work explicitly does not include them.

\section{Transferability}

To a certain degree, glocalization theory already addresses some aspects of transferability. The concept of the universal not only refers to the defining characteristics of a cultural phenomenon, but also explains what common generalities apply across populations and space. Thus, when dealing with certain global-local cultures, such as supporters groups at large, researchers can expect to find multiple similarities between groups. Further, there are certain universal facets as evidenced with Giulianotti's development of an actual taxonomy of soccer consumers. Thus, one can assume that these central tenants will be present at least to some degree among all supporters. Nonetheless, there are multiple differences, which usually lie beneath the surface.

For instance, globally, one can expect that, in general, supporters groups will differentiate themselves the most from their closest rivals. On the other hand, groups in Europe or South America may not be as keen as the Timbers Army to say that they are similar to other groups, even at larger geographic levels. They have not had to look outside of their own countries to follow the sport or find examples of supporters groups. As certain supporter traditions become more diffuse (e.g., the ultras style), however, it is conceivable that certain groups will identify and compare themselves to others at larger geographic levels. Without further research, it is unclear whether foreign supporters 
groups, especially in countries with long supporter traditions, are as globally aware of other groups as are the Timbers Army.

As mentioned, within the United States, supporters groups are characterized by hybridity. However, because differences between supporters groups are likely to lie within the particulars of their respective groups the question becomes, what kind of hybrid will be present? For instance, while we can expect to find a hybrid aspect in DC United's Barra Brava, it is much more likely to have a heavier South and Central American influence compared to the more European leaning Timbers Army. These types of differences likely have to do with the original members' demographics, countries of origin, and foreign allegiances in terms of teams and leagues, as well as those of people who joined later. Furthermore, supporters groups within the U.S. and throughout the world are of different sizes and have different organizational structures. Finally, there very well may be differences in racial, ethnic, and gender composition of supporters groups. These are all important considerations that should be undertaken in future research exploring American supporters groups.

While the particulars of this study may not extend to other specific groups, the approach and findings are certainly transferrable to other supporter populations, both within the United States and in other countries. Within the United States, other supporters groups can be expected to have an outward looking approach to the world especially regarding soccer, a strong affinity to their city, and are likely to use the same mixed soccer speak as the Timbers Army. Moreover, like the TA, they are likely to exhibit hybrid forms of support and incorporate multiple influences from around the world. 
Outside of the United States, ethnographic explorations of the ways in which supporters view themselves at local and global levels may offer multiple points of comparison and further insight pertaining to the ways in which people experience and view their world through participation in supporters groups. In the end, because supporters groups are so widespread and hold so much importance for those who participate in them, exploring the phenomenon further can open new avenues for understanding how people experience globalization

The following sums up this entire thesis rather concisely. Leading up to the beginning of the MLS season, the Timbers ran an advertising campaign entitled "We are Timbers," that featured 'regular' people ${ }^{38}$ from Portland prominently displayed on billboards throughout the city. In addition, the Timbers organization interviewed each person and presented their profiles on the Timbers' website. One of the questions they asked Abram Goldman-Armstrong, one of those featured who is also active in the Timbers Army, was, "With those elements - the environmentalism, the European feel, etc. $-[\ldots]$ How does that synergy work in your opinion and why?" In Abram's words:

That's a tough question but I think that it's a natural fit and an extension of the kind of creativity and more global view of culture and society. As far as the Timbers go, when I started going to the games in 2001 at the first match, I was singing songs that I had learned watching soccer games in Ireland. There were a lot of people that had an English-style supporters tradition and there were people who had more Italian-style supporters traditions and South American-style supporters traditions and those kind of all fed together. I think in Portland, there's this looking to the outside, beyond the American borders. We had creative people and people who have different influences so we created our own style of support. (Costello 2010)

\footnotetext{
${ }^{38}$ This is to say that they were not models.
} 


\section{Chapter 6: Conclusion}

This research focused on the Timbers Army and the ways in which this American supporters group constructs its identity and how individual supporters see themselves and the group in relation to other supporters groups. On one hand, this work applied cultural globalization theory and related concepts of cultural hybridization and glocalization to identify and understand the processes that help create the Timbers Army. On the other hand, the TA helps elucidate some of the rather abstract concepts related to these theories.

Although the theoretical concepts about globalization and the impact on identity were used to guide this research, the application of these theories during analysis was not a linear process. It instead emerged through an iterative engagement with the data and other potential theoretical applications. Cultural globalization theory initially appeared to be the obvious perspective to use considering the global expanse of the game. However, within soccer, the socio-cultural, political and historical aspects of particular locales and regions are so engrained among fans and supporters that globalization theory alone could not explain these processes of localization and the development and presentation of a local identity within a global field. Thus, it was necessary to use the additional concept of glocalization to complement hybridization as both address local and global processes of cultural exchange.

Throughout the research, I explored other theoretical perspectives; primarily theories relating to the hermeneutics of subcultural groups, theories of culture, ritual and meaning, and finally, symbolic interactionism. These theories helped identify and analyze 
some aspects of the TA such as identifying the use of symbols, patterns of behavior, and their meanings along with recognizing cross-cultural symbols and other aspects of supporter culture, but aside from symbolic interactionism, they fell short in the ability to apply the findings beyond a simple description of symbols, behaviors and norms. Of note, some of the concepts arising from the analysis and discussion, particularly that of reverse awareness and external legitimization, are perhaps the first steps of using soccer cultures to explore a form of symbolic interaction at a global level. However, developing this was out of the scope of this thesis as it would have been a substantial undertaking, requiring the development of a theoretical framework incorporating another entire body of literature. Furthermore, it was important to first focus on the aspects of globalization and glocalization as these fit the data better than other theories, and they provide a foundation for further inquiry and the incorporation of additional theoretical perspectives.

Glocalization and cultural hybridization were the most apt theories to apply in this case as they almost perfectly describe the process whereby the TA came into existence and where Timbers supporters situate themselves and the TA within both local and global contexts (as well as points in between). While they apply here it is important to consider other theories of globalization when looking at global social and cultural phenomena. There may, in fact, be examples where the convergence thesis explains situations better than the hybridization theory, especially when looking at the relationship between culture and global flows of capital. Additionally, there are likely to be situations where people are constrained by factors such as social position, income, and access to media and travel that preclude the individual (and group) agency necessary for glocalization to occur. In 
the specific realm of soccer supporters additional structural factors may include rules imposed by front offices on supporters groups that limit their ability to interact with players and club officials, to claim a certain section of the stadium, or to behave in certain ways such as standing for the entire match. Thus, glocalization and cultural hybridization work in this and other cases, but are not likely to explain all aspects and dimensions of globalization and it is important for researchers to explore alternative perspectives and explanations.

Moving beyond a discussion of the applicability of the theoretical concepts, this research is relevant to a number of specific fields of study. First, it applies to the sociology of soccer. This field, while certainly drawing from and overlapping with the sociology of sport, treats soccer as a socio-cultural institution wherein individuals and groups interact with one another in complex ways. Because of the global nature of soccer and its relatively marginal status in the American cultural landscape, this work serves as a first step at exploring a potential shift in global and national awareness among Americans that have embraced the culture of soccer support. This work also adds a significant piece to the field by studying supporter culture in a primarily overlooked, yet growing, population of Americans who, until recently, have had to look outside of the United States for inspiration in the creation of their specific supporter identities. Second, the work is important as it pertains to group dynamics, structure, and identity. In this regard, it illustrates how a small group of people can grow into a much larger community through the use of informal roles, norms of behavior, and expectations that then lead to a strong sense of social solidarity. Finally, this research is important to the study of the 
processes and intersections of globalization and localization because it provides an empirical case wherein individuals are extremely aware of and draw inspiration from both the local and the global in the construction and presentation of a group identity. Furthermore, it shows how the global can become the impetus for the creation and assertion of a local identity that combines influences from multiple geographic scales. This is, as far as I know, the first study to use a real-world example to articulate the idea that globalization, rather than eroding local cultures, actually becomes a major driving force in the creation of them.

While this thesis is applicable to a number of fields of sociological inquiry, it also is the first study to look at soccer supporters within the United States. As such, there are numerous possibilities to build upon this work. Although this does not serve as a comprehensive list, the following suggestions would be particularly insightful in exploring the burgeoning supporter culture in the United States.

First, it appears that supporters groups within the United States, and specifically within the MLS, are either growing or becoming more visible. Because there is a dearth of research on these groups, it would be beneficial to produce more ethnographies in order to have a better picture of the organizational structure and roles, the influences that create the specific supporters' identities, and to create a more complete profile of supporters groups in the US. This would likely produce narratives emphasizing the similarities and differences among American supporters groups and how they see themselves in regards to one another and other international supporters groups. It would also provide a more vivid picture of the different identities within soccer in an American 
context and how particular groups construct these identities by engaging the global. One especially fruitful area of research in this regard may include exploring the impact that immigrant populations have on the construction and further emergence of supporters groups, particularly in places with large Latino populations.

Once profiles of different groups have been established, comparative studies would provide further insight into determining why some groups are more successful and larger than others. This of course may also involve asking a question regarding why certain areas of the country have more supporters and fans than others. These comparative studies could then have implications outside of supporter culture as they may shed more light on social groups, organizational structure, as well as the sociopolitical manifestations of soccer in the United States.

One specific place that could be particularly illuminating for exploring glocal and hybrid supporters groups would be Montreal. While the Montreal Impact soccer team resides in Canada, like Toronto and Vancouver they play in the MLS and thus share a lot of the structural and some of the cultural aspects of the game. They begin playing in the MLS in 2012, having previously been in the USL along with the Timbers and bring with them an already established supporters group. Exploring the additional intersections of Quebecois identity within the supporters group would possibly open up more avenues for understanding how soccer becomes a vehicle for the presentation of social identities within a similar, yet distinct socio-cultural environment.

Finally, some soccer teams in MLS have more than one supporters groups. These teams offer the potential to explore the similarities and differences among supporters 
groups that interact with one another frequently. In addition, they provide an arena through which to explore social groupings and the reasons for joining one group versus another. In a similar vein, Los Angeles is the only city in the country to host two soccer teams: the Los Angeles Galaxy with some of the world's most famous players, most notably David Beckham; and Chivas USA with a direct link to its parent Mexican club Guadalajara. The potential for exploring class, race and immigration between the two sides and their supporters is particularly intriguing in this case.

In conclusion, the Timbers Army demonstrates how a small, localized group of concerted individuals can grow into a much larger complex group that interacts with the global. It also shows how thinking about globalization as a purely uni-directional, homogenizing force is problematic. While some view globalization as a process that ultimately erodes the local, the Timbers Army - and perhaps supporters groups in general - illustrates how the local and the global are not necessarily at odds with one another. Instead, there is an interdependent relationship between the two, and in this case, globalization becomes the facilitator for asserting a fiercely local identity and community. 


\section{References}

Andrews, Allison. 2008. 2008 United Soccer Leagues First Division Attendance. (http://www.soccercityusa.com/2008uslatt.html). Retrieved Sept 7, 2010.

Archetti, Eduardo. 1999. Masculinities: Football, Polo and the Tango in Argentina. New York, NY: Berg.

Appadurai, Arjun. 1996. Modernity at Large: Cultural Dimensions of Globalization. Minneapolis, MN: University of Minnesota Press.

Bairner, Alan and Peter Shirlow. 2001. "Real and Imagined: Reflections on Football Rivalry in Northern Ireland" in Armstrong and Giulianotti (eds.) Fear and Loathing in World Football. New York, NY: Berg.

Bernache-Assoulant, Iouri, Patrick Bouchet, Sarah Avergne, and Marie-Françoise Lacassagne. 2011. "Identity Crossbreeding in Soccer Fan Groups: A Social Approach. The Case of Marseille (France).” Journal of Sport and Social Issues. 35(1):72-100.

Busse, Phil. 2005. “Timbers Fans Gone Wild.” The Portland Mercury; June 30, 2005. (http://www.portlandmercury.com/news/timber-fans-gonewild/Content?oid=33973). Retrieved May 20, 2009.

Charmaz, Kathy. 2006. Constructing Grounded Theory: A Practical Guide through Qualitative Analysis. Thousand Oaks, CA: Sage Publications.

Costello, Brian. 2010. "We Are Timbers: Abram.” Portland Timbers Official Website. (http://www.portlandtimbers.com/news/2010/12/we-are-timbers-abram). Retrieved February 24, 2011. 
De Biasi, Rocco and Pierre Lanfranchi. 1997. "The Importance of Difference: Football Identities in Italy" in Entering the Field: New Perspectives on World Football. Gary Armstrong and Richard Giulianotti, (eds.) New York: Berg. Pp. 87-104

Dunmore, Tom. 2009. “The Capo.” Pitch Invasion. (http://pitchinvasion.net/blog/2009/06/10/the-capo/). Retrieved 8.30.10.

Dunning, Eric, Patrick Murphy, Ivan Waddington, and Antonios Astrinakis (eds.). 2002. Fighting Fans: Football Hooliganism as a World Phenomenon. Dublin, Ireland: University College Dublin Press.

Durkheim, Emile. 2001. The Elementary Forms of Religious Life, trans. by Carol Cosman. Oxford: Oxford University Press.

Galeano, Eduardo. 1998. Soccer in Sun and Shadow, trans. by Mark Fried. New York: Verso.

Geertz, Clifford, 1965. "Religion as a Cultural System" in Anthroplogical Approaches to the Study of Religion, Michael Banton, ed. London: Tavistock Publications. Pp. 146.

Giulianotti, Richard. 2002. "Supporters, Followers, Fans, and Flaneurs: A Taxonomy of Spectator Identities in Football." Journal of Sport and Social Issues. 26 (1): 2546.

Giulianotti, Richard. 2004 (1999). Football: A Sociology of the Global Game. Malden, Ma: Blackwell Publishers, Inc.

Giulianotti, Richard. 2005. Sport: A Critical Sociology. Malden, MA: Polity Press. 
Giulianotti, Richard and Roland Robertson. 2004. "The Globalization of Football: A Study in the Glocalization of the "Serious Life." British Journal of Sociology, 55 (4): 445-568.

Giulianotti, Richard and Roland Robertson. 2006. "Glocalization, Globalization and Migration: The Case of Scottish Football Supporters in North America." International Sociology. 21(2): 171-198.

Giulianotti, Richard and Roland Robertson. 2007. "Recovering the Social: Globalization, Football and Transnationalism" in Giulanotti and Robertson (eds.) Globalization and Sport. Malden, MA: Blackwell. Pp. 58-78.

Giulianotti, Richard and Roland Robertson. 2009. Globalization and Football. Thousand Oaks, CA: Sage Publications.

Goldbatt, David. 2006. The Ball is Round. A Global History of Soccer. New York, NY: Riverhead Books.

Gray, Mike. 2009. “MLS 2009 Supporter's Group Awards.” Letters From Pibe (blog). (http://www.bigsoccer.com/forum/blog.php?b=6747). Retrieved August 1, 2010.

Gupta, Akhil and James Ferguson. 1992. "Beyond 'Culture': Space, Identity, and the Politics of Difference." Cultural Anthropology. 7(1): 6-23.

Hannerz, Ulf. 1996. Transnational Connections: Culture, People, Places. New York, NY: Routledge.

Hobsbawm, Eric. 1983. "Introduction: Inventing Traditions" in Hobsbawm and Ranger (eds.) The Invention of Tradition. Cambridge, MA: Cambridge University Press. Pp. 1-14. 
Hognestad, Hans. 2009. “Transglobal Scandinavian? Globalization and the Contestation of Identities in Football." Soccer and Society. 10 (3-4): 358-373.

Klein, Gabriele. 2003. "Image, Body and Performativity: The Constitution of Subcultural Practice in the Globalized World of Pop" (trans. by Rupert Weinzierl) in David Muggel and Rupert Weinzierl (eds.) The Post-Subcultures Reader. Oxford: Oxford International Publishers Ltd. Pp. 41-49.

Locher, Julie. 2003. “Cuisine and Globalization: Homogeneity, Heterogeneity, and Beyond" in Robertson and White (eds.) Globalization: Critical Concepts in Sociology, Vol. 6. London and New York: Routledge. Pp 243-260.

Lofland, John and Lyn Lofland. 1995. Analyzing Social Settings: A Guide to Qualitative Observation and Analysis, $3^{\text {rd }}$ Ed. Belmont, CA: Wadsworth Publishing Co. Magazine, Roger. 2007. "Football Fandom and Identity in Mexico: the Case of the Pumas Football Club and Youthful Romanticism," in Football in the Americas: Futbol, Futebol, Soccer, Rory Miller and Liz Crolley (eds.) London: Institute for the Study of the Americas. Pp. 112-125.

Massey, Doreen. 1994. Space, Place, and Gender. Minneapolis, MN: University of Minnesota Press.

Panfichi, Aldo and Jorge Thieroldt. "Identity and Rivalry: The Football Clubs and Barras Bravas in Peru," in Football in the Americas: Futbol, Futebol, Soccer, Rory Miller and Liz Crolley, eds. London: Institute for the Study of the Americas. Pp. 112-125. 
Pfenning, Cliff and Zach Dundas. "Hometown Hooligans*: (*And we Mean that in the Nicest Way!) The Portland Timbers' Die-Hard Fans Prove that in Soccer, Army Life is Grand." Willamette Week; July 6, 2005. (http://wweek.com/story.php?story=6493\#comments_add). Retrieved May 19, 2009

Porat, Amir. 2010. "Football Fandom: A Bounded Identification.” Soccer and Society. 11(3): 277-290.

Pieterse, Jan Nederveen. 2004. Globalization and Culture: Global Mélange. Oxford: Rowman and Littlefield Publishers.

Ritzer, George. 2007. The Globalization of Nothing 2. Thousand Oaks, CA: Pine Forge Press.

Robertson, Roland. 1992. Globalization: Social Theory and Global Culture. London: Sage Publications.

Social Issues Research Centre (SIRC). 2008. Football Passions. (http://www.sirc.org/football/football_passions.pdf). Retreived March 4, 2012. Sounders FC Public Relations (NA). 2009. “Sounders FC Shatter MLS Attendance Records." Sounders FC News and Features, Oct 24, 2009. (http://www.soundersfc.com/News/Articles/2009/10-October/Attendance.aspx). Retrieved Sept 7, 2010.

Spaiij, Ramon and Carles Vinas. 2005. "Passion, Politics, and Violence: A Sociohistorical Analysis of Spanish Ultras." Soccer and Society. 6(1): 79-96. 
Timbers Army Myspace Page. N.d. Retrieved December 9, 2008

(profile.myspace.com/index.cfm?fuseaction=user.viewProfile $\&$ friendID $=121420$ 057).

Tossell, David. 2003. Playing for Uncle Sam: The Brits' Story of the North American Soccer League. Edinburgh, UK: Mainstream Publishers.

Tucker, William. 1965. “Max Weber's Verstehen.” The Sociological Quarterly. 6(2): 157-165.

Turner, Victor, 1967. "Symbols in African Ritual," in Turner, The Forest of Symbols. Cornell University Press. Pp. 19-47.

Tylor, Edward B. 1871. Primitive Culture: Researches into the Development of Mythology, Philosophy, Religion, Art, and Custom; Volume 1. London: Bradbury, Evan, and Co.

Williams, John, Eric Dunning, and Patrick Murphy. 1986. "The Rise of the English Soccer Hooligan." Youth and Society. 17( 4): 362-380.

Wilson, Amanda. 2008. "A Soccer Tournament with a Social Conscious” Christian Science Monitor. (http://www.csmonitor.com/USA/Sports/2008/0725/p25s07alsp.html). Retrieved February 20, 2012. 


\section{Appendix A. Informed Consent Form}

\section{American Soccer Supporters: Cultural Hybridization through the Beautiful Game, A Case Study of the Timbers Army}

You are being asked to participate in a research study conducted by Jesse Wagner, a Masters student in Sociology at Portland State University. The purpose of this study is to highlight and explore the frequently ignored yet growing soccer culture in the United States. This study emphasizes the experiences of under-acknowledged American soccer supporters by focusing on the instance of the Timbers Army, an unofficial supporter organization for the Portland Timbers, one of the best-known organizations of its type within the U.S. You were chosen because of your experience with the organization, and I hope that you will share your knowledge with me.

If you choose to participate, the interview will last approximately 45 minutes to an hour. At the end, you will have the opportunity to provide any additional information you wish. The interview will be digitally recorded and transcribed for use in the final report. Your decision to participate is not binding; you may withdraw from the study at any point without any repercussions from the university or myself.

All information that you provide will remain confidential. It will not be connected to you in any way. In the final report, pseudonyms will be used in place of real names; you may provide the pseudonym of your choice. This form is the only place where your actual name will appear and will be stored in my locked office. All potentially identifying information will be obscured in the final report and will remain confidential. You may withdraw from the study without providing a reason. Additionally, you may skip any question for any reason if you do not want to answer it. You may also receive a copy of the transcript if you desire.

This thesis project is being conducted as a requirement for a Masters Degree in Sociology. If you have questions or concerns regarding your rights as a participant in this research project, please do not hesitate to contact the Human Subjects Research Review Committee, Office of Research and Sponsored Projects, 600 Unitus Bldg., Portland State University, (503) 725-4288/ 1-877-4804400. If you have questions, concerns, or suggestions regarding the study itself, you may contact Jesse Wagner at 126 NE Stanton St., Portland, OR 97212, (804) 502-2724, wagnerjh@ @ pdx.edu. Additional inquiries may be addressed to my thesis advisor, Dr. Randy Blazak, at cfrb@pdx.edu.

By signing below, you are indicating that you have read and understand the above information and agree to participate in this study. You may withdraw your consent at any time without penalty. You will receive a copy of this document for your own records.

\begin{tabular}{l}
\hline Participant's Name \\
Jesse Wagner \\
\hline Researcher's Name
\end{tabular}

Participant's Signature
$\overline{\text { Researcher's Signature }}$

$\overline{\text { Date }}$




\section{Appendix B. Interview Guide}

1) How many years have you lived in the Portland area?

2) How long have you been a part of the Timbers Army?

3) Do you play soccer or follow other professional teams? (If follow other teams: which ones? If play soccer: How long? For a team or pick-up?)

4) If you were to describe the Timbers Army to someone who didn't know what it was, what would you say?

5) What does it mean to be a member of the Timbers Army?

6) How did you get involved with the Timbers Army?

7) What is it that sustains your participation?

8) What do you do in the off-season (for example, follow other leagues, other sports, maintain contact with the Timbers Army, join in meetings, etc.)?

9) Have you experienced or noticed any personal changes (for example, the way you view the world, the United State, Portland, other sports or anything else) due to your involvement with the Timbers Army? 
10) In your opinion how does the Timbers Army compare to other supporter organizations in the United States? In other countries?

11) How has the Timbers Army changed over the years? In what ways do you expect it will change in the future?

12) Can you tell me about the friends and foes of the Timbers Army in terms of other supporter organizations? (If needed: how did this come about?)

13) Is there anything else you want to add?

If you do not mind, I have a few demographic questions that will finish up this interview. What is your:

Age -

Gender -

Occupation -

Country of Origin -

Race/Ethnicity - 
Appendix C. Stadium Seating Map*

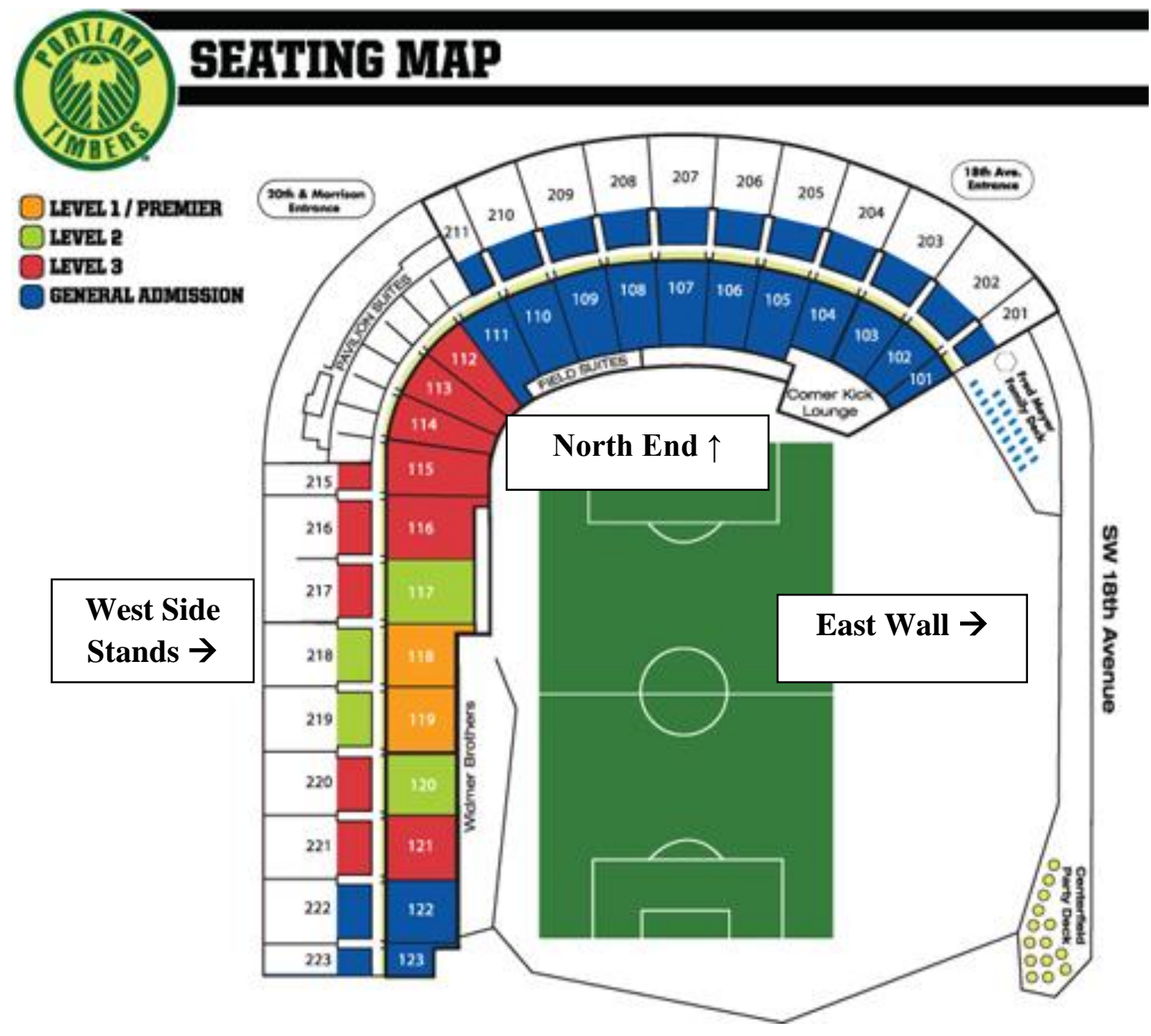

${ }^{*}$ Labels inserted. 


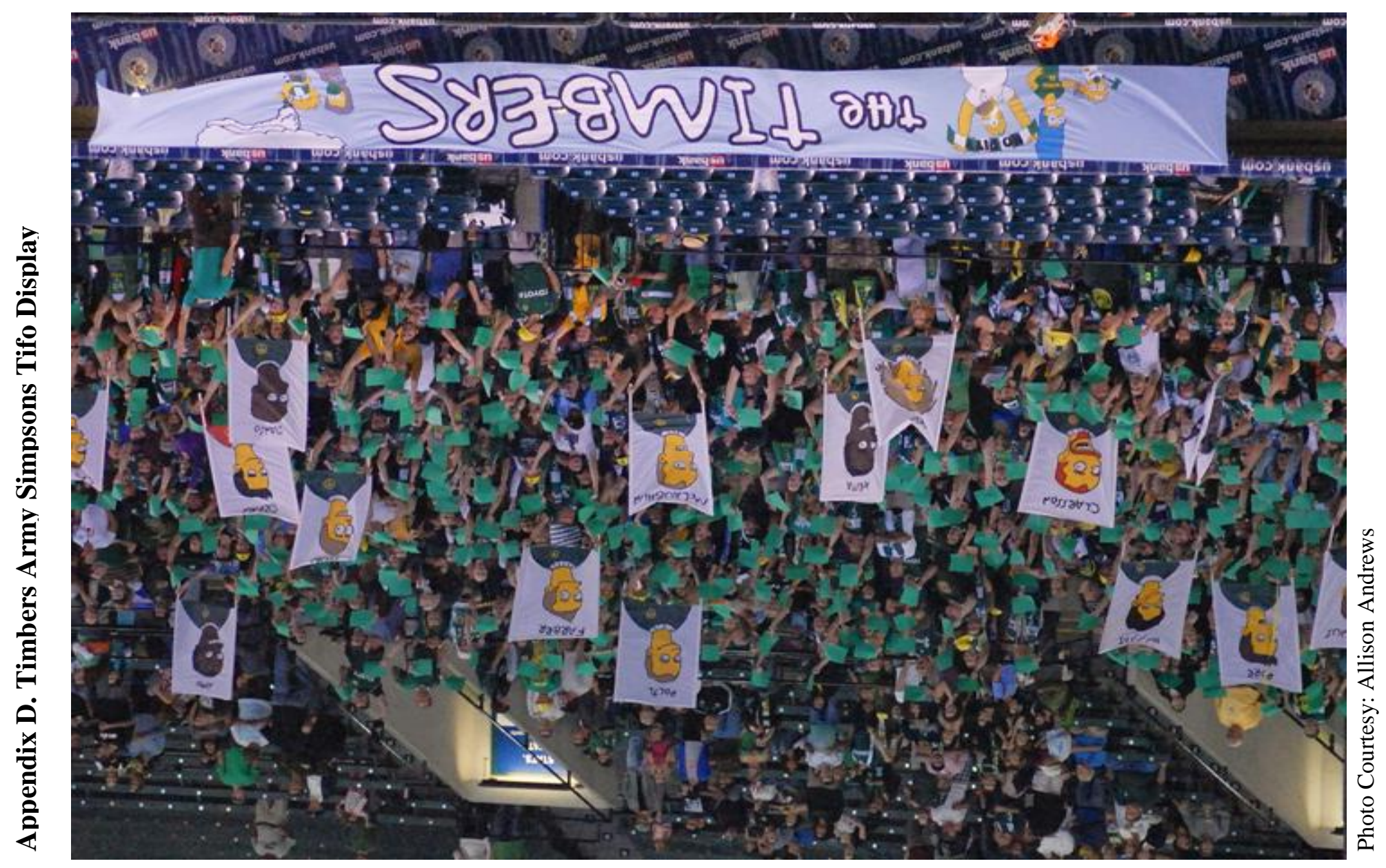




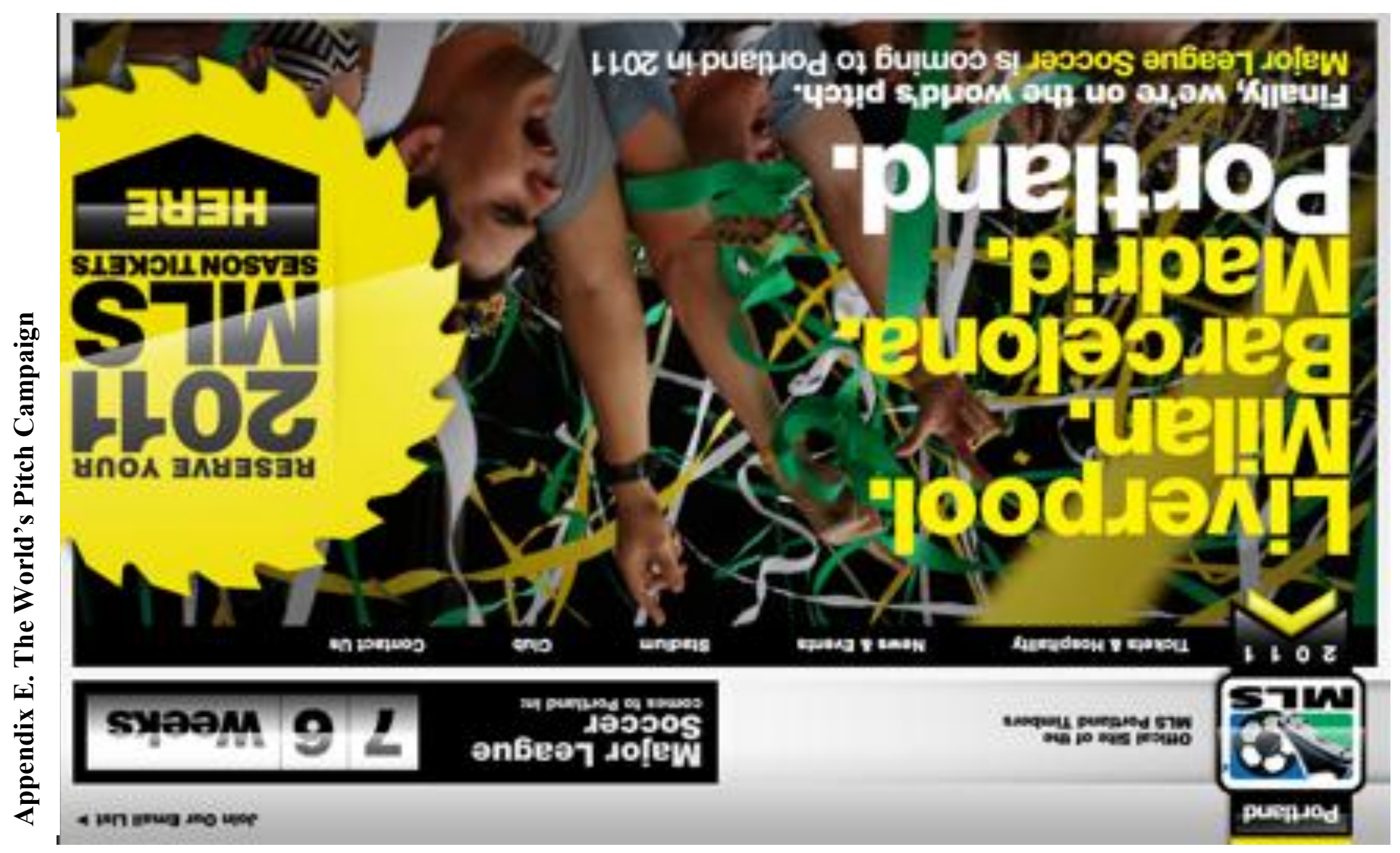

